\title{
Hidden in plain sight : capturing freshmen emotional experiences and their effects on performance at university
}

Citation for published version (APA):

Niculescu, A. C. (2015). Hidden in plain sight : capturing freshmen emotional experiences and their effects on performance at university. [Doctoral Thesis, Maastricht University]. Datawyse / Universitaire Pers Maastricht. https://doi.org/10.26481/dis.20151016an

Document status and date:

Published: 01/01/2015

DOI:

10.26481/dis.20151016an

Document Version:

Publisher's PDF, also known as Version of record

\section{Please check the document version of this publication:}

- A submitted manuscript is the version of the article upon submission and before peer-review. There can be important differences between the submitted version and the official published version of record.

People interested in the research are advised to contact the author for the final version of the publication, or visit the DOI to the publisher's website.

- The final author version and the galley proof are versions of the publication after peer review.

- The final published version features the final layout of the paper including the volume, issue and page numbers.

Link to publication

\footnotetext{
General rights rights.

- You may freely distribute the URL identifying the publication in the public portal. please follow below link for the End User Agreement:

www.umlib.nl/taverne-license

Take down policy

If you believe that this document breaches copyright please contact us at:

repository@maastrichtuniversity.nl

providing details and we will investigate your claim.
}

Copyright and moral rights for the publications made accessible in the public portal are retained by the authors and/or other copyright owners and it is a condition of accessing publications that users recognise and abide by the legal requirements associated with these

- Users may download and print one copy of any publication from the public portal for the purpose of private study or research.

- You may not further distribute the material or use it for any profit-making activity or commercial gain

If the publication is distributed under the terms of Article $25 \mathrm{fa}$ of the Dutch Copyright Act, indicated by the "Taverne" license above, 


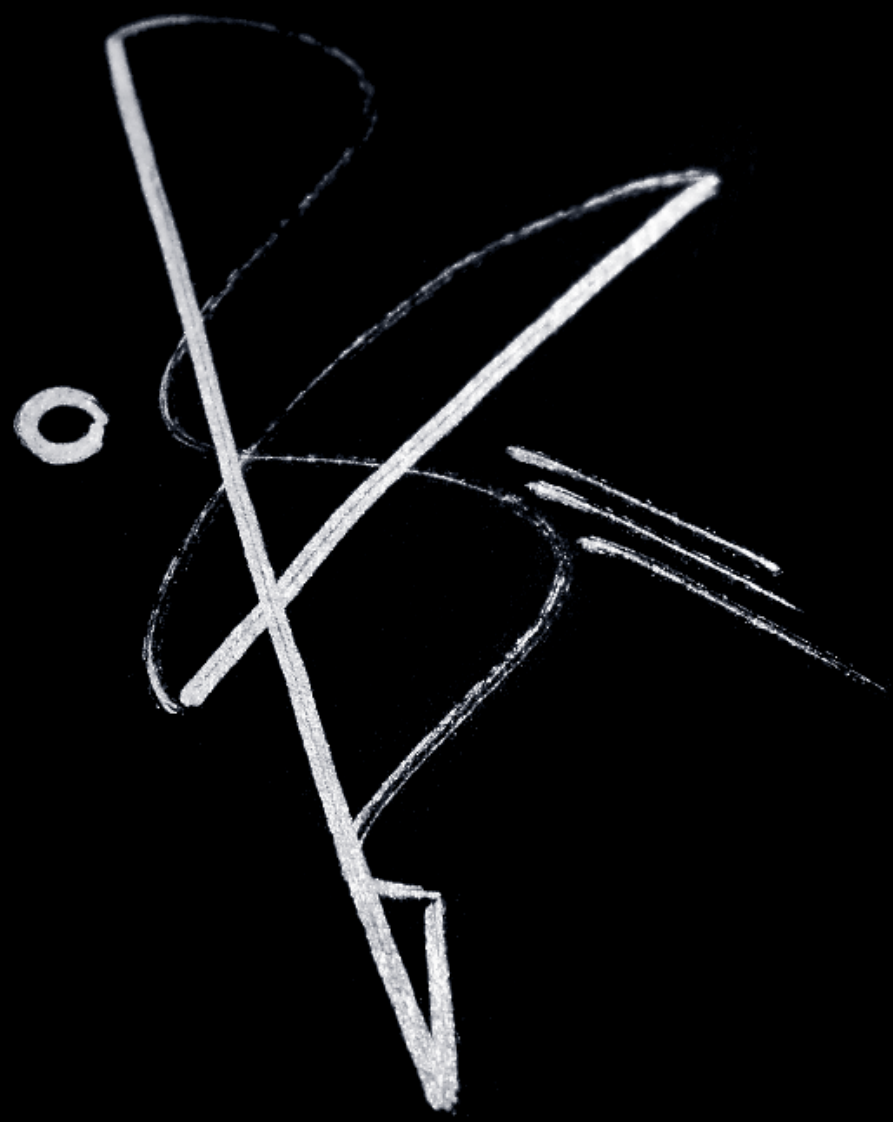

Hidden in Plain Sight

\section{CAPTURING FRESHMEN EMOTIONAL EXPERIENCES AND THEIR EFFECTS ON PERFORMANCE AT UNIVERSITY}


The research presented in this dissertation was conducted at the School of Business and Economics (SBE), Department of Educational Research and Development, Maastricht University, The Netherlands.

The research described in this dissertation was partly funded under a grant from Maastricht University, Leading in Learning Program.

Cover design and chapter illustrations: A.C. NICULESCU

Layout and printing: Datawyse | Universitaire Pers Maastricht

(C) Copyright 2015 Alexandra Corina Niculescu, Maastricht, The Netherlands

All rights reserved. No part of this dissertation may be reproduced or transmitted in any form or by any means, electronic or mechanical, including photocopying, recording or any information storage or retrieval system without permission from the author, or when appropriate, from the publisher of the publications. 


\section{$\mathrm{H}_{\text {idden in }} \mathrm{P}_{\text {lain }} \mathrm{S}_{\text {ight }}$ CAPTURING FRESHMEN EMOTIONAL EXPERIENCES AND THEIR EFFECTS ON PERFORMANCE AT UNIVERSITY}

\section{Proefschrift}

ter verkrijging van de graad van doctor aan de universiteit Maastricht op gezag van de Rector Magnificus, Prof. Dr. L.L.G. Soete,

volgens besluit van het College van Decanen, in het openbaar te verdedigen, op Vrijdag 16 Oktober 2015 om 10:00 uur

door Alexandra Corina Niculescu 


\section{Promotoren}

Prof. Dr. Wim Gijselaers

Prof. Dr. Mien Segers

\section{Co-promotoren}

Dr. Dirk Tempelaar

Prof. Dr. Amber Dailey-Hebert (Park University, USA)

\section{Beoordelingscommissie}

Prof. Dr. Rudolf Müller (voorzitter)

Prof. Dr. Diana Dolmans

Prof. Dr. Sofie Loyens (Erasmus Universiteit Rotterdam, NL)

Prof. Dr. Reinhard Pekrun (Ludwig-Maximilians Universität, München, DE) 
In loving memory of my father who dedicated his life teaching students how to love Mathematics 



\section{Contents}

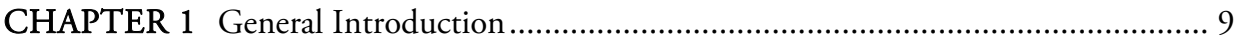

CHAPTER 2 Feelings and performance in the first year at university Learningrelated emotions as predictors of achievement outcomes in mathematics and statistics.....

CHAPTER 3 Exploring the antecedents of learning-related emotions and their relations with achievement outcomes

CHAPTER 4 Extending the change-change model of achievement emotions The inclusion of negative learning emotions....

CHAPTER 5 Capturing the freshmen experience at university An empirical study on how achievement emotions shape engagement in the curriculum..

CHAPTER 6 General Discussion

Valorisation addendum

Summary

Acknowledgments

About the author. 137

List of publications. 



\section{CHAPTER 1}

\section{General Introduction}

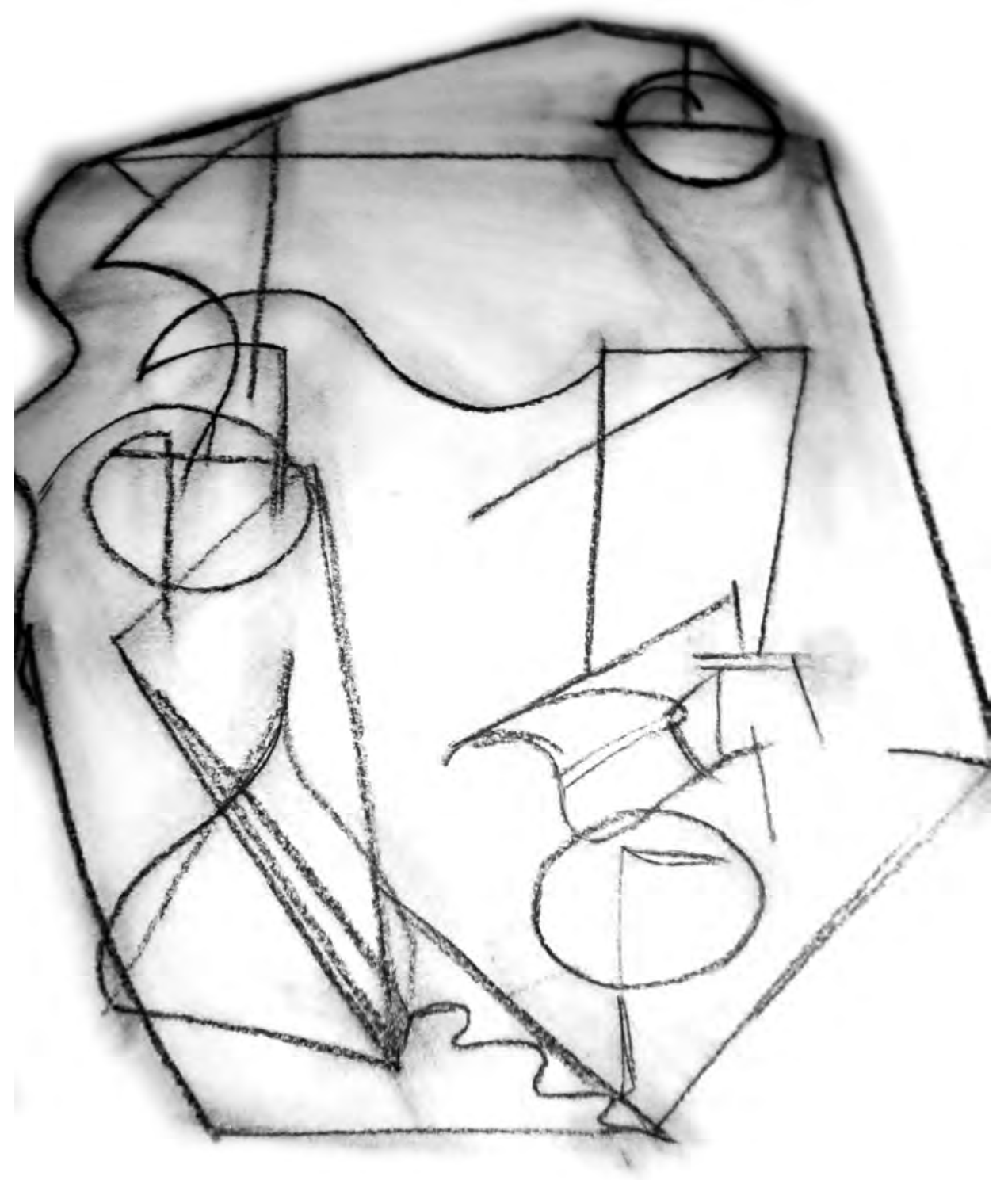




\section{CHAPTER 1}

"When we educators fail to appreciate the importance of students' emotions, we fail to appreciate a critical force in students' learning. One could argue, in fact, that we fail to appreciate the very reason that students learn at all" (Immordino-Yang and Damasio 2007, p. 9). 


\section{REFLECTIONS ON HIGHER EDUCATION}

These days, more young adults are enrolling in higher education to attain a degree. "The knowledge factory", as the university was referred to by Aronowitz (2000), has become (in most cases) only a "ticket to jobs and goods" (Aronowitz, 2000, p.8). Indeed, in today's world, the reasons for attending higher education primarily focus on obtaining a minimum qualification to enter the job market in the first place and, second, to have a chance competing for a job when faced with the "sea of change that has afflicted the job market" (Aronowitz, 2000, p.8). This is already the case for the last fifteen years and the world continues to rapidly change. Nowadays, the changing student population does place greater demands on the higher education institutions in terms of what they expect to get out of their degree. At the same time, a big problem has become the competitive pressure placed on these young adults to perform which, implicitly, translates into "success", both academically and further in life (Stipek, 2011). But how do we understand, beyond defining, success in higher education? What do we expect from a successful student and, if we go beyond A- grade stereotypes, what does a successful student even look like? This kind of inquiry brings us to the overall question: When is education actually successful?

Traditionally, it was considered that "education is successful when the student identifies with social and cultural authorities" (Aronowitz, 2000, p.9). The social reality of the job market however, presents an even more harsh perspective where "the B.A. degree signifies that the graduate can tolerate boredom and follow rules" (Aronowitz, 2000, p.10). This is unfortunately true, and in a world obsessed with the idea of success, the pressure to perform generates alarming levels of anxiety. Beyond that, maybe as worrying, it can "take the fun out of learning" (Stipek, 2011, p. 1481). From this standpoint, it can be said that the idea of success in higher education is probably overrated. This is in line with current theories on motivation, which claim that making students focus solely on standardized performance outcomes, such as grades, has a detrimental effect on developing their passion for a particular subject (Schunk, Pintrich, \& Meece, 2008). More recently, Chomsky (2011) was arguing along the same lines:

"Students are now trained to pass tests but not to think, as if the outcome of education are grades. In these conditions it is difficult to design interventions aimed to increase passing while making students learn. Which is a paradox! "(Chomsky, 2011, "Reflections on Higher Education", para. 2).

But today's conceptions about learning, training and instruction in higher education are full of paradoxes. These paradoxes are grounded in somewhat out-dated underlying assumptions, which still govern the way we conceive education and train young adults in formal settings, such as universities. For the present thesis, we consider it relevant to point to only one of these assumptions, which is: the student is the one responsible for his/her own learning and success. To understand this fallacy, we will remind the reader of a few important standpoints. To start with, the university discourse currently revolves around the learned; the phrase learner-centred has become "an unquestioned mantra" (Boud, 2006, p. 19). At the same time, it seems that today's universities are making fewer and fewer efforts to place the students at the core of their consideration. In addition, higher education adopted the view 
that the student is accountable for his/her own learning and success. This is supported by traditional views on learning, ability, intelligence (Carroll, 1993; Cattell, 1987; Guilford, 1967; Newell \& Simon, 1972) which placed such constructs "in the head of the learner" (Barab \& Plucker, 2002, p.166). Such conceptions ignore the crucial role of the educational environment on students' experiences, in other words, that student learning is actually an interaction between individual characteristics and the characteristics of the educational environment - when one is situated in this context (Barab \& Plucker, 2002).

By contrast, universities should change their isolated perspective on the learners by placing them in the educational context. Over the last twenty-five years, extensive research on learning and thinking styles, as well as achievement motivation, confirms the importance of the person - in - situation (Entwistle, 1998; Nijhuis, Segers, \& Gijselaers, 2008; Prevatt, Petscher, Proctor, Hurst, \& Adams, 2006; Tempelaar, Van der Loeff, Gijselaers, \& Nijhuis, 2011; Weiner, 1992). For example, Richardson (2011) argues that a learner's study approach is equally influenced by their perceptions of learning and by the educational context. Furthermore, Nijhuis, Segers, and Gijselaers (2008) show that depending on the learning environment, students adapt their learning strategies to what they perceive as necessary for what is required in each course. From a learner's perspective, Tempelaar et al. (2007) prove similar findings for achievement motivation: although containing an important generic component, achievement motivations are dominantly coursespecific. Overall, this line of research attributes learning and performance to a dynamic process of interaction between the student and the environment. From this perspective, individuals can perform - the same or similar problems - differently when placed in different settings. For instance, classic studies on mathematical performance (Lave, 1986; Reed \& Lave, 1979) show that when performing arithmetic calculation in a supermarket, shoppers were correct $90 \%$ of the situations. Giving the same individuals similar problems in a math test situation, revealed only $57 \%$ correct solutions. This suggests that, in fact, individual performance is site specific instead of a characteristic of the individual.

The discourse outlined above highlights that success is a function of the individual placed in a certain achievement context that is favourable for learning and engagement. To understand success requires examining the interaction between the learner and the environment. While it is common knowledge that intrinsically motivated and passionate students will engage better at all levels from academic, social and personal-emotional, higher education today pays little attention to this interaction (Pekrun \& Linnenbrink-Garcia, 2012). Therefore, changing our approach to how we train young adults to become successful in today's world requires that we go beyond providing them with the necessary skills to answer standardized exam questions only. It requires a science of education in which efforts should be made towards reducing their stress, perceived pressure and obsession to obtain success at any cost. Ultimately, we should re-phrase a question such as: What is it that makes students fail or succeed? into How we can engage students - emotionally and intellectually -in their learning process? 


\section{INTRODUCTION}

Success and study progress in higher education are issues of emerging interest. In The Netherlands, a substantial proportion of students who enrol in a study program leave higher education without completing the first year (Beekhoven, De Jong, \& Van Hout, 2003; Berg \& Hofman, 2005; CBS, 2012). The effects are noticed primarily in the expensive administrative (e.g. changes at the course and program level) and remedial (e.g. counselling) costs of education, institutions have to suffer. Beyond that, in recent years, low progress rates and poor student achievement have been recognized as a waste of human potential for both the higher education systems and for society.

To cope with these unwanted developments, higher education institutes respond with several measures, e.g. 1) Study choice awareness interviews, 2) Selection interviews, 3) Admission tests, and 4) raffle, central and decentral. These developments not only apply to the Netherlands, but also to many other Western countries. Therefore, a deeper insight in the learning achievements, and the mechanisms needed to enhance the learning process, might improve the study success in higher education.

\section{BACKGROUND}

\section{Factors influencing the acquisition of learning achievements}

The first year at university is widely acknowledged as a period of transition, in which most of the students come with high expectations for achievement and experience a lot of pressure under situations over which they have low control (Perry, 2001; Hall, Perry, Ruthig, Hladkyj, \& Chipperfield, 2006). The transition to college comes along with a variety of changes, to which the freshman has to adapt not only academically but also socially and emotionally (Baker \& Siryk, 1999).

As Tinto (1987) points out, the degree of one's social and academic integration influences the likelihood of persistence or departure. Drawing on Tinto's theory, two lines of research can be identified in explaining learning achievements: 1) factors involving the educational environment, and 2) factors focusing on the students' characteristics.

\section{Factors involving the educational environment.}

Recent studies demonstrate the importance of how learning environments are designed on student's academic adaptation to college (Christie, Munro, \& Fisher, 2004; Wilcox, Winn, $\&$ Fyvie-Gauld, 2005). Other research focused on the role of the learning environment, such as curriculum characteristics (Schmidt, Cohen-Schotanus, \& Arends 2009; Schmidt et al. 2010). For example, Schmidt et al. (2010) identified that certain curriculum features, such as extensive lecturing, impede students' time availability for self-study with a detrimental effect on graduation (the association between time available for self-study and graduation and lecturing and graduation resulted respectively in correlations of $r=.44$ and $r=-$ .56). Furthermore, Beekhoven, De Jong, \& Van Hout (2003) showed that courses, which involved a higher number of study hours, proved to be more effective in earning credits 
among first year students. Earlier, Gijselaers and Schmidt (1995) evaluated what might influence the time spent on self-study, and proved that both self-study and achievement depend on the amount of time allocated to instruction as planned by the instructional design. On an even higher level, the review of Schmidt, Muijtjens, Van der Vleuten, and Norman (2012) looking at curriculum effects over student attrition, supports the value of problem-based learning for achievement in medical education. In summary, the influence of the environment is a well-researched issue showing that differential effects on learning outcomes depend on the core characteristics a learning environment displays.

\section{Factors focusing on the students' characteristics}

For decades, Tinto's work (1987) has been one of the most frequently used models in explaining student success in higher education. In Tinto's view, the way students adjust to the learning environment is the key to understand how they perform academically. Tinto (1987) argues that individuals enter institutions with a range of backgrounds, personal attributes, skills, previous education and experiences which can directly impact their adjustment, to influence in turn their persistence. For that purpose, he introduced the term of adjustment to college, which was defined as a continuous interaction process between the student and the institution itself. Recent evidence (Credé \& Niehorster, 2012) shows that depending on how adjustment was conceptualized, relations between college GPA and different adjustments constructs range from $r=.09$ (for social adjustment) to $r=.32$ (for academic adjustment). Classical research followed Tinto's perspective and focused on the role of student variables, such as personality, cognitive factors and demographic variables (Arias, Ortiz \& Dehon, 2013; Credé \& Niehorster, 2011; Noftle \& Robins, 2007; Poropat, 2009). For example, looking at the role of student variables, a meta-analysis of the Five Factor Model of personality and academic performance (Poropat, 2009) finds Conscientiousness consistently associated with college GPA (a population correlation of $r=.24$ ). Following a long tradition, research on classical stable attributes, such as cognitive performance measures, has proven that although high school GPA and other standardized test scores are the best predictors of academic success in the first year, they are not able to predict college retention (Schuh, 1999). Two review studies (Robbins et al., 2004; Richardson \& Abraham, 2012) conclude that individual characteristics, like self-efficacy, effort regulation, and achievement motivation are highly correlated with learning outcomes. However, the evidence concerning learning achievements, by looking at student factors such as learning strategies or motivation, has not been yet systematically mapped in the light of such recent theories. Focusing on factors which are not fixed is of particular relevance since they can be influenced by educational interventions. To date, over the past 20 years learning strategies have been shown as one of the most relevant predictors of several academic outcomes across college education (Entwistle, 1998; Prevatt, Petscher, Proctor, Hurst, \& Adams, 2006). More recently, motivational and emotional research have shared interesting findings with regard to achievement in college, and placed more emphasis on aspects of students' psychological well-being (Pekrun, Goetz, Titz, \& Perry, 2002; Tempelaar, Van der Loeff, Gijselaers, \& Nijhuis, 2011). In particular, Pekrun's work (2000) has unearthed 
important contributions for modelling student learning by attributing engagement to emotions experienced in achievement settings.

\section{Previous efforts}

A significant amount of work has already been accomplished in the research of learning achievements, many reviews have been conducted and further analysed in an attempt to elucidate what works and what does not work in education (Cameron, Roxburgh, Taylor, \& Lauder, 2011; Credé \& Niehorster, 2011; Marzano, Pickering, \& Pollock, 2001; Pascarella \& Terenzini, 1991; Valentine et al., 2011). Probably the most extensive work remains John Hattie's Visible learning; a synthesis of over 800 meta-analyses relating to achievement (Hattie, 2009). His work draws on "about 800 meta-analyses, which encompassed 52,637 studies, and provided 146,142 effect sizes [...] these studies are based on many millions of students" (Hattie, 2009; p. 15). This notable effort encompasses evidence at all educational levels. In the same tradition as the classical contributions, the factors described by Hattie $(2009,2012)$, (e.g. feedback, students' prior cognitive ability, instructional quality) can be categorized as coming from two main influences on achievement in educational settings: the student and the environment characteristics. Hattie (2012) draws the attention upon several limitations of these previous perspectives: First, they tend to examine the separate effects of each factor while neglecting the interaction they might have with each other. Second, the majority of these studies do not make explicit or phrase in an accessible vocabulary the implications for educational practice. And third, the most surprising conclusion is that from a long list of influences on achievement "everything works if the criterion for success is to enhance achievement" (Hattie, 2012; p. 2); in other words, any intervention will have an effect, even if this is minimal. Finally, it is important to note that the framework of these studies doesn't include recent theories stressing the role of motivation and emotion associated with the specific educational context, which allows the possibility of being influenced by educational interventions.

\section{THEORETICAL FRAMEWORK}

Nowadays, the focus of Tinto's theory (which places students adjustment to the institution at the core of his framework) has become even more important when Western societies are recognizing intangible assets, such as intellectual capital, as fundamental sources of wealth and progress (Lin \& Edvinsson, 2012). Considering his theory, the question still remains "what happens to students when they enter a new environment?" To answer this question, imagine, for example, a student enrolling in a mathematics course in the first year of university. Although the student may be very intelligent, depending on the previous experience with mathematics, certain favourable or negative beliefs may already be held about mathematics. These beliefs can influence whether the person enjoys the course and believes (s)he can succeed within it, or whether the person feels hopeless and disengaged. Furthermore, before entering the course, the student may be prone to engage in certain behaviours, which can be beneficial or detrimental towards learning. For instance, one may be able to effectively plan his/her study time or, on the contrary, have a tendency to procrastinate. These 
cognitions and behaviours can influence a student's experience and have consequences on either how one engages and performs in the course or the likelihood of dropping out.

Tinto (1987) argues that individual departure from institutions can be viewed as arising out of a longitudinal process of interactions between an individual, the other members of the system and the institution itself. Central to this process is students' adaptation or engagement, a key concept to understand persistence and dropout in college. Over time, engagement has been conceptualized differently, from adjustment or adaptation (Baker \& Syrik, 1999; Tinto, 1987) to multifaceted views, including behavioral, cognitive and emotional aspects of engagement (Fredricks, Blumenfeld, \& Paris, 2004; Connell \& Wellborn, 1994). This wide range of indicators is needed to understand the totality of students' experiences in the context of first year at university. Such transition period brings several challenges for freshmen, among which an achievement setting that is different from high school, higher academic standards, increased competition, high expectations and perceived pressure to perform (Daniels et al., 2014; Perry, Hall, \& Ruthig, 2005). Much has been written about the uncertainty and negative emotional experiences accompanying this complex and difficult period (Hall, Perry, Ruthig, Hladkyj, \& Chipperfield, 2006; Linnenbrink-Garcia \& Pekrun, 2011; Ruthig et al., 2007). As yet, few scholars have conducted a comprehensive analysis covering the entire first year at university period, to most effectively understand students' engagement through emotional and affective variables (Beard, Clegg, \& Smith, 2007; Perry, Hladkyj, Pekrun, \& Pelletier, 2001; Putwain, Larkin, \& Sander, 2013; Stupnisky, Perry, Hall, \& Guay, 2012). Using contemporary perspectives on motivation and emotions (Martin, 2007; Pekrun, 2006), the present work interprets the classic emotional adjustment (Tinto, 1987) problem to get more insight into freshmen's experiences at university.

The first year of university is recognized as a period of transition for most students (Baker \& Syrik, 1999; Tinto, 1997), in which unpleasant emotions seem particularly intense (Stupnisky et al., 2012). Emotions experienced in academic settings, known as achievement emotions, contribute to students' motivation and can influence academic performance within a course (Pekrun, 2006). Such emotions emerge from students' beliefs about their capacity to influence academic outcomes and the value given to these outcomes, referred to respectively as appraisals of control and value (Pekrun, Goetz, Titz, \& Perry, 2002). At the same time, students enter the university holding a set of generic predispositions toward learning in general, such as adaptive and maladaptive cognitions and behaviors, which will also influence their emotional experiences within a course (Martin, 2007). Furthermore, in a longitudinal context, reciprocal linkages can occur between these constructs (Pekrun, 2006) where appraisals, emotions and performance influence each other over time in a feedback loop beyond a course setting: the contribution of academic emotions in a certain course, for instance, can be observed later on in how students perform in another course. This is an important consideration for educational practice, as emotions are not only end states but also processes which can have long-lasting effects on students' academic achievement (Goetz, Pekrun, Hall, \& Haag, 2006; Pekrun, Hall, Goetz, \& Perry, 2014). 


\section{Achievement emotions}

A first iteration to explain students' engagement through their emotional experience in the first year of university was Tinto's (1987) work. For that purpose, he introduced the term of adjustment to college which was defined as a continuous interaction process between the student and the institution itself. More recently, self-regulated, motivational and emotional learning research has emphasized aspects of students' psychological well-being, and the resulting impact on academic achievements (Pekrun, 2000; Richardson, 2011; Tempelaar, Gijselaers, Schim van der Loeff, \& Nijhuis, 2007). In particular, research on achievement emotions prompts a re-appraisal of the classical models to address the student experience and engagement within a specific course setting (Pekrun et al., 2002). Overall, in this perspective, the learning behavior is driven by personal factors which interact with determinants at the course level to ultimately affect students' emotional experiences and achievement outcomes.

Pekrun (2006) follows contemporary theories on process emotions (Scherer, 2000), to describe emotions as "sets of interrelated psychological processes including affective, cognitive, physiological and motivational components" (Pekrun, Goetz, Frenzel, Barchfeld, \& Perry, 2011, p. 37). For example, being uneasy, worrying, being aroused or wishing to quit a course, reflect these different components with an emotion. More generally, achievement emotions are conceptualized as trait-like (habitually, recurring emotions) or state-like types ("momentary occurrences within a specific situation at a specific point in time", cf. Pekrun 2006, p. 317). While a continuum between state and trait emotions is proposed to describe the achievement emotions encountered within a course (Pekrun et al., 2011), the core characteristic which makes the distinction between the two is the temporal generality of an emotion, as trait achievement emotions, for example, can also be situation specific (such as trait test anxiety). The Control-Value Theory of Achievement Emotions (CVTAE; Pekrun, 2006) provides a three-dimensional taxonomy of emotions, represented by the valence, focus and activation of emotions. Emotional valence can be positive (enjoyment) or negative (anxiety, hopelessness, boredom). The focus describes the emotions experienced in relation to an achievement activity (e.g. boredom experienced whilst preparing homework) or outcome (e.g. anxiety towards performing at an exam). Outcome focused emotions can be retrospective, like anger, following an episode of participating in classroom instruction, for example. At the same time, outcome emotions can be prospective, such as hopelessness anticipating an outcome that is difficult to achieve. The activation component describes emotions as activating (i.e. anxiety leading to action) versus deactivating (i.e. hopelessness leading to disengagement). Hence, activation has to do with the degree of physiological arousal involved in that emotion.

To sum up, academic emotions can be described in terms of components (affective, motivational, cognitive and physiological), dimensions (valence, focus and activation) and temporal specificity (state or trait-type). A last attribute of the academic emotions in Pekrun's theory (2006) is the situational context, in which the emotional experiences are contextualized over different achievement situations within a course, meaning that they can be experienced in different academic situations within a course: 1) being in class, 2) taking 
exams and, 3) studying outside of class (while learning or when preparing homework). Since in the first year of university students are expected to engage in more individual selfstudy beyond just attending lectures, the experience of achievement emotions in learning situations (such as when preparing the homework, for example) is particularly important in this period. Indeed, according to the CVTAE, first year university students experience a variety of learning - related emotions, whether the emotions are positive or negative.

\section{Learning-related emotions and achievement outcomes}

According to Pekrun, Goetz, Titz, \& Perry (2002), the three most important academic settings to experience emotions in a course include: 1) being in class, 2) taking tests and exams, and 3) studying outside of class. As a consequence, each setting is used to measure one type of emotion: class-related, test-related and learning-related emotions. Learningrelated emotions (LREs) are a particular type of achievement emotions, usually experienced in learning situations outside classroom instruction, such as studying or doing homework (Goetz et al., 2012; Pekrun et al., 2002; Pekrun et al., 2011). While other emotional settings, such as taking texts/exams, have been extensively studied, few studies have investigated situations that occur outside the class (Linnenbrink, 2006; Schutz \& Pekrun, 2006; Putwain, Sander et al., 2013; Trautwein et al., 2009). An exception is research on test emotions, (test anxiety in particular), where accepted interventions are helpful in training students to deal with their negative emotional states before or during the exam (Ergene, 2003). While this approach helps students manage negative emotions and clearly benefits the learner in the limited setting of an exam, its scope does not capture the full experience of the learning process for the duration of a full-length course. In order to get more insight into students' emotional experiences outside of the exam situation, investigating the learning situation within a course is needed. In this context, LREs are of particular relevance given their substantial relation with achievement outcomes as shown in correlations as high as $r=.41$ (Goetz et al., 2012). In addition, learning in this setting (e.g. while preparing homework) evokes stronger negative emotions when compared, for example, with the emotional experience of learning in the classroom (Verma et al., 2002). To capture more of the students' emotional experiences within the different learning settings encountered in a course, our study links learning-related emotions and achievement outcomes at the course level. To address this issue we excluded test and class-related emotions and focused solely on the emotional experience of studying outside the classroom, either during individual study or when preparing homework.

\section{Learning - related emotions and their antecedents}

According to the Control-Value Theory of Achievement Emotions (CVTAE; Pekrun, 2006), discrete learning-related emotions (LREs) arise from the appraisal of achievement activities and outcomes. Emotions that result from such appraisals can indirectly influence achievement outcomes. There are two dimensions of appraisals: control and value. The appraisal of control refers to a student's belief about whether he/she has control over learn- 
ing activities/outcomes; the appraisal of value describes the subjective value attributed to these activities/outcomes. These appraisals are considered direct antecedents of LREs and are acquired at the course level (Pekrun, 2006). As a general rule, low and high levels of control appraisals influence emotions differently (Pekrun, 2000). For instance, low control leads to an increased level in negative emotions (e.g., learning anxiety) and a more elevated level of control favours a heightened experience of positive emotions (such as learning enjoyment). In a longitudinal context, this postulate implies that increasing levels of control and value appraisals will raise the levels of positive emotions, (such as joy), and lower the levels of negative emotions, (like anxiety). Likewise, a decrease in the levels of the antecedents has an opposite effect. In other words, this assumption - referred to as the changechange parameterization of CVTAE (Buff, 2014) - has two practical implications: increasing the levels of LREs' antecedents is expected to raise the levels of positive emotions and decrease the levels of negative emotions. This assumption was empirically investigated and confirmed by Buff (2014) for the positive LRE of enjoyment. Indeed, Buff (2014) found that positive changes in perceived control and value lead to positive changes in enjoyment of learning in mathematics for sixth graders. The transition from high school to university would shape an excellent context to investigate changes in negative LREs, as a consequence of changes in direct antecedent variables (such as appraisals of control, for instance). Nevertheless, up to now, empirical evidence testing the change-change assumption in this period has not been dated in introductory courses in particular and, in the first year at university, more generally. The present work tries to fill in this gap.

There are also more general expectancies and predispositions towards learning at university that students already hold when entering a course, which can be considered generic antecedents of LREs. Since appraisals of control and value are based on these generic tendencies, the latter can be considered distal antecedents of learning emotions. Students enter a new course holding background characteristics (intelligence, personality, high school GPA etc.) but also possessing a set of adaptive and impeding cognitions, and adaptive and impeding behaviors, towards learning in the new setting of university (Martin, 2007). Therefore, we applied the 'motivation and engagement wheel' framework of Martin $(2007,2009)$ as a model for distal antecedents of learning-related emotions (LREs). The motivation and engagement wheel breaks down all motivation and engagement concepts into four categories: adaptive cognitions, adaptive behaviors, impeding cognitions, and maladaptive behaviors. These four categories each consist of two or three sub-dimensions. For adaptive cognitions, the dimensions consist of self-belief, valuing school, and learning focus. Furthermore, the adaptive behavioral dimensions include persistence, planning, and task management. Conversely, the impeding or deactivating antipodes of the cognitions (that obstruct learning rather than enhance it) include anxiety, failure avoidance and uncertain control. The maladaptive behaviors are twofold: self-handicapping and disengagement. The concepts operating in this motivation and engagement wheel represent generic orientations that are relatively stable over contexts (Martin, 2009). For this reason, in Pekrun's Theory, such generic orientations can be integrated as distal antecedents of both control and value appraisals and LREs. Although it may appear that some of the concepts (e.g. selfbelief/efficacy, persistency and control) from the "motivation and engagement wheel" are closely related to the appraisal of control in the CVTAE, it is important to ensure clarity 
between them: while the distal antecedents are more trait-type of constructs, the direct antecedent (appraisal of control) is a subject specific type of appraisal.

Figure 1 summarizes the conceptual model used in our study.

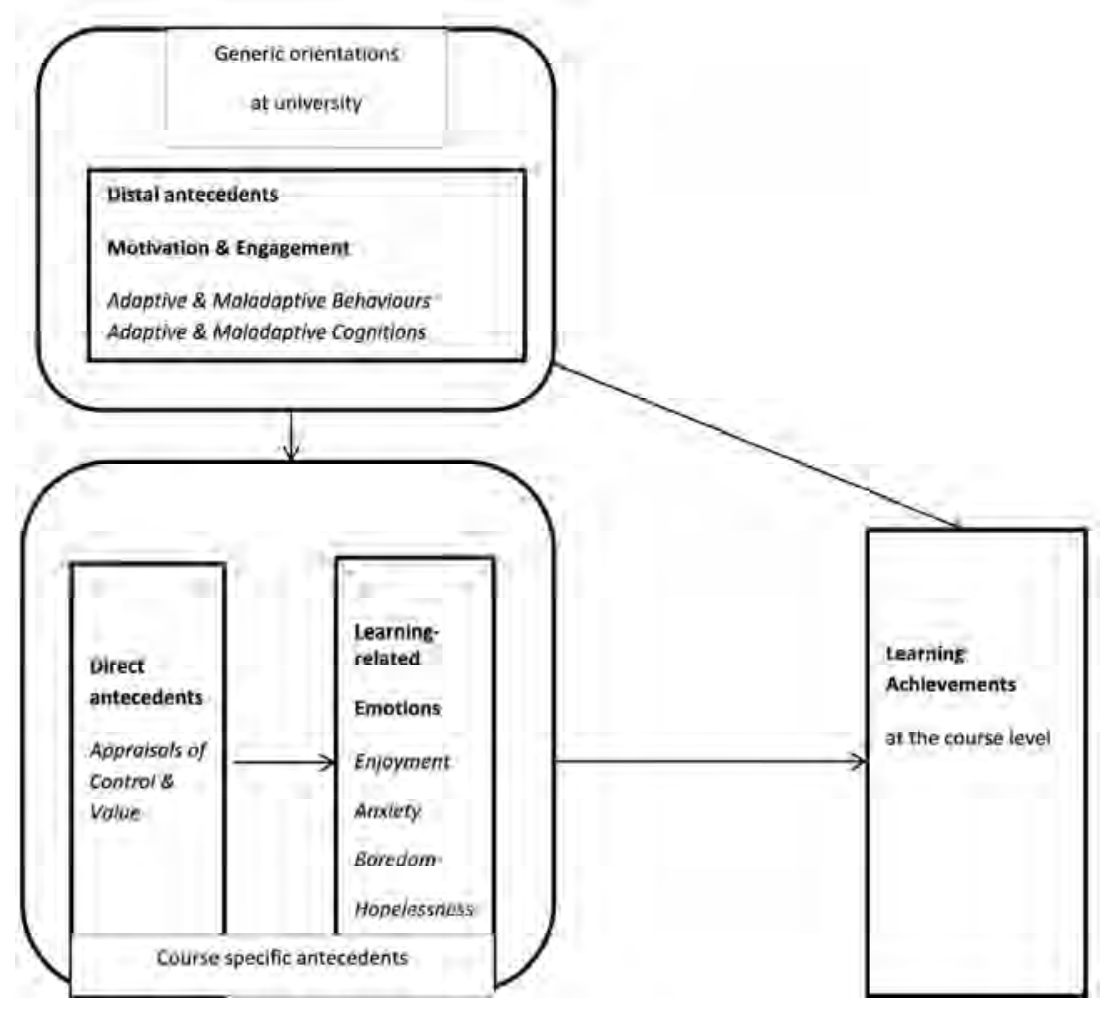

Figure 1. The conceptual framework of the study

\section{AIM, OBJECTIVES AND RESEARCH QUESTION}

Because it is important to show how the individual experiences the new pedagogical environment in the interaction with the characteristics a person brings in a new setting in the first year at university, we aimed to answer the follow question:

How do achievement learning-related emotions and their direct and distal antecedents explain students' achievement in the first year at university?

More specifically, we want to capture the freshmen experience at university through emotional and motivational variables. In this way, practical strategies to intervene on students' characteristics and learning environments can be formulated.

Using Pekrun's (2006) framework as the leading approach, we build further on the work of Tempelaar et al. (2012) that acknowledges the importance of achievement motivation and 
emotion on learning when students enter university. Furthermore, we follow Buff s (2014) methodological approach to look at the relationships between changes in control appraisals and changes in achievement emotions over two, first-year courses. To provide a more complete picture of the first year of university experience, we also included distal antecedents of achievement emotions (the prior characteristics students bring with them before they enter university) from Martin's framework (Martin, 2007), and their potential effects on these emotions and their changes.

For the purpose of this thesis, we focus on four academic emotions experienced in learning-related situations: the positive emotion Enjoyment and the negative emotions Anxiety, Boredom and Hopelessness. Class-related emotions and test emotions were deemed to be beyond the scope of our study, as learning Enjoyment, Anxiety and Boredom are shown to be particularly salient in academic settings (Goetz et al., 2006). Furthermore, the choice of these learning-related emotions is justified by previous research showing them as the prime emotions related to academic achievement (Pekrun, 2000, 2006; Pekrun et al., 2011, 2002).

To answer our research question, we used a large sample $(N=3451)$, employed in a longitudinal research design. We included two courses, one at the beginning and the other at the end of the first year at university.

\section{DISSERTATION OUTLINE}

Chapter 2 examines the predictive value of four learning emotions - Enjoyment, Anxiety, Boredom and Hopelessness - on two achievement outcomes within a mathematics and statistics course: 1) participation in the final exam and, for those students who attended the exam, 2) explain their performance in the course.

Chapter 3 looks how distinct LREs emerge from course contextualized appraisals and distal generic antecedents and further, how they influence achievement outcomes in a first year university mathematics and statistics course.

Chapter 4 follows Buffs (2014) empirical study, in an attempt to investigate the relationships between changes in control appraisals and changes in both positive and negative learning-related emotion (LREs). This study focuses on control appraisals as antecedent factors for both positive and negative academic emotions in the first year at university. According to the Control-Value Theory of Achievement Emotions, these emotions emerge from control appraisals. Then, this study investigates if changes in control appraisals relate to changes in academic emotions at two instances over the duration of a course.

Chapter 5 aims to look at how LREs emerge in the first year at university and how they further develop over two different course subjects. This investigation extend (expands) upon Buffs (2014) approach by including negative, as well as positive multiple LREs to further test the assumption that negative LREs also change over time. This is in line with the Control-Value Theory of Achievement Emotions change-change hypothesis in two ways: within a course and over two different course subjects in the first year at university. 
This dissertation is a collection of closely related studies that are presented in chapters two to five. Since every chapter was written to be read on its own, repetition and overlap across chapters are inevitable.

\section{REFERENCES}

Aronowitz, S. (2000). The knowledge factory: dismantling the corporate university and creating true higher education. Boston: Beacon

Asmar, C. (2005). Internationalising students: reassessing diasporic and local student difference. Studies in Higher Education, 30(3), 291-309.

Baker, R. W., \& Siryk, B. (1999). SACQ Student Adaptation to College Questionnaire (2nd edition ed.). Los Angeles: Western Psychological Services.

Barab, S. A., \& Plucker, J. A. (2002). Smart people or smart contexts? Cognition, ability, and talent development in an age of situated approaches to knowing and learning. Educational Psychologist, 37(3), 165-182.

Barrie, S. C. (2007). A conceptual framework for the teaching and learning of generic graduate attributes. Studies in Higher Education, 32(4), 439-458.

Beard, C., Clegg, S., \& Smith, K. (2007). Acknowledging the affective in higher education. British Educational Research Journal, 33(2), 235-252. http://doi.org/10.1080/01411920701208415

Beekhoven, S., De Jong, U., \& Van Hout, H. (2003). Different courses, different students, same results? An examination of differences in study progress of students in different courses. Higher Education, 46(1), 37-59.

Berg, M. N. V. D., \& Hofman, W. H. A. (2005). Student Success in University Education: A Multimeasurement Study of the Impact of Student and Faculty Factors on Study Progress. Higher Education, 50(3), 413-446. http://doi.org/10.1007/s10734-004-6361-1

Boud, D. (2006). "Aren't we all learned-centred now?"; the bittersweet flavour of success. In P.Ashwin (ed) Changing higher education: The development of learning and teaching. London: Routledge.

Cameron, J., Roxburgh, M., Taylor, J., \& Lauder, W. (2011). An integrative literature review of student retention in programmes of nursing and midwifery education: why do students stay? Journal of Clinical Nursing, 20(910), 1372-1382. http://doi.org/10.1111/j.1365-2702.2010.03336.x

Carroll, J. B. (1993). Human cognitive abilities: A survey of factor-analytic studies. New York: Cambridge University Press.

Cattell, R. B. (1987). Intelligence: Its structure, growth and action. Amsterdam: Elsevier.

Centraal Bureau voor de Statistiek CBS (2012). Number of school dropouts down in the Netherlands and the EU (Web magazine). Retrieved March 19, 2015, from http://www.cbs.nl/enGB/menu/themas/onderwijs/ publicaties/artikelen/archief/2014/2014-3940-wm.htm

Christie, H., Munro, M., \& Fisher, T. (2004). Leaving university early: exploring the differences between continuing and non-continuing students. Studies in Higher Education, 29, 617-636.

Connell, J., \& Wellborn, J. (1994). Engagement versus disaffection: Motivated patterns of action in the academic domain. Rochester, NY: University of Rochester.

Credé, M., \& Niehorster, S. (2011). Adjustment to College as Measured by the Student Adaptation to College Questionnaire: A Quantitative Review of its Structure and Relationships with Correlates and Consequences. Educational Psychology Review, 24(1), 133-165. http://doi.org/10.1007/s10648-011-9184-5

Entwistle, N., \& Waterston, S. (1988). Approaches to studying and levels of processing in University students. British Journal of Educational Psychology, 58, 258 - 265.

Ergene, T. (2003). Effective Interventions on Test Anxiety Reduction: A Meta-Analysis. School Psychology International, 24(3), 313-328. http://doi.org/10.1177/01430343030243004

Goetz, T., Nett, U. E., Martiny, S. E., Hall, N. C., Pekrun, R., Dettmers, S., \& Trautwein, U. (2012). Students' emotions during homework: Structures, self-concept antecedents, and achievement outcomes. Noncognitive Skills in Education: Emerging Research and Applications in a Variety of International Contexts, 22(2), 225-234. http://doi.org/10.1016/j.lindif.2011.04.006 
Goetz, T., Pekrun, R., Hall, N., \& Haag, L. (2006). Academic Emotions from a Social-Cognitive Perspective: Antecedents and Domain Specificity of Students' Affect in the Context of Latin Instruction. British Journal of Educational Psychology, 76(2), 289-308.

Guilford, J. P. (1967). The nature of human intelligence. New York: McGraw-Hill.

Hall, N. C., Perry, R. P., Ruthig, J. C., Hladkyj, S., \& Chipperfield, J. G. (2006). Primary and Secondary Control in Achievement Settings: A Longitudinal Field Study of Academic Motivation, Emotions, and Performance1. Journal of Applied Social Psychology, 36(6), 1430-1470.

Hattie, J. (2009). Visible learning. A synthesis of over 800 meta-analyses relating to achievement. New York: Routledge.

Immordino-Yang, M. H., \& Damasio, A. (2007). We feel, therefore we learn: The relevance of affective and social neuroscience to education. Mind, Brain, and Education, 1(1), 3-10.

Lave, J. (1986). The values of quantification. In J. Law (Ed.), Power, action, and belief. (pp. 88-111). Boston, MA: Routledge \& Kegan Paul

Lin, C. Y., \& Edvinsson, L. (2012). National intellectual capital model and measurement. International Journal of Knowledge-Based Development, 3(1), 58-82. http://doi.org/10.1504/IJKBD.2012.045570

Linnenbrink-Garcia, L., \& Pekrun, R. (2011). Students' emotions and academic engagement: Introduction to the special issue. Students' Emotions and Academic Engagement, 36(1), 1-3. http://doi.org/10.1016/ j.cedpsych.2010.11.004

Marzano, R. J., Pickering, D. J., \& Pollock, J. E. (2001). Classroom instruction that works: Research-based strategies for increasing student achievement. Alexandria, VA: Association for Supervision and Curriculum Development.

Newell, A., \& Simon, H. A. (1972). Human problem solving. Englewood Cliffs, NJ: Prentice Hall.

Niculescu, A., Nijhuis, J., Gijselaers, W. (2010), Curriculum design, student's nationality and its effects on adaptation to university: What makes the difference? Paper presented on the annual meeting of the American Educational Research Association, Denver, US, April 2010.

Niculescu, A., Segers, de Regt, E., Gijselaers, W. (2012), A Tutor Feedback Intervention in Problem-Based Learning and its Effects on Student Learning. Paper presented on the annual meeting of the American Educational Research Association, Vancouver, Canada, April 2012.

Nijhuis, J., Segers, M., \& Gijselaers, W. (2008). The extent of variability in learning strategies and students' perceptions of the learning environment. Learning and Instruction, 18(2), 121-134. http://doi.org/ 10.1016/j.learninstruc.2007.01.009

Pascarella, E. T., \& Terenzini, R T. (1991). How college affects students: findings and insights from twenty years of research. San Francisco: Jossey-Bass.

Pekrun, R. (2000). A social-cognitive, control-value theory of achievement emotions. In J. Heckhausen (Ed.), Motivational psychology of human development: Developing motivation and motivating development. (pp. 143163). New York, NY US: Elsevier Science. Retrieved from http://search.ebscohost.com/login.aspx? direct=true $\& \mathrm{db}=$ psyh \&AN=2001-10168-007\&site=ehost-live \&scope $=$ site

Pekrun, R. (2006). The Control-Value Theory of Achievement Emotions: Assumptions, Corollaries, and Implications for Educational Research and Practice. Educational Psychology Review, 18(4), 315-341.

Pekrun, R., Goetz, T., Frenzel, A. C., Barchfeld, P., \& Perry, R. P. (2011). Measuring emotions in students' learning and performance: The Achievement Emotions Questionnaire (AEQ). Contemporary Educational Psychology, 36(1), 36-48. http://doi.org/10.1016/j.cedpsych.2010.10.002

Pekrun, R., Goetz, T., Titz, W., \& Perry, R. P. (2002). Academic emotions in students' self-regulated learning and achievement: A program of qualitative and quantitative research. Educational Psychologist, 37(2), 91-106.

Pekrun, R., \& Linnenbrink-Garcia, L. (2012). Academic Emotions and Student Engagement. In S. L. Christenson, A. L. Reschly, \& C. Wylie (Eds.), Handbook of Research on Student Engagement (pp. 259-282). Springer US. Retrieved from http://dx.doi.org/10.1007/978-1-4614-2018-7_12

Perry, R. P., Hladkyj, S., Pekrun, R. H., \& Pelletier, S. T. (2001). Academic control and action control in the achievement of college students: A longitudinal field study. Journal of Educational Psychology, 93(4), 776.

Prevatt, F., Petscher, Y., Proctor, B. E., Hurst, A., \& Adams, K. (2006). The revised learning and study strategies inventory - An evaluation of competing model. Educational and Psychological Measurement, 66(3), 448-458.

Putwain, D. W., Larkin, D., \& Sander, P. (2013). A reciprocal model of achievement goals and learning related emotions in the first year of undergraduate study. Contemporary Educational Psychology, 38(4), 361-374. http://doi.org/10.1016/j.cedpsych.2013.07.003 
Putwain, D. W., Sander, P., \& Larkin, D. (2013). Using the $2 \times 2$ framework of achievement goals to predict achievement emotions and academic performance. Learning and Individual Differences, 25(0), 80-84. http://doi.org/10.1016/j.lindif.2013.01.006

Richardson, J. T. E. (2011). Approaches to studying, conceptions of learning and learning styles in higher education. Applying Styles Research to Educational Practice, 21(3), 288-293. http://doi.org/10.1016/ j.lindif.2010.11.015

Reed, H. J., \& Lave, J. (1979). Arithmetic as a tool for investigating relations between culture and cognition. American Ethnologist, 6 (93), 58-82

Robbins, S., Lauver, K., Huy, L., Davies, d., Langley, R., Carlstrom, A., (2004) Do Psychological and Study Skill Factors Predict college outcomes? A Meta-Analysis, Psychological Bulletin, 130 (2), 261-288.

Ruthig, J. C., Perry, R. P., Hladkyj, S., Hall, N. C., Pekrun, R., \& Chipperfield, J. G. (2007). Perceived control and emotions: interactive effects on performance in achievement settings. Social Psychology of Education, 11(2), 161-180. http://doi.org/10.1007/s11218-007-9040-0

Schmidt, H., Cohen-Schotanus, J., van der Molen, H., Splinter, T., Bulte, J., Holdrinet, R., \& van Rossum, H. (2010). Learning more by being taught less: a "time-for-self-study" theory explaining curricular effects on graduation rate and study duration. Higher Education, 60(3), 287-300. http://doi.org/10.1007/s10734-0099300-3

Schmidt, H. G., Cohen-Schotanus, J., \& Arends, L. R. (2009). Impact of problem-based, active learning on graduation rates for 10 generations of Dutch medical students. Medical Education, 43(3), 211-218. http://doi.org/10.1111/j.1365-2923.2008.03287.x

Schmidt, H. G., Muijtjens, A. M. M., Van der Vleuten, C. P. M., \& Norman, G. R. (2012). Differential Student Attrition and Differential Exposure Mask Effects of Problem-Based Learning in Curriculum Comparison Studies. Academic Medicine, 87(4), 463-475. http://doi.org/10.1097/ACM.0b013e318249591a

Schuh, J. H. (1999). Examining the Effects of Scholarships on Retention in a Fine Arts College. Journal of College Student Retention, 1(3), 193-202,.

Schunk, D. H., Pintrich, P. R., \& Meece, J. L. (2013). Motivation in education: Theory, research, and applications (ed. 4). NJ: Pearson.

Stipek, D. (2011). Education Is Not a Race. Science, 332(6037), 1481-1481. http://doi.org/10.1126/science. 1209339

Stupnisky, R. H., Perry, R. P., Hall, N. C., \& Guay, F. (2012). Examining perceived control level and instability as predictors of first-year college students' academic achievement. Contemporary Educational Psychology, 37(2), 81-90. http://doi.org/10.1016/j.cedpsych.2012.01.001

Tempelaar, D. T., Gijselaers, W. H., Schim van der Loeff, S., \& Nijhuis, J. F. H. (2007). A structural equation model analyzing the relationship of student achievement motivations and personality factors in a range of academic subject-matter areas. Applications of Latent Variable Modeling in Educational Psychology Research, 32(1), 105-131. http://doi.org/10.1016/j.cedpsych.2006.10.004

Tempelaar, D. T., Loeff van der, S. S., Gijselaers, W. H., \& Nijhuis, J. F. H. (2011). On subject variations in achievement motivations: A study in Business subjects. Research in Higher Education, 52, 395-419.

Tinto, V. (1987). Leaving college, Rethinking the causes and cures of student attrition. Chicago: The University of Chicago.

Tinto, V. (1998). Colleges as Communities: Taking Research on Student Persistence Seriously. The Review of Higher Education 21(2), 167-177.

Trautwein, U., Schnyder, I., Niggli, A., Neumann, M., \& Lüdtke, O. (2009). Chameleon effects in homework research: The homework-achievement association depends on the measures used and the level of analysis chosen. Contemporary Educational Psychology, 34(1), 77-88. http://doi.org/10.1016/j.cedpsych. 2008.09.001

Valentine, J. C., Hirschy, A. S., Bremer, C. D., Novillo, W., Castellano, M., \& Banister, A. (2011). Keeping AtRisk Students in School: A Systematic Review of College Retention Programs. Educational Evaluation and Policy Analysis, 33(2), 214-234. http://doi.org/10.3102/0162373711398126

Verma, S., Sharma, D., \& Larson, R. W. (2002). School stress in India: Effects on time and daily emotions. International Journal of Behavioral Development, 26(6), 500-508. http://doi.org/10.1080/ 01650250143000454

Weiner, B. (1992). Human motivation: Metaphors, theories, and research. Newbury Park, CA: Sage

Wilcox, P., Winn, S., \& Fyvie-Gauld, M. (2005). It was nothing to do with the university, it was just the people: the role of social support in the first-year experience of higher education. Studies in Higher Education, 30(6), 707-722. 


\section{CHAPTER 2}

Feelings and performance in the first year at university

Learning-related emotions as predictors of achievement outcomes in mathematics and statistics

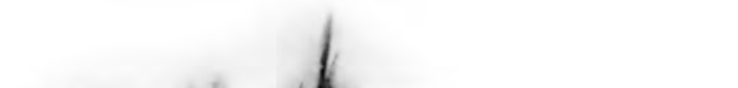

This chapter is submitted as:

Niculescu, A., Tempelaar, D., Leppink, J., Dailey-Hebert, A., Segers, M., \& Gijselaers, W. (under review). Feelings and performance in the first year at university: Learning-related emotions as predictors of achievement outcomes in mathematics and statistics. Electronic Journal of Research in Educational Psychology 


\section{ABSTRACT}

This study examined the predictive value of four learning emotions - Enjoyment, Anxiety, Boredom and Hopelessness - on achievement outcomes. Using a large sample $(\mathrm{N}=2337)$ of undergraduate first year students enrolled in a mathematics and statistics course, we first showed significant differences in the emotional experiences between the students who attended - as compared to those who were absent for the exam. Second, the present study revealed emotions, particularly learning hopelessness, and a prior mathematics background, to have a strong predictive value for student performance in the course. This relation was consistent over three consecutive academic years. Recommendations for improving educational practice have been formulated and are shared in this article. 


\section{INTRODUCTION}

The first year of university is a crucial area to investigate, notoriously recognized as a period of transition in which a significant majority of students experience adjustment difficulties. The struggle of this transition period involves novel situations that challenge students to make academic, social, and emotional adjustments in order to adapt to their new educational environment (Baker \& Siryk, 1984; Daniels et al., 2014; Pascarella \& Terenzini, 1991). Tinto's (1987) research provides a classic demonstration of how students' adaptation to a new learning environment is the key to understand how they perform academically. Likewise, other studies have shown that poor adjustment was linked to low achievement scores (Credé \& Niehorster, 2012) and even withdrawal at the course level (Ruthig et al., 2008). For instance, Credé and Niehorster's (2012) meta-analysis found correlations between college GPA and different adjustment constructs - ranging from $r=.09$ (for social adjustment) to $r=.32$ (for academic adjustment). In relation to adaptation, classical approaches have also identified that student variables - such as personality, cognitive factors or demographics, - are indeed able to predict achievement outcomes in college (Arias Ortiz \& Dehon, 2013; Credé \& Niehorster, 2011, 2012; Noftle \& Robins, 2007; Poropat, 2009). For example, a meta-analysis of the Five Factor Model of Personality (Poropat, 2009) finds Conscientiousness consistently associated with college GPA (a population correlation of $r=$ .24). Despite reaching acceptable predictive values for achievement outcomes in these approaches, which focused on student variables, substantial variance has been left unaccounted for (Pascarella \& Terenzini, 2005). More recently, contemporary research has introduced the importance of academic emotions on achievement outcomes (Pekrun \& LinnenbrinkGarcia, 2014). Pekrun's work $(2000,2006)$ has emerged as one of the first frameworks to acknowledge the centrality of emotions in achievement settings. This line of research demonstrates relatively stronger relationships with achievement outcomes, as shown in substantial correlations of discrete emotions and individual performance in the $.30-.50$ range (Pekrun et al., 2011). Over the past twenty years, serious theoretical advances have been made on understanding the role of academic emotions in achievement situations (Goetz et al., 2006; Pekrun, 1992; Stöber \& Pekrun, 2004; Zeidner, 1998). However, a lack of empirical research exists on the role these emotions have in explaining achievement outcomes (Linnenbrink, 2006; Elliot \& Pekrun, 2007) and in explaining ecologically valid situations (such as when students enter university). Therefore, to better predict achievement outcomes in the first year of college, more research is needed on the role of academic emotions in these settings. To fill in this gap, our study aims to investigate the predictive value of achievement emotions on course outcomes among first year university students.

In the following section, we will first introduce academic emotions and then describe the particular types of academic emotions experienced within the different settings of a course. Next, we will summarize the empirical evidence linking academic emotions with achievement outcomes in the first year of university - more specifically, in mathematics and statistics courses. We conclude this section with the specific aim and the hypotheses of our study. 


\section{Conceptual framework}

To get a better understanding and prediction of achievement outcomes, contemporary research on self-regulated, motivational and emotional learning has emphasized aspects of students' psychological well-being and the resulting influence on academic achievements (Pekrun et al., 2002; Tempelaar et al., 2012). To date, two recent review studies (Robbins et al., 2004; Richardson et al., 2012) conclude that individual characteristics, such as selfefficacy, effort regulation, and achievement motivation are highly correlated with learning outcomes. In particular, Pekrun's work (2000) expands on this perspective and describes academic emotions as subjective experiences, which arise as a reaction to the course setting. Academic emotions are defined in this context as "emotions that are directly linked to achievement activities and outcomes" (Pekrun et al., 2011, p. 37). Therefore, research on academic emotions prompts a re-appraisal of the classical models on self-regulated and motivational learning, to address the student experience within a specific course (Pekrun et al., 2002). Of particular relevance is the role of academic emotions in abstract or difficult subjects, such as Mathematics and Statistics. In such courses, even for students with high cognitive abilities, learning is impeded by negative attitudes and beliefs students hold towards such courses (Gal \& Ginsburg, 1994; Garfield \& Ben-Zvi, 2007). Not surprisingly, research shows that students experience elevated levels of unpleasant emotions when enrolled in courses on Mathematics or Statistics (Dettmers et al., 2011). Furthermore, Dettmers' et. al. study found that elevated levels of negative emotions influence students' amount of effort and disengagement from study, to predict negative achievement in mathematics.

\section{Academic emotions and the Control-Value Theory of Achievement Emotions}

The Control Value of Achievement Emotions (CVTAE; Pekrun, 2006) builds upon classical theories of emotions, such as expectancy-value (Pekrun, 1992; Turner \& Schallert, 2001), transactional approaches (Lazarus \& Folkman, 1984) and attribution theory (Weiner, 1985). It also builds upon contemporary models of emotions and their effects on performance (Fredrickson, 2001; Pekrun et al., 2002; Zeidner, 2007). However, CVTAE goes beyond these approaches by placing the emotional experiences in achievement situations, which helps to distinguish between two types of emotions: activity and outcomerelated emotions (Pekrun et al., 2011). For instance, boredom felt while attending lectures is an activity emotion; and anxiety anticipated towards the exam is an outcome-related emotion. Pekrun (2006) follows contemporary theories on process emotions (Scherer, 2005), to describe emotions as "sets of interrelated psychological processes including affective, cognitive, physiological and motivational components" (Pekrun et al., 2011, p. 37). For example, being uneasy, worrying, being aroused, or wishing to quit a course, reflect these different components within an emotion. The CVTAE further depicts emotions as having a valence. In this respect, emotional valence can be either positive (enjoyment) or negative (anxiety, hopelessness, boredom). Beyond this distinction, an important attribute of academic emotions in the CVTAE is the situational context, in which the emotional experiences are contextualized over different achievement situations within a course: being 
in class, taking exams and studying outside of class. To summarize, academic emotions can be described in terms of: 1) activity or outcome, dependent upon their focus; 2) valence, as either positive or negative emotions, and 3) situational in context, depending on the different settings of a course in which emotions are experienced (in class, while learning, or while completing an exam). Finally, CVTAE proposes that academic emotions predict learning related behaviors (such as learning strategies), which in turn influence achievement outcomes.

\section{Learning-related emotions and achievement outcomes}

According to Pekrun et al. (2002), the three most important academic settings to experience emotions in a course include: 1) being in class, 2) taking tests and exams, and 3) studying outside of class. As a consequence, each setting is used to measure one type of emotion: class-related, test-related and learning-related emotions. Learning-related emotions (LREs) are a particular type of achievement emotions, usually experienced in learning situations outside classroom instruction, such as studying or doing homework (Goetz et al., 2012; Pekrun et al., 2002; Pekrun et al., 2011). While other emotional settings, such as taking texts/exams, have been extensively studied, few studies have investigated situations that occur outside the class (Linnenbrink, 2006; Schutz \& Pekrun, 2006; Putwain, Sander et al., 2013; Trautwein et al., 2009). An exception is research on test emotions, (test anxiety in particular), where accepted interventions are helpful in training students to deal with their negative emotional states before or during the exam (Ergene, 2003). While this approach helps students manage negative emotions and clearly benefits the learner in the limited setting of an exam, its scope does not capture the full experience of the learning process for the duration of a full-length course. In order to get more insight into students' emotional experiences outside of the exam situation, investigating the learning situation within a course is needed. In this context, LREs are of particular relevance given their substantial relation with achievement outcomes as shown in correlations as high as $r=.41$ (Goetz et al., 2012). In addition, learning in this setting (e.g. while preparing homework) evokes stronger negative emotions when compared, for example, with the emotional experience of learning in the classroom (Verma et al., 2002). To capture more of the students' emotional experiences within the different learning settings encountered in a course, our study links learning-related emotions and achievement outcomes at the course level. To address this issue we excluded test and class-related emotions and focused solely on the emotional experience of studying outside the classroom, either during individual study or when preparing homework.

\section{Empirical evidence linking learning-related emotions and achievement outcomes}

Earlier advances have supported the influence of emotional experiences on academic performance by providing empirical evidence with a main focus on domain differences (Leone \& Richards, 1989; Verma et al., 2002). More recently, the focus was brought on structural relations between different types of academic emotions and achievement outcomes (Dettmers et al., 2011; Goetz et al., 2012; Goetz et al., 2013 ). This recent research discusses 
students' emotional experiences during mathematics homework (Dettmers et al., 2011; Goetz et al., 2012). Generally speaking, the homework assignments are considered "emotionally charged activities" (Dettmers et al., 2011, p. 25), where students seem to experience the most unpleasant emotions when compared with other academic situations (Leone \& Richards, 1989). For instance, Dettmers et. al. (2011) focused on the experience of unpleasant emotions during homework and demonstrated how elevated anxiety and boredom levels shape effort and disengagement in study, to predict negative achievement in mathematics. Dettmers et al. study, conducted in a sample of $9^{\text {th }}$ and $10^{\text {th }}$ grade students, found correlation between unpleasant emotions and mathematics achievement in the range of $r=-.14$ to $r=-.26$. Similar values were displayed by Goetz et al. (2012) in a sample of $11^{\text {th }}$ grade students: the range of correlations between homework emotions and mathematics achievement was between $r=.03$ and $r=.41$. Overall, these studies have shown that LREs are able to predict course achievements in primary (Leone \& Richards, 1989; Verma et al., 2002) and secondary education (Dettmers et al., 2011; Goetz et al., 2012). To our best knowledge, LREs in the first year of university have received little attention (Putwain, Sander, \& Larkin, 2013; Putwain, Larkin, \& Sander, 2013; Tempelaar et al., 2012) despite their potential to predict achievement outcomes. There remains a window in the first year of university in which more empirical evidence could be added on the role of LREs in predicting achievement outcomes (Beard, Clegg, \& Smith, 2007). This is especially relevant now, when the study of students' emotional experiences and coping strategies still forms an almost neglected field (Linnenbrink-Garcia \& Pekrun, 2011).

\section{This study}

Building on Pekrun's framework, we focus on four academic emotions experienced in learning-related situations: the positive emotion Enjoyment and the negative emotions Anxiety, Boredom and Hopelessness. Class-related emotions and test emotions were deemed to be beyond the scope of our study, as learning Enjoyment, Anxiety and Boredom are shown to be particularly salient in academic settings (Goetz et al., 2006).

\section{Aim}

The present study examines the predictive value of four learning emotions - Enjoyment, Anxiety, Boredom and Hopelessness - on two achievement outcomes within a mathematics and statistics course: 1) participation in the final exam and, for those students who attended the exam, 2) explain their performance in the course.

\section{Hypotheses}

Previously, research has shown that negative LREs have a strong impact on academic performance in mathematics and statistics domains (Dettmers et al., 2011) as well as other subjects (Putwain, Larkin, et al., 2013; Trautwein et al., 2009). Furthermore, in introductory courses, negative emotions are able to predict student withdrawal at the course level 
(Ruthig et al., 2008). In particular Hopelessness, a "neighboring emotion" of Anxiety, has shown high correlation with achievement outcomes and an ability to longitudinally predict disengagement from study (Pekrun et al., 2002, 2004). In line with these previous findings, we hypothesize the four LREs to have an influence on two achievement outcome in a course: 1) on the participation in final exam and, for those who participated in the exam, 2) on their overall performance in the course. We formulated the following hypotheses:

H1. Students who were absent for the exam show less learning Enjoyment, more learning Anxiety, more Boredom, and more Hopelessness than the students who attended the exam.

H2. The positive emotion enjoyment, has a positive influence on students' performance; the negative emotions, anxiety, boredom and hopelessness, have a negative influence on performance.

\section{METHOD}

\section{Sample}

The sample consisted of first year university students $(N=2337)$, enrolled in an undergraduate Economics and an International Business degree programs at a Dutch University over three consecutive academic years $2010(N=600), 2011(N=847)$ and $2012(N=$ $890)$. In the academic year 2010, the students were on average 20.0 years (range $17.4-$ 30.7 ), in 2011 the average age was 21.3 (range 18.2 - 41.7), and in 2012, 19.6 (range 17.0 - 27.4). In all three academic years, most of the students were male $(60.6 \%$ in 2010 , $64.6 \%$ and $62.2 \%$ in 2011 and 2012 , respectively). The participants had a predominantly international background, with a vast majority of German nationality $(55.2 \%$ in 2010 , $58.5 \%$ in 2011 and $51.7 \%$ in 2012), followed by Dutch (28.5\% in 2010, 24.2\% in 2011, and $27.4 \%$ in 2012) and Belgian (5.2\% in 2010, 5.6\% in 2011, and 6.0\% in 2012), while the remaining were mostly European. Consequently, most students had a foreign $(66.7 \%$ in 2010, 78.8\% in 2011 and 66.9\% in 2012) instead of a Dutch secondary education diploma. Overall, a high proportion of our participants had previously been educated in the field of mathematics $(25.4 \%$ had a MathMajor level for the year 2010, 32.4\% for 2011 and $33.1 \%$ for 2012).

\section{Setting}

The program offered by this school has two main characteristics: first, it has a strong international focus which is reflected in a high proportion of students with an international background and, in English being the main language of instruction. Second, the university uses Problem-Based Learning (PBL) as its leading educational approach (Barrows \& Tamblyn, 1980). PBL involves students working in small groups to solve problems under the guidance of a tutor (Wilkerson \& Gijselaers, 1996). While PBL is the dominant mode of instruction, in a limited number of courses, the tutorial groups are supplemented by traditional lectures. The course chosen as a setting in the present study, Quantitative Methods I (QM I) represents a combination of both educational approaches. QM I is a 
compulsory introduction to mathematics and statistics, in which students from both Economics and International Business tracks enroll. The course is scheduled in the first term of the academic year, and is the first of a series of required courses in our faculty. It has a duration of eight weeks (out of which, seven weeks are scheduled for education and the last week is reserved for exams). In weeks three, five and seven of the course, voluntary math and statistics quizzes are planned which, if performed successful, would add a bonus score to the final course grade. Every week, students are expected to prepare homework assignments which, if solved, grant students some bonus points. This course has a high audience (approximately 1000 students each year) and is notoriously known among new students for two main reasons. First, the material is often regarded as being difficult and unattractive; mathematics concepts are difficult for students who either lack, or only have poor prior knowledge. Second, this is a key course for first years entering our faculty, as failing one of the QM courses directly implies issues of study delay in the first year at this university. These reasons, together with the fact that the design of the course remained unchanged over the years, made QM I a good candidate for testing the hypotheses assumed in our study.

\section{Design and Procedure}

In week four of the course, participants completed an online questionnaire about their LREs regarding the specific subject of the course. The timing was chosen to capture sufficient experience of the learning activities. In the last week of the course students participated in the written exam. For issues of cross validation, these measurements and the timing were kept identical and repeated over three consecutive academic years in 2010, 2011 and 2012. All students included in this study provided informed consent for the use of data collected by means of online questionnaires and in order to link the data with their study results.

\section{Variables and Measures}

Learning-related emotions (LREs) were the independent variables in the present study, measured through the four learning scales, Enjoyment, Anxiety, Boredom and Hopelessness, of the Achievement Emotions Questionnaire (AEQ) developed by Pekrun et al. (2011). Considering that LREs are a specific type of academic emotions which entail several components (cognitive, behavioral, motivational and affective), the AEQ construction takes these components into account for each emotion scale. Items were answered on a 7-point Likert scale ( 1 = 'completely disagree' and 7 = 'completely agree') and re-phrased to better match the subject investigated in this study. The AEQ is a self-report questionnaire with good psychometric qualities: both the factorial validity and the internal consistency of the learning-related scales of the AEQ have been evidenced in the literature (Pekrun et al., 2011). In our study, the factorial validity was acceptable (see Table 2), while the reliability coefficients were very good (see Table 4). 
Student participation in the final exam was the first outcome variable, allowing for absence and attendance at the exam. Exam participation was operationalized through having obtained or lacking a grade after the first round of examinations took place.

Student achievement was the second outcome variable, measured through the official QM I grade, which was comprised of three separate parts: MathPerformance, StatsPerformance and BonusPerformance. First, the two performance outcomes MathPerformance and StatsPerformance were assessed in a final written exam which covered a mathematics component and a statistics component, graded separately. Second, the BonusPerformance represented the sum of bonus scored in quizzes and homework. Quizzes, although optional, were available for both mathematics and statistics in an online format. Some further bonus could be achieved by doing weekly homework, containing assignments for mathematics and statistics.

Additionally, given the strong diversity in nationalities in the current sample, a factor we accounted for was prior education. There are considerable differences in the secondary education systems, which can affect the overall performance in a mathematics and statistics course. For most educational systems, the difference is made at three minimum levels which prepare their graduates for higher education: programs aimed for arts and humanities, programs for social sciences, and programs for sciences. To enroll in an Economics or International Business track at our university, students are required to have been educated at an intermediate level, which is provided in a social sciences program. Although the required levels are assumed to be equivalent across countries, the national curricula differ based on the focus given to mathematical topics. Even within a nation, another source of diversity can be found in the type of mathematical specialization (minor and major) of student's high school education. In social sciences programs it can be expected that all students had, at minimum, a mathematics minor specialization. Last but not least, a gender gap seems to persist in secondary education with respect to higher levels of Anxiety towards Mathematics, more frequently reported by female rather than male students (Hyde et al., 1990). This is intriguing, as no actual relevant differences between the females and males are actually documented with respect to achievement outcomes (Lindberg et al., 2010). Given this evidence, another factor we accounted for was gender. Therefore, as control variables we included gender (Female and Male), prior education in terms of secondary education diploma (International versus Dutch Diploma or VWO) and level of introductory mathematics education (distinguishing between two tracks, MathMajor and MathMinor) to account for potential differences in students' LREs (Pekrun et al., 2002, 2004) and when predicting achievement that might be due to prior mathematical education rather than emotions (cf. Tempelaar et al., 2012).

\section{Preliminary data analysis}

In order to investigate the factorial validity of the four LREs assessed with the AEQ, we used confirmatory factor analysis (CFA), a latent variable approach. Prior to fitting the measurement models, we checked the assumptions of normality at item level through SPSS 21. Values of skewness and kurtosis were in the expected range of chance fluctuations in that statistic. Mplus version 7 (Muthén \& Muthén, 2012) was used to perform CFA. Be- 
cause no large departures from normality were detected, we used Maximum Likelihood estimation. Given the relatively large sample size, we report the Chi-square/degrees of freedom ratio instead of the p-value (Byrne, 2011), an index with a recommended value smaller than two (Schermelleh-Engel et al., 2003). In addition, we report the Comparative Fit Index (CFI), the Non-Normed Fit Index (NNFI, also known as TLI) and the Root Mean Square Error of Approximation (RMSEA) as indicators of goodness of fit. Hu and Bentler (1999) suggested for CFI/TLI values larger than .90 for a satisfactory fit and for RMSEA values should not exceed .08 and preferably be .06 or lower.

Before proceeding with further analyses, another set of normality checks was run on the adjusted scales (cf. CFA,) which showed no serious departures from normality (i.e., no extreme skewness, multimodality or any extreme cases).

\section{Testing hypotheses}

H1 was investigated by means of MANOVA in which all four LREs were treated as correlated responses and absence at exam as factor. To control for gender effects, prior education, and level of introductory mathematics, we also included these variables in the MANOVAs, and the multiple linear regressions. Finally, we estimated models which included the prediction of each LRE by all demographic variables. Next, we performed a multiple linear regression to investigate the predictive value of the four learning emotions for achievement outcomes in each academic year (H2). All analyses were based on a subset of students for which background characteristics, LREs variables and performance data were all available. This subset comprised 2337 students, $80.09 \%$ of the total of 2918 students enrolled.

\section{RESULTS}

\section{Tests of factorial invariance of the four LREs}

Since our hypotheses proposed to test the same relations over three different time instances of the same course using the same instrument, there is an implicit assumption that the instrument structure is the same at each point of measurement. It is therefore necessary to demonstrate the factorial validity equivalence of the instruments used with each of the three measurement occasions.

For this purpose, we ran three first-order CFA models employed over the three cohorts in all academic years (2010, 2011 and 2012). We started with confirming the theoretical model described in the original AEQ, based on 43 items serving as indicators for the four dimensions of the academic emotions. The results of this analysis are reported as basic mod$e l(A)$ and are presented in Table 1 . Some fit problems were found $\left(\chi^{2} / \mathrm{df}>3\right.$, CFI and TLI below 0.90 ). In all data sets, the factor loadings were significant (all $p<.01$ ). However, the $R^{2}$ was below .25 for two items (LJOP1D and LJOP2D)* We also found high correlations

\footnotetext{
*According to the AEQ item labels
} 
(factor $r$ above .80 ) between the Anxiety and Hopelessness factors, as the two are known as "neighboring" emotions and have already been shown as highly correlated (Pekrun et al., 2002, 2004). The correlations between the other factors though, ranged from about .40 (for Boredom and Anxiety, for example) to .60 (Hopelessness with Enjoyment).

Table 1. Basic model (A): 4 factors (Enjoyment, Anxiety, Boredom, Hopelessness) with no cross-loadings

\begin{tabular}{llllll}
\hline Time point & $\chi 2, \mathrm{df}$ & CFI / TLI & RMSEA $(95 \% \mathrm{CI})$ & Items R2 below 0.25 & Factor $\mathrm{r}$ above 0.80 \\
\hline 2010 & $3394.162,854$ & $0.865 / 0.857$ & $0.070(0.068 ; 0.073)$ & LJOP1D, LJOP2D & A-H: 0.898 \\
2011 & $3661.659,854$ & $0.876 / 0.869$ & $0.062(0.060 ; 0.064)$ & LJOP1D, LJOP2D & A-H: 0.911 \\
2012 & $4029.202,854$ & $0.877 / 0.870$ & $0.065(0.063 ; 0.067)$ & LJOP1D, LJOP2D & A-H: 0.890 \\
\hline
\end{tabular}

Note. $\mathrm{A}=$ Anxiety; $\mathrm{H}=$ Hopelessness.

Furthermore, better fit on the separate data sets (see Table 2) was achieved after adjusting the model in two stages: first, by consecutively removing nine items, out of which six reflected the physiological component of each of the enjoyment, anxiety and hopelessness scales (LJOP1D, LJOP2D, LJOC2A, LJOM3A, LAXP2D, LAXP2D, LAXC3A, LHLP1B, LHLP2D). Then, following the recommended high modification indices, two residual covariance paths (LBOA1D with LBOC3D; LHLC2A with LHLC1D) ${ }^{1}$ were added. Both LBOA1D and LBOC3D items refer to excessive boredom experienced during studying for this course; LHLC2A and LHLC1D) describe resignation concerning the abilities to learn in the course. Table 3 gives the full overview of standardized factor loadings, factor correlations, and residual covariance paths for the adjusted model (B).

Table 2. Adjusted model (B) with 2 residual covariance paths: (LBOA1D with LBOC3D; LHLC2A with $L H L C 1 D$ ) and removed items (LJOP1D, LJOP2D, LJOC2A, LJOM3A, LAXP2D, LAXP2D, LAXC3A, LHLP1B, LHLP2D)

\begin{tabular}{|c|c|c|c|c|c|}
\hline Time point & $\chi^{2}, \mathrm{df}$ & CFI / TLI & RMSEA $(95 \% \mathrm{CI})$ & Items R2 below 0.25 & Factor $\mathrm{r}$ above 0.80 \\
\hline 2010 & $1886.696,519$ & $0.911 / 0.903$ & $0.066(0.063 ; 0.070$ & & A-H: 0.913 \\
\hline 2011 & $2070.889,519$ & $0.916 / 0.909$ & $0.059(0.057 ; 0.062)$ & & A-H: 0.914 \\
\hline 2012 & $2297.568,519$ & $0.916 / 0.909$ & $0.062(0.059 ; 0.065)$ & & A-H: 0.901 \\
\hline
\end{tabular}

Note. $\mathrm{A}=$ Anxiety; $\mathrm{H}=$ Hopelessness. 


\section{CHAPTER 2}

Table 3. Adjusted model (B): Standardized factor loadings, factor correlations, and residual covariance paths for the four data sets

\begin{tabular}{|c|c|c|c|c|}
\hline & Time point & 2010 & 2011 & 2012 \\
\hline \multirow[t]{34}{*}{ Factor loadings } & E by LJOA1B & 0.709 & 0.700 & 0.699 \\
\hline & E by LJOM1D & 0.691 & 0.624 & 0.646 \\
\hline & E by LJOA2D & 0.823 & 0.820 & 0.822 \\
\hline & E by LJOC1D & 0.852 & 0.857 & 0.839 \\
\hline & E by LJOA3D & 0.651 & 0.656 & 0.654 \\
\hline & E by LJOM2A & 0.619 & 0.639 & 0.592 \\
\hline & A by LAXM1B & 0.767 & 0.710 & 0.722 \\
\hline & A by LAXP1B & 0.848 & 0.798 & 0.770 \\
\hline & A by LAXA1B & 0.777 & 0.757 & 0.741 \\
\hline & A by LAXC1D & 0.730 & 0.745 & 0.734 \\
\hline & A by LAXM2D & 0.674 & 0.630 & 0.633 \\
\hline & A by LAXA2D & 0.804 & 0.800 & 0.780 \\
\hline & A by LAXC2D & 0.805 & 0.781 & 0.822 \\
\hline & A by LAXA3A & 0.669 & 0.683 & 0.641 \\
\hline & B by LBOM1B & 0.738 & 0.675 & 0.707 \\
\hline & B by LBOM2B & 0.733 & 0.624 & 0.652 \\
\hline & B by LBOP1D & 0.752 & 0.752 & 0.780 \\
\hline & B by LBOP2D & 0.774 & 0.764 & 0.791 \\
\hline & B by LBOC3D & 0.621 & 0.618 & 0.597 \\
\hline & B by LBOA1D & 0.799 & 0.801 & 0.810 \\
\hline & B by LBOC1D & 0.741 & 0.695 & 0.748 \\
\hline & B by LBOP3D & 0.864 & 0.823 & 0.870 \\
\hline & B by LBOA2D & 0.871 & 0.820 & 0.842 \\
\hline & B by LBOA3D & 0.693 & 0.672 & 0.670 \\
\hline & B by LBOC2D & 0.830 & 0.778 & 0.837 \\
\hline & H by LHLA1B & 0.867 & 0.839 & 0.873 \\
\hline & H by LHLM1D & 0.802 & 0.753 & 0.770 \\
\hline & H by LHLM2D & 0.792 & 0.751 & 0.782 \\
\hline & H by LHLC1D & 0.781 & 0.749 & 0.760 \\
\hline & H by LHLA2D & 0.877 & 0.851 & 0.873 \\
\hline & H by LHLC2A & 0.783 & 0.778 & 0.791 \\
\hline & H by LHLC3A & 0.788 & 0.742 & 0.791 \\
\hline & H by LHLA3A & 0.763 & 0.679 & 0.771 \\
\hline & H by LHLC4A & 0.782 & 0.752 & 0.774 \\
\hline \multirow[t]{6}{*}{ Factor correlations } & A with E & -0.565 & -0.479 & -0.533 \\
\hline & B with E & -0.555 & -0.461 & -0.548 \\
\hline & B with A & 0.448 & 0.400 & 0.357 \\
\hline & H with $\mathrm{E}$ & -0.590 & -0.540 & -0.618 \\
\hline & $\mathrm{H}$ with $\mathrm{A}$ & 0.913 \# & $0.914 \#$ & $0.901 \#$ \\
\hline & H with B & 0.543 & 0.460 & 0.494 \\
\hline \multirow[t]{2}{*}{ Residual covariance paths } & LBOA1D with LBOC3D & -0.240 & -0.206 & -0.125 \\
\hline & LHLC2A with LHLC1D & 0.275 & 0.285 & 0.240 \\
\hline
\end{tabular}

Note. $\mathrm{E}=$ Enjoyment; $\mathrm{A}=$ Anxiety; $\mathrm{B}=$ Boredom; $\mathrm{H}=$ Hopelessness. All values statistically significant at the $\alpha=$ 0.005 level, the largest $\mathrm{p}$-value is approximately 0.001 . The ' $\#$ ' factor correlations above 0.80 . 
As can be seen from Table 3, the same items load on the same factors across all cohorts. Imposing equality constraints for factor loadings across cohorts would lead to loss of fit and imply a bad fitting model rather than a more parsimonious model with a fair fit. Again, we identified high correlations (factor $\mathrm{r}$ above .90) between the Anxiety and Hopelessness factors. Still, the correlations between the other factors were in the range of .40 and .60. Overall, a four-factor structure according to the theoretically distinct concepts as proposed by Pekrun et al. (2002) is consistent within the course investigated in our study.

\section{Descriptives}

Before presenting the outcomes of testing the hypotheses, mean levels for the four LREs for all participants and then decomposed per gender, previous education and prior level of math are summarized in Table 4 and Table 5.

Table 4. Means (M), standard deviations (SD) and Cronbach's alpha of the adjusted four learning emotions scales, for all participants

\begin{tabular}{|c|c|c|c|c|c|c|c|c|c|}
\hline & \multicolumn{9}{|c|}{ Time point } \\
\hline & \multicolumn{3}{|l|}{2010} & \multicolumn{3}{|l|}{2011} & \multicolumn{3}{|l|}{2012} \\
\hline & M & SD & $a$ & M & SD & $\alpha$ & M & SD & $a$ \\
\hline Enjoyment & 3.95 & 1.12 & 0.867 & 3.87 & 1.10 & 0.862 & 3.99 & 1.07 & 0.855 \\
\hline Anxiety & 3.71 & 1.27 & 0.915 & 3.60 & 1.21 & 0.905 & 3.75 & 1.23 & 0.902 \\
\hline Boredom & 2.88 & 1.15 & 0.938 & 2.84 & 1.08 & 0.924 & 2.86 & 1.13 & 0.934 \\
\hline Hopelessness & 2.99 & 1.28 & 0.944 & 2.92 & 1.18 & 0.929 & 3.01 & 1.28 & 0.941 \\
\hline
\end{tabular}

Note. $N=600$ for $2010, N=847$ for 2011 and $N=890$ for 2012 .

Table 5. Means (M), standard errors (SE) of the four learning emotions decomposed for Gender, previous education and Math level

\begin{tabular}{llllllllll}
\hline & Gender & $\mathrm{M}$ & $\mathrm{SE}$ & Diploma & $\mathrm{M}$ & $\mathrm{SE}$ & Math level & $\mathrm{M}$ & SE \\
\hline Enjoyment & Female & 3.92 & 0.03 & International & 4.11 & 0.02 & Math major & 4.16 & 0.04 \\
& Male & 3.90 & 0.03 & Dutch & 3.70 & 0.04 & Math minor & 3.65 & 0.03 \\
Anxiety & Female & 3.69 & 0.04 & International & 3.59 & 0.03 & Math major & 3.23 & 0.04 \\
& Male & 3.47 & 0.03 & Dutch & 3.56 & 0.05 & Math minor & 3.92 & 0.03 \\
\multirow{2}{*}{ Boredom } & Female & 2.87 & 0.03 & International & 2.71 & 0.02 & Math major & 2.85 & 0.04 \\
& Male & 3.02 & 0.03 & Dutch & 3.18 & 0.04 & Math minor & 3.04 & 0.03 \\
Hopelessness & Female & 3.03 & 0.04 & International & 2.81 & 0.03 & Math major & 2.57 & 0.04 \\
& Male & 2.83 & 0.03 & Dutch & 3.05 & 0.05 & Math minor & 3.29 & 0.03 \\
\hline
\end{tabular}

As can be seen from Table 5, females are, on average, more anxious and more hopeless while males are more bored. Furthermore, international students enjoy the course more than Dutch students who are, on average, more bored and hopeless. Finally, having a MathMajor level makes students enjoy more the course while feeling less hopelessness, less anxiety and less boredom towards the course than fellow students with a MathMinor prior level. 


\section{Hypothesis 1}

In $\mathrm{H} 1$ we assumed differences in the four LREs between the students who attended - as compared to those who did not show up to the exam. Since the design was rather unbalanced with respect to the same size of the groups, we tested the equality of covariance matrices using Box's $M$ test. Results of Box's $M$ test (14.999) were not significant $(p=0.142)$ which indicated that the assumption of equality of covariance matrices was met. Results of MANOVA reveal overall significant effects (Pillai's Trace $=0.006, \mathrm{~F}=3.571, p=0.007$ ) for all of the four LREs (detailed values are displayed in Table 6). Although of very small magnitude (partial eta-squared $=0.006$ ), these effects are in the expected direction: on average, students who were absent at the exam enjoyed less, were more anxious, more bored and more hopeless learning for the course, than the students who attended the final exam.

Table 6. Means (M), standard errors (SE) of the adjusted four learning emotions scales decomposed for exam participation, and F-values for the MANOVA Analysis

\begin{tabular}{llllll}
\hline & Exam Participation & $\mathrm{M}$ & $\mathrm{SE}$ & $\mathrm{F}$ & Eta-squared \\
\hline Enjoyment & Present & 3.96 & 0.02 & $4.566^{*}$ & 0.002 \\
& Absent & 3.69 & 0.12 & & \\
\multirow{2}{*}{ Anxiety } & Present & 3.67 & 0.03 & $8.666^{* *}$ & 0.004 \\
& Absent & 4.09 & 0.14 & & \\
Boredom & Present & 2.85 & 0.02 & $11.208^{* *}$ & 0.005 \\
& Absent & 3.28 & 0.13 & & \\
Hopelessness & Present & 2.96 & 0.03 & $8.222^{* *}$ & 0.004 \\
& Absent & 3.37 & 0.14 & & \\
\hline
\end{tabular}

Note. $N=2256$ present, $N=81$ absent; ${ }^{*} p<.05 ;{ }^{* *} p<.01$.

\section{Hypothesis 2}

In $\mathrm{H} 2$ we assumed that the four LREs are able to predict students' performance in the course. Furthermore, we expected the positive LRE of enjoyment to have a positive influence on students' performance and the negative emotions to have a negative influence on performance. Given the high correlations between Hopelessness and Anxiety, before interpreting the regression results, the assumption of non-multicollinearity was also assessed. VIF and Tolerance statistic indicate that the results of regression were not biased: Tolerance statistic values are above 0.20 (Menard, 1995) for all the factors, while VIF are far below 10 (Myers, 1990). We first investigated the hypothesized relations in the 2010 sample. For a cross validation, we then looked at the same relations in the following two academic years $(2011,2012)$. The results of the multiple linear regression analyses as well as of the simple linear regression are presented for each academic year in Table 7, Table 8 and Table 9 respectively. Concerning their predictive value, the four LREs together with a prior level of Math are able to explain $18 \%$ variance in grade in the 2010 cohort. The results are pretty similar for 2011 and 2012 respectively: 19\% and 14\% variance is explained in grade, with a dominant contribution of Hopelessness and MathMajor. Furthermore, not in line with the 
expected relations, Anxiety and Boredom are not significant predictors of grade in 2010; these results replicate for 2011 or 2012. Enjoyment is statistically significant in 2010 only. Hopelessness and MathMajor, on the other hand, are statistically significant in 2010 and, repeatedly in 2011 and 2012; this indicates them as consistent predictors of grade across different cohorts. Subsequent linear regression also reveals that Hopelessness and MathMajor are the only consistent predictors of Grade: higher Hopelessness predicts a lower grade while having been previously educated in Math (having a MathMajor background) leads to a higher grade. Regarding the size and direction of the expected relations, Hopelessness indicates a medium to somewhat strong negative (Lipsey \& Wilson, 2001) effect on grade. This effect is comparable for all data sets: standardized regression coefficients ( $\beta$ 's) in the full model are in 2010, 2011 and 2012 respectively: $-0.277,--0.346,-0.370 ; \beta$ 's in the only (Hopelessness and MathMajor) model are in chronological order: -0.344, -0.391, 0.329 . Enjoyment $(\beta=0.096)$ has only a positive small effect on grade, and that is exclusively true for the 2010 cohort.

Table 7. Summary of the regression analyses for variables predicting Grade in 2010

\begin{tabular}{|c|c|c|c|c|}
\hline & $B(S E)$ & $\beta$ & Collinearity & Statitics \\
\hline \multicolumn{5}{|l|}{ Demographics model } \\
\hline Gender & $-0.204(0.182)$ & -0.046 & & \\
\hline Prior education & $-0.221(0.203)$ & -0.045 & & \\
\hline Math Major & $1.311(0.190)$ & $0.288^{* * *}$ & & \\
\hline$R^{2}$ & 0.082 & & & \\
\hline Full model & & & Tolerance & VIF \\
\hline Enjoyment & $0.186(0.094)$ & $0.096^{*}$ & 0.633 & 1.580 \\
\hline Anxiety & $-0.052(0.124)$ & -0.031 & 0.274 & 3.655 \\
\hline Boredom & $0.068(0.090)$ & 0.036 & 0.638 & 1.568 \\
\hline Hopelessness & $-0.434(0.131)$ & $-0.258^{* *}$ & 0.244 & 4.097 \\
\hline Math Major & $0.877(0.182)$ & $0.194^{* * *}$ & 0.916 & 1.092 \\
\hline$R^{2}$ & 0.179 & & & \\
\hline \multicolumn{5}{|l|}{ Only model } \\
\hline Hopelessness & $-0.526(0.067)$ & $-0.313^{* * *}$ & & \\
\hline Math Major & $0.919(0.180)$ & $0.203^{* * *}$ & & \\
\hline$R^{2}$ & 0.172 & & & \\
\hline
\end{tabular}

Note. All values statistically significant at the $\alpha=0.005$ level, the largest p-value is approximately 0.001 . 
Table 8. Summary of the regression analyses for variables predicting Grade in 2011

\begin{tabular}{|c|c|c|c|c|}
\hline & $B(S E)$ & $\beta$ & Collinearity & Statitics \\
\hline \multicolumn{5}{|c|}{ Demographics model } \\
\hline Gender & $-0.056(0.147)$ & -0.013 & & \\
\hline Diploma & $0.358(0.175)$ & 0.069 & & \\
\hline Math Major & $1.266(0.151)$ & $0.283^{* * *}$ & & \\
\hline$R^{2}$ & 0.090 & & & \\
\hline Full model & & & Tolerance & VIF \\
\hline Enjoyment & $-0.023(0.073)$ & -0.012 & 0.696 & 1.437 \\
\hline Anxiety & $-0.043(0.101)$ & -0.025 & 0.299 & 3.350 \\
\hline Boredom & $0.024(0.073)$ & 0.012 & 0.731 & 1.367 \\
\hline Hopelessness & $-0.579(0.108)$ & $-0.325^{* * *}$ & 0.273 & 3.661 \\
\hline Math Major & $0.862(0.151)$ & $0.193^{* * *}$ & 0.885 & 1.129 \\
\hline$R^{2}$ & 0.188 & & & \\
\hline \multicolumn{5}{|l|}{ Only model } \\
\hline Hopelessness & $-0.595(0.059)$ & $-0.335^{* * *}$ & & \\
\hline Math Major & $0.868(0.148)$ & $0.194^{* * *}$ & & \\
\hline$R^{2}$ & 0.187 & & & \\
\hline
\end{tabular}

Note. All values statistically significant at the $\alpha=0.005$ level, the largest p-value is approximately 0.001 .

Table 9. Summary of the regression analyses for variables predicting Grade in 2012

\begin{tabular}{|c|c|c|c|c|}
\hline & $B(S E)$ & $\beta$ & Collinearity & Statitics \\
\hline \multicolumn{5}{|c|}{ Demographics model } \\
\hline Gender & $-0.203(0.157)$ & -0.044 & & \\
\hline Diploma & $-0.203(0.157)$ & 0.049 & & \\
\hline Math Major & $1.188(0.162)$ & $0.246^{* * *}$ & & \\
\hline$R^{2}$ & 0.066 & & & \\
\hline Full model & & & Tolerance & VIF \\
\hline Enjoyment & $-0.169(0.090)$ & -0.079 & 0.581 & 1.721 \\
\hline Anxiety & $0.060(0.104)$ & 0.033 & 0.326 & 3.066 \\
\hline Boredom & $-0.056(0.081)$ & -0.027 & 0.661 & 1.513 \\
\hline Hopelessness & $-0.610(0.111)$ & $-0.340^{* * *}$ & 0.270 & 3.704 \\
\hline Math Major & $0.908(0.162)$ & $0.188^{* * *}$ & 0.920 & 1.087 \\
\hline$R^{2}$ & 0.141 & & & \\
\hline \multicolumn{5}{|l|}{ Only model } \\
\hline Hopelessness & $-0.508(0.060)$ & $-0.283^{* * *}$ & & \\
\hline Math Major & $0.869(0.160)$ & $0.180^{* * *}$ & & \\
\hline$R^{2}$ & 0.137 & & & \\
\hline
\end{tabular}

Note. All values statistically significant at the $\alpha=0.005$ level, the largest p-value is approximately 0.001 . 


\section{DISCUSSION}

This investigation extends the scope of previous research in primary and secondary education (Dettmers et al., 2011; Goetz et al., 2012; Trautwein et al., 2009) to look at the role of learning-related emotions in predicting achievement outcomes in the first year of university. To the best of our knowledge, only few studies in first year samples (Putwain, Larkin et al., 2013) tried to prove similar relations (Putwain, Sander et al., 2013; Tempelaar et al., 2012). Most notably, we found that learning hopelessness, together with a previous mathematics background, are able to predict substantially academic achievement. Furthermore, this relation was confirmed over different cohorts in three consecutive academic years. The fact that having a previous mathematics background enables students to obtain a higher grade is not surprising: recent studies have already confirmed this finding (Alexander, 2005; Tempelaar et al., 2012). However, showing a negative emotion, Hopelessness, as the strongest predictor of academic achievement is an important outcome that deserves further elaboration. On one hand, it aligns with the studies of Dettmers et al. (2011) and Trautwein et al. (2009) which showed that indeed negative emotions during homework predict negative achievement. On the other hand, it differs from these studies in two regards: these authors used either single items (Dettmers et al., 2011) or a composite measure of negative emotions including anger, anxiety and boredom (Trautwein et al., 2009). We show that discrete learning hopelessness - measured with multiple items - are the strongest factor for achievement in mathematics and statistics. One aspect to stress is that even though high correlations were found between the hopelessness and anxiety factors (at all-time points), the chance of a suppression effect was rejected by additional analyses which showed no real concern of multicollinearity in the data. Consequently, as not all factors had the same influence in predicting achievement - and since learning hopelessness was shown to have the strongest contribution - future efforts should assess particularly this factor in mathematics and statistics courses.

Next, we looked at differences in LREs between students who attended, as compared to those who were absent for the first round of final examination. In line with earlier studies (Ruthig et al., 2008), we found that students who were absent for the exam experienced less enjoyment, more anxiety, more boredom and more hopelessness than the students who attended the final exam. What is particularly relevant is that these differences were already visible in week four, half-way through the course. This knowledge offers the opportunity to intervene early in an educational setting, using these emotions as potential indicators for early withdrawal at the course level.

Finally, some methodological concerns should be outlined. First, while confirming the theoretical model described in the original AEQ posed some fit problems, a better fit on the separate datasets was achieved after removing a set of items. Most of these items were reflecting a physiological component within an emotion. We consider this modification reasonable for the context of learning outside the classroom in a mathematics and statistics course: certain emotional components, such as the cognitive, affective or motivational, could play a more important role in the emotional experience of learning than the physiological one. More explicitly, "getting physically excited when the QM course is going well" or "when the QM course is going well, it gives a rush" might not be the most relevant items - in terms of describing the particular emotional experience of learning situation in this 
course. From a methodological point of view, it further indicates that the choice of items made to accurately capture students' emotional experiences should depend on the particular context in which a student is placed within a certain course (such as learning while doing homework as compared to taking an exam). Second, concerning the factorial invariance of the instrument, we found that a four-factor structure according to the theoretically distinct concepts as proposed by Pekrun et al. (2002) was stable within the subject of Mathematics and Statistics. Since we focused on discrete LREs, we consider important to observe a consistent finding across all time points: the co-occurrence (factor $r$ above .90) of Anxiety and Hopelessness factors. In our sample, this could be explained by conceptual differences in the emotional components (physiological, affective, cognitive and emotional) - which were not taken into account in the original item construction (Pekrun et al., 2004). To date, previous studies testing the divergent validity of these two emotions argue that while anxiety is characterized by motivation to avoid failure, hopelessness shows low motivation and resignation (Pekrun et al., 2004). At last, such a finding can be explained by the fact that both concepts fall under the same category of low control emotions (Scherer, 2005).

\section{Limitations and further research}

Our study used an ecological design to make a good case for the value of LREs as predictors of academic achievement in a mathematics and statistics course in the first year of university study. The design included a large sample and an instrument with confirmed validity and reliability. However, as with any new design, some limitations exist.

First, for the prediction of achievement outcomes, we only focused on average effects in our sample. Such an approach overlooks the amount of intra-individual variability and therefore does not take into account the individual differences in academic performance. Future studies that aim to go beyond the group level of predicting achievement should employ a design able to capture such information.

Second, we measured LREs midway through the course, assuming that they would remain relatively stable. Although students need a minimum period to get an impression of the new educational environment, we cannot be sure whether assessing their emotional experiences earlier in the course could have also proven to be useful for a reliable prediction of outcomes. Future research could make use of an earlier assessment and test the individual stability of students' emotional experiences; this could be used to longitudinally predict if students will attend the final exam and, for those who will, explain their performance in the course.

Third, we referred to only one course to draw our conclusions concerning the relation between LREs and achievement. To further show that this is indeed specific for particular academic subjects, such as Mathematics and Statistics, the same relation should be replicated over different academic subjects and among more student samples. 


\section{Recommendations for educational practice}

The results of this study become particularly relevant when considering how they can be translated into everyday practice. Accordingly, this could help both students as well as educators in participating to- and co-creating what has been previously referred to as "emotionally sound" educational environments (Astleitner, 2005). In order to address this educational goal, we suggest two main practical recommendations which are based on our findings.

The first finding refers to the role of hopelessness in how students perform academically. From this perspective, educational interventions could focus particularly at decreasing its intensity - as early as possible in a course - as hopelessness is an outcome-focused, prospective emotion which needs time to develop over a course. There is consensus that emotions can be influenced through their antecedents (Pekrun et al., 2006), so hopelessness could be indirectly targeted at this level. For instance, Tempelaar et al. (2012) study focused on epistemological views about effort in mathematics and statistics course - a component of the implicit theories of intelligence model (Dweck, 1999) - as distal antecedents of achievement emotions (Tempelaar et al., 2012). They concluded that negative effort views - the belief students hold towards exerting effort as something which signals lacks of intelligence, therefore negative - had a substantial impact on learning hopelessness (as expressed in a $\beta$ estimate of .86). Effort beliefs however, are in Dweck's (1990) view still malleable and can be intervened upon. Future interventions could address such an antecedent, in an effort to prevent the development of hopelessness over a mathematics and statistics course.

The second finding refers to the role of previous knowledge, having a mathematics major or minor background, in how students perform in the course. In this respect, effective interventions are known in helping students' performance by improving their prior knowledge (Rienties et al., 2008). Rienties et al. (2008) designed a series of online remedial programs especially for prospective first year students at university. One of these interventions was conducted in a mathematics course and showed that it is possible to improve deficient prior knowledge of students before entering the university. The effects were shown on both short term in student performance in the course, and on long term on study success in the first year at university. Educational practice could adopt such programs given their proved effectiveness in improving student success as well as for their cost-effectiveness.

\section{Conclusion}

Our study draws upon previous research using the CVTAE to show the value of learningrelated emotions as predictors of achievement outcomes in a mathematics and statistics course. We found the four LREs investigated here, as well as a mathematics background, as useful predictors for the exam scores. In particular, negative achievement was mainly predicted by the negative emotion hopelessness. Knowing this course took place in a period of transition - the first year of university study, together with the fact that absent students experienced more unpleasant emotions than students who participated in the exam, points to an early identification of these student characteristics as potential indicators for early withdrawal at the course level. Beyond the prevention of student withdrawal, our study 
suggests theoretically- and empirically-proven possibilities for improving success in the first year at university study.

\section{REFERENCES}

Alexander, P. A. (2005). Psychology in learning and instruction. Prentice Hall.

Arias Ortiz, E., \& Dehon, C. (2013). Roads to Success in the Belgian French Community's Higher Education System: Predictors of Dropout and Degree Completion at the Université Libre de Bruxelles. Research in Higher Education, 54(6), 693-723. doi:10.1007/s11162-013-9290-y

Astleitner, H. (2000). Designing emotionally sound instruction: The FEASP-approach. Instructional Science, 28(3), 169-198.

Baker, R. W., \& Siryk, B. (1999). SACQ Student Adaptation to College Questionnaire (2nd edition ed). Los Angeles: Western Psychological Services.

Barrows, H. \& Tamblyn, R. (1980). Problem based learning: An approach to medical education. New York, Springer.

Beard, C., Clegg, S., \& Smith, K. (2007). Acknowledging the affective in higher education. British Educational Research Journal, 33(2), 235-252 doi:10.1080/01411920701208415

Byrne, B. M. (2011). Structural Equation Modelling with Mplus. Routledge: New York.

Credé, M., \& Niehorster, S. (2011). Adjustment to College as Measured by the Student Adaptation to College Questionnaire: A Quantitative Review of its Structure and Relationships with Correlates and Consequences. Educational Psychology Review, 24(1), 133-165. doi:10.1007/s10648-011-9184-5

Daniels, L. M., Perry, R. P., Stupnisky, R. H., Stewart, T. L., Newall, N. E. G., \& Clifton, R. A. (2014). The longitudinal effects of achievement goals and perceived control on university student achievement. European Journal of Psychology of Education, 29(2), 175-194. doi:10.1007/s10212-013-0193-2

Dettmers, S., Trautwein, U., Lüdtke, O., Goetz, T., Frenzel, A. C., \& Pekrun, R. (2011). Students' emotions during homework in mathematics: Testing a theoretical model of antecedents and achievement outcomes. Students' Emotions and Academic Engagement, 36(1), 25-35. doi:10.1016/j.cedpsych.2010.10.001

Dweck, C. S. (1999). Self-theories: Their role in motivation, personality, and development. Philadelphia: Psychology Press

Elliot, A. J., \& Pekrun, R. (2007). Emotion in the hierarchical model of approach-avoidance achievement motivation. In P. A. Schutz \& R. Pekrun (Eds.), Emotion in education. (pp. 57-73). San Diego, CA US: Elsevier Academic Press.

Ergene, T. (2003). Effective Interventions on Test Anxiety Reduction: A Meta-Analysis. School Psychology International, 24(3), 313-328. doi:10.1177/01430343030243004

Fredrickson, B. L. (2001). The role of positive emotions in positive psychology: The broaden-and-build theory of positive emotions. American Psychologist, 56, 218-226.

Gal, I., \& Ginsburg, L. (1994). The Role of Beliefs and Attitudes in Learning Statistics: Towards an Assessment Framework. Journal of Statistics Education, V2N2: Gal. (n.d.).

Garfield, J., \& Ben-Zvi, D. (2007). How Students Learn Statistics Revisited: A Current Re view of Research on Teaching and Learning Statistics. International Statistical Re view, 75(3), 372-396. doi:10.1111/j.17515823.2007.00029.x

Goetz, T., Lüdtke, O., Nett, U. E., Keller, M. M., \& Lipnevich, A. A. (2013). Characteristics of teaching and students' emotions in the classroom: Investigating differences across domains. Contemporary Educational Psychology, 38(4), 383-394. doi:10.1016/j.cedpsych.2013.08.001

Goetz, T., Nett, U. E., Martiny, S. E., Hall, N. C., Pekrun, R., Dettmers, S., \& Trautwein, U. (2012). Students' emotions during homework: Structures, self-concept antecedents, and achievement outcomes. Noncognitive Skills in Education: Emerging Research and Applications in a Variety of International Contexts, 22(2), 225-234. doi:10.1016/j.lindif.2011.04.006

Goetz, T., Pekrun, R., Hall, N., \& Haag, L. (2006). Academic emotions from a social-cognitive perspective: Antecedents and domain specificity of students' affect in the context of Latin instruction. British Journal of Educational Psychology, 76(2), 289-308. doi:10.1348/000709905X42860 
Hyde, J. S., Fennema, E., Ryan, M., Frost, L. A., \& Hopp, C. (1990). Gender comparisons of mathematics attitudes and affect. Psychology of Women Quarterly, 14(3), 299-324. doi:10.1111/j.14716402.1990.tb00022.x

Hu, L., \& Bentler, P. M. (1999). Cutoff criteria for fit indexes in covariance structure analysis: Conventional criteria versus new alternatives. Structural Equation Modeling: A Multidisciplinary Journal, 6(1), 1-55. doi:10.1080/10705519909540118

IBM Corp. Released 2013. IBM SPSS Statistics for Windows, Version 22.0. Armonk, NY: IBM Corp.

Lazarus, R. S., \& Folkman, S. (1984). Stress, appraisal, and coping. New York: Springer.

Leone, C., \& Richards, H. (1989). Classwork and homework in early adolescence: The ecology of achievement. Journal of Youth and Adolescence, 18(6), 531-548. doi:10.1007/BF02139072

Lindberg, S. M., Hyde, J. S., Petersen, J. L., \& Linn, M. C. (2010). New trends in gender and mathematics performance: A meta-analysis. Psychological Bulletin, 136(6), 1123-1135. doi:10.1037/a0021276

Linnenbrink, E. A. (2006). Emotion Research in Education: Theoretical and Methodological Perspectives on the Integration of Affect, Motivation, and Cognition. Educational Psychology Review, 18(4), 307-314. doi:10.1007/s10648-006-9028-x

Linnenbrink-Garcia, L., \& Pekrun, R. (2011). Students' emotions and academic engagement: Introduction to the special issue. Contemporary Educational Psychology, 36(1), 1-3. doi:10.1016/j.cedpsych.2010.11.004

Lipsey, M. W., \& Wilson, D. B. (2001). Practical Meta Analysis. Applied Social Research Methods Series, Vol. 49.

Menard, S. (1995). Applied logistic regression analysis: Sage university series on quantitative applications in the social sciences. Thousand Oaks, CA.

Myers, R. H. (1990). Classical and modern regression with applications (Vol. 2). Belmont, CA: Duxbury Press.

Muthén, L. K., \& Muthén, B. O. (1998-2011). Mplus User's Guide. Sixth Edition. Los Angeles, CA: Muthén \& Muthén.

Noftle, E. E., \& Robins, R. W. (2007). Personality predictors of academic outcomes: Big five correlates of GPA and SAT scores. Journal of Personality and Social Psychology, 93(1), 116-130. doi:10.1037/00223514.93.1.116

Pascarella, E. T., \& Terenzini, R T. (1991). How college affects students: findings and insights from twenty years of research. San Francisco: Jossey-Bass.

Pascarella,E., \&Terenzini,P.(2005). How college affects students (Vol. 2): A third decade of research. SanFrancisco:Jossey-Bass.

Pekrun, R. (1992). Expectancy-value theory of anxiety: Overview and implications. In D. G. Forgays, T. Sosnowski, \& K. Wrzesniewski (Eds.), Anxiety: Recent developments in cognitive, psychophysiological, and health research. (pp. 23-41). Washington, DC US: Hemisphere Publishing Corp.

Pekrun, R. (2000). A social cognitive, control-value theory of achievement emotions. In J.Heckhausen (Ed.), Motivational psychology of human development. Oxford, England: Elsevier Science.

Pekrun, R. (2006). The Control-Value Theory of Achievement Emotions: Assumptions, Corollaries, and Implications for Educational Research and Practice. Educational Psychology Review, 18(4), 315-341.

Pekrun, R., Goetz, T., Frenzel, A. C., Barchfeld, P., \& Perry, R. P. (2011). Measuring emotions in students' learning and performance: The Achievement Emotions Questionnaire (AEQ). Contemporary Educational Psychology, 36(1), 36-48. doi:10.1016/j.cedpsych.2010.10.002

Pekrun, R., Goetz, T., Perry, R. P., Kramer, K., Hochstadt, M., \& Molfenter, S. (2004). Beyond test anxiety: Development and validation of the test emotions questionnaire (TEQ). Anxiety, Stress \& Coping, 17(3), 287316.doi:10.1080/10615800412331303847

Pekrun, R., Goetz, T., Titz, W., \& Perry, R. P. (2002). Academic emotions in students' self-regulated learning and achievement: A program of qualitative and quantitative research. Educational Psychologist, 37(2), 91-106.

Pekrun, R., \& Linnenbrink-Garcia, L. (Eds.). (2014). International handbook of emotions in education. New York : Routledge, Taylor \& Francis.

Poropat, A. E. (2009). A meta-analysis of the five-factor model of personality and academic performance. Psychological Bulletin, 135(2), 322-338. doi:10.1037/a0014996

Putwain, D. W., Larkin, D., \& Sander, P. (2013). A reciprocal model of achievement goals and learning related emotions in the first year of undergraduate study. Contemporary Educational Psychology, 38(4), 361-374. doi:10.1016/j.cedpsych.2013.07.003

Putwain, D. W., Sander, P., \& Larkin, D. (2013). Using the $2 \times 2$ framework of achievement goals to predict achievement emotions and academic performance. Learning and Individual Differences, 25(0), 80-84. doi:10.1016/j.lindif.2013.01.006 


\section{CHAPTER 2}

Richardson, M., Abraham, C., \& Bond, R. (2012). Psychological Correlates of University Students' Academic Performance: A Systematic Review and Meta-Analysis. Psychological Bulletin, 138(2), 353-387 doi: $10.1037 / \mathrm{a} 0026838$

Rienties, B., Tempelaar, D., Dijkstra, J., Rehm, M., \& Gijselaers, W. (2008). Longitudinal Study of Online Remedial Education Effects. In N. Barsky, M. Clements, J. Ravn, \& K. Smith (Eds.), The Power of Technology for Learning (Vol. 1, pp. 43-59). Springer Netherlands. Retrieved from http://dx.doi.org/10.1007/978-14020-8747-9_3

Robbins, S., Lauver, K., Huy, L., Davies, D., Langley, R., \& Carlstrom, A., (2004). Do Psychological and Study Skill Factors Predict college outcomes? A Meta-Analysis, Psychological Bulletin, 130 (2), 261-288.

Ruthig, J., Perry, R., Hladkyj, S., Hall, N., Pekrun, R., \& Chipperfield, J. (2008). Perceived control and emotions: interactive effects on performance in achievement settings. Social Psychology of Education, 11(2), 161180.

Schutz, P. A., \& Pekrun, R. (2007). Introduction to emotion in education. In P. A. Schutz \& R. Pekrun (Eds.), Emotion in education. (pp. 3-10). San Diego, CA US: Elsevier Academic Press.

Schermelleh-Engel, K., Mossbrugger, H., \& Müller, H. (2003). Evaluating the fit of structural equation models: Tests of significance and descriptive goodness-of-fit measures. Methods of Psychological Research Online, 2, 2374.

Scherer, K. R. (2005). What are emotions? And how can they be measured? Social Science Information, 44(4), 695-729. doi: $10.1177 / 0539018405058216$

Stöber, J., \& Pekrun, R. (2004). Advances in test anxiety research. Anxiety, Stress \& Coping: An International Journal, 17(3), 205-211.

Tempelaar, D. T., Niculescu, A., Rienties, B., Gijselaers, W. H., \& Giesbers, B. (2012). How achievement emotions impact students' decisions for online learning, and what precedes those emotions. The Internet and Higher Education, 15(3), 161-169. doi:10.1016/j.iheduc.2011.10.003

Tinto, V. (1987). Leaving college, Rethinking the causes and cures of student attrition. Chicago: The University of Chicago.

Trautwein, U., Schnyder, I., Niggli, A., Neumann, M., \& Lüdtke, O. (2009). Chameleon effects in homework research: The homework-achievement association depends on the measures used and the level of analysis chosen. Contemporary Educational Psychology, 34(1), 77-88. doi:10.1016/j.cedpsych.2008.09.001

Turner, J. E., \& Schallert, D. L. (2001). Expectancy-value relationships of shame reactions and shame resiliency. Journal of Educational Psychology, 93, 320-329.

Verma, S., Sharma, D., \& Larson, R. W. (2002). School stress in India: Effects on time and daily emotions. International Journal of Behavioral Development, 26(6), 500-508. doi:10.1080/01650250143000454

Weiner, B. (1985). An attributional theory of achievement motivation and emotion. Psychological Review, 92 , 548-573.

Wilkerson, L., \& Gijselaers, W. H. (1996). Bringing problem-based learning to higher education: Theory and practice. San Francisco: Jossey-Bass.

Zeidner, M. (1998). Test anxiety: The state of the art. Springer.

Zeidner, M. (2007). Test anxiety in educational contexts: What I have learned so far. In P. A. Schutz \& R. Pekrun (Eds.), Emotion in education (pp. 165-184). San Diego, CA: Academic 


\section{CHAPTER 3}

\section{Exploring the antecedents of learning-related emotions and their relations with}

achievement outcomes

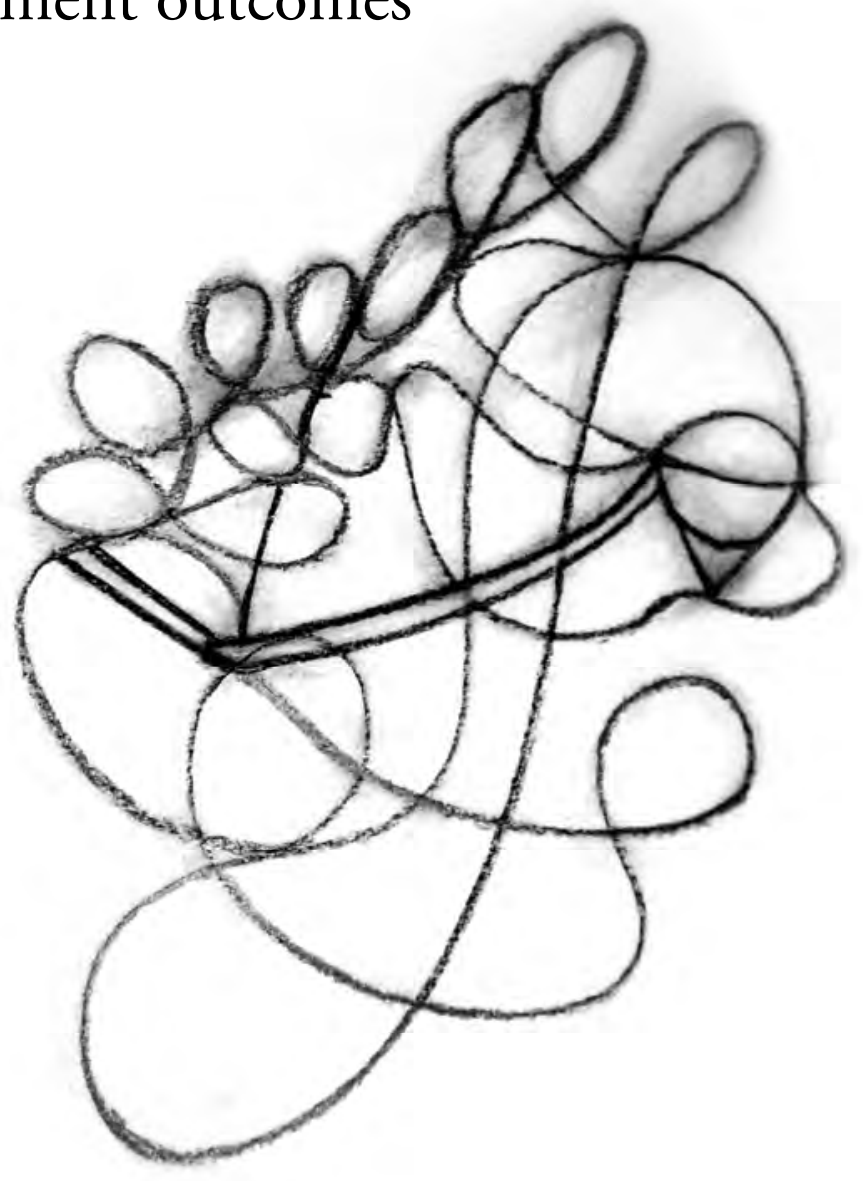

This chapter was published as:

Niculescu, A., Tempelaar, D., Dailey-Hebert, A., Segers, M., \& Gijselaers, W. (2015). Exploring the antecedents of learning-related emotions and their relations with achievement outcomes. Frontline Learning Research, 3 (1), 1-16. http://dx.doi.org/ 10.14786/flr.v3i1.136 


\section{ABSTRACT}

Recent work suggests that learning-related emotions (LREs) play a crucial role in performance especially in the first year of university, a period of transition for most students; however, additional research is needed to show how these emotions emerge. We developed a framework which links a course-contextualized antecedent - academic control in Pekrun's (2006) Control Value Theory of Achievement Emotions - with generic antecedents - adaptive and maladaptive cognitions and behaviors from Martin's (2007) Motivation and Engagement Wheel framework - to explain a classical problem: the emergence of LREs in a transition period. Using a large sample $(\mathrm{N}=3451)$ of first year university students, our study explores these two antecedents to better understand how four LREs (enjoyment, anxiety, boredom and hopelessness) emerge in a mathematics and statistics course. Through the use of path-modelling, we found that academic control has a strong effect on all four LREs - with the strongest impact observed for learning hopelessness and secondary, for learning anxiety. Academic control, on its turn, builds on contributions from adaptive and mal-adaptive cognitions. Furthermore, adaptive cognitions have an impact on learning enjoyment (positive) and on boredom (negative). Surprisingly though, the maladaptive behaviors impact positively learning enjoyment and negatively learning anxiety. Following this, we predicted performance outcomes in the course and found again academic control as the main predictor, followed by learning hopelessness. Overall, this study brings evidence that adaptive and maladaptive cognitions and behaviours act as important antecedents of academic control, the main predictor of LREs and course performance outcomes. 


\section{INTRODUCTION}

The first year experience of university is known as a transition period (Baker \& Syrik, 1999; Tinto, 1997), when students are confronted with novel situations over which they have low control, yet still hold high expectations for success (Perry, Hladkyj, Pekrun, Clifton, \& Chipperfield, 2005). These conditions typically create negative emotional reactions towards learning in academic situations (Stupnisky, Perry, Hall, \& Guay, 2012), which can lead to voluntary withdrawal at the course level (Ruthig et al., 2007) and overall poor performance across all courses taken at the university (Hall, Perry, Ruthig, Hladkyj, \& Chipperfield, 2006). Such emotions, known as achievement related emotions, can have serious consequences on how students perform within a course (Pekrun et al., 2011). This is particularly true for mathematics and statistics courses, in which students experience high levels of negative emotions, especially in learning- or homework-related situations (Dettmers et al., 2011; Goetz et al., 2012). Within these courses, negative emotions emerge from beliefs about a low capacity to influence outcomes (Frenzel, Pekrun, \& Goetz, 2007; Pekrun, 2000), referred to as appraisals of control (Pekrun, Goetz, Titz, \& Perry, 2002). At the same time, students come into these courses holding generic predispositions towards learning at university, such as adaptive and maladaptive cognitions and behaviours, which will also influence their experiences within a course (Martin, 2007).

Although we know that emotions experienced in learning- or homework-related situation are particularly important for performance (Leone \& Richards, 1989; Verma, Sharma, \& Larson, 2002), additional research is needed in the first year of university to help us understand how these emotions emerge and how they can be influenced (Putwain, Sander, $\&$ Larkin, 2013). Such information can inform the design of educational interventions to create "emotionally sound" (Astleitner, 2000) learning environments which can potentially improve academic achievement.

The present study focuses on two different antecedents of achievement learning-related emotions: 1) the course contextualized antecedents (appraisal of control) and, 2) the generic antecedents towards learning at university (adaptive and maladaptive cognitions and behaviours). Both antecedents need to be integrated, as they are complementary in providing information about the emergence of emotions in a course setting. Direct antecedents are necessary for explaining the emergence of distinct emotions at a course level and distal antecedents can explain the individual differences that arise in the emergence of these emotions. Finally, relations and implications for academic achievement are further discussed.

\subsection{Theoretical framework}

Over the past twenty years we have seen a growing interest in, and increased research that explores the role of achievement emotions across various educational contexts and course settings. Such research investigates different functions of academic emotions within a course, such as their effects on self-regulation (Artino Jr. \& Jones II, 2012), learning engagement (Ainley \& Ainley, 2011), learning choices (Tempelaar, Niculescu, Rienties, Gijselaers, \& Giesbers, 2012) and achievement (Dettmers et al., 2011; Goetz, Frenzel, Pekrun, \& Hall, 2006; Goetz et al., 2012). The transition required in the first year of uni- 
versity involves several challenges which may include perceived competition and pressure to perform - both demanding heightened self-reliance and autonomy (Perry, Hladkyj, Pekrun, \& Pelletier, 2001). Since students are expected to engage in more individual selfstudy, the importance of achievement emotions in individual learning- or homework- related situations (as compared to the classroom setting, for example) is particularly important. These emotions are referred to in the literature as achievement learning-related emotions (Pekrun, 2000). At the same time, a closer investigation of students' experiences is necessary to clarify how learning-related emotions (LREs) emerge at the course level.

\subsubsection{Achievement emotions}

Achievement emotions are defined as "emotions that are directly linked to achievement activities and outcomes" (Pekrun et al., 2011, p. 37). In the Control-Value Theory of Achievement Emotions (Pekrun, 2006b), emotional experiences have a situational context, meaning that they can be experienced in different academic situations within a course: 1) being in class, 2) taking tests and exams and, 3) studying outside of class (while learning or when preparing homework). Of particular interest are the emotions experienced in learning-related situations as students seem to experience the most unpleasant emotions when compared with other academic situations, such as learning in the classroom (Leone \& Richards, 1989). Indeed, according to the CVTAE, first year university students experience a variety of learning-related emotions, whether the emotions are positive or negative.

\subsubsection{Learning - related emotions and their course contextualized antecedents}

According to the Control-Value Theory of Achievement Emotions (CVTAE; Pekrun, 2006), discrete learning-related emotions (LREs) arise from the appraisal of achievement activities and outcomes. Emotions that result from such appraisals can indirectly influence achievement outcomes. There are two dimensions of appraisals: control and value. The appraisal of control refers to a student's belief about whether he/she has control over learning activities/outcomes; the appraisal of value describes the subjective value attributed to these activities/outcomes. These appraisals are considered direct antecedents of LREs and are acquired at the course level (Pekrun, 2006).

Control appraisals describe the perceived controllability of one's own competency towards achievement activities and outcomes; as a general rule, low and high levels of control appraisals influence emotions differently (Pekrun, 2000). For instance, low control leads to an increased level in negative emotions (e.g., learning anxiety) and a more elevated level of control favours a heightened experience of positive emotions (such as learning enjoyment). Empirical evidence shows that the appraisal of control longitudinally relates to emotions (Perry et al., 2001; Perry et al., 2005), as well as to subsequent academic achievement in the first year of university (Hall et al., 2006; Ruthig et al., 2008; Stupnisky et al., 2012). For instance, Perry et al. (2001) found that students who reported higher levels of primary control also felt less bored (-.48) and less anxious (-.35) towards the course, and obtained higher final grades (.27). Similar relations are shown by Hall et al. (2006): correlations between primary control and several emotions (anger, regret, happiness and pride) are in the range of -.27 to .24 ; primary control relates positively to the final 
course grade (.21) as well as to cumulative GPA (.25). Overall, this correlational evidence suggests relations between primary control, emotions and performance which are of moderate size (Cohen, 1992). There are also documented gender differences in the beliefs students hold towards their abilities to perform in mathematics (female students tend to generally believe they are not very good at mathematics), with implications on how the two genders feel about this subject (Robinson \& Clore, 2002; Frenzel et al., 2007). Finally, the implications of studying course specific antecedents of LREs is relevant when explaining the development of emotions over time and, indirectly, for understanding their consequences on achievement.

\subsubsection{Generic antecedents of learning-related emotions}

There are also more general expectancies and predispositions towards learning at university students already hold when entering a course, which can be considered generic antecedents of LREs and achievement. Students enter a new course holding background characteristics (intelligence, personality, high school GPA etc.) but also possessing a set of adaptive and impeding cognitions, and adaptive and impeding behaviors, towards learning in the new setting of university (Martin, 2007). Therefore, we applied the 'motivation and engagement wheel' framework of Martin $(2007,2009)$ as a model for distal antecedents of learning-related emotions (LREs). The motivation and engagement wheel breaks down all motivation and engagement concepts into four categories: adaptive cognitions, adaptive behaviors, impeding cognitions, and maladaptive behaviors. These four categories each consist of two or three sub-dimensions. For adaptive cognitions, the dimensions consist of self-belief, valuing school, and learning focus. Student's confidence to do well in university, their belief that learning will be useful and relevant, and their interest in learning new topics/developing new skills, all contribute to various academic outcomes (Martin, 2011). Furthermore, the adaptive behavioral dimensions include persistence, planning, and task management. To date, a study of Martin and Marsh (2006) shows that self-efficacy, control, planning, low anxiety, and persistence predict enjoyment and class participation. Conversely, the impeding or deactivating antipodes of the cognitions (that obstruct learning rather than enhance it) include anxiety, failure avoidance and uncertain control. The maladaptive behaviors are twofold: self-handicapping and disengagement. In turn, selfhandicapping (as a disruptive behaviour) can predict negative academic outcomes (Martin, Marsh, \& Debus, 2001). Although the experience of the adaptive and mal-adaptive cognitions and behaviors can differ on average for female and male students (Liem \& Martin, 2012), the concepts operating in this motivation and engagement wheel represent generic orientations that are relatively stable over contexts (Martin, 2009). For this reason, in Pekrun's Theory, such generic orientations can be integrated as distal antecedents of LREs. Although it may appear that some of the concepts (e.g. self-belief/efficacy, persistency and control) from the "motivation and engagement wheel" are closely related to the appraisal of control in the CVTAE, it is important to ensure clarity (distinction) between them: while the distal antecedents are more trait-type of constructs, the direct antecedent (appraisal of control) is a subject specific type of appraisal. Overall, the motivation and engagement concepts play an important role in students' cognitive appraisals, in their emotions during 
learning, and in achievement outcomes (Martin \& Marsh, 2006; Martin, 2011). Figure 1 summarizes the conceptual model used in our study.

To sum-up, the added value of integrating both direct and distal antecedents into one framework is to explain: 1) the emergence of distinct emotions through direct antecedents, and 2) through distal antecedents, the individual differences that arise in learning emotions when students enrol in a course.

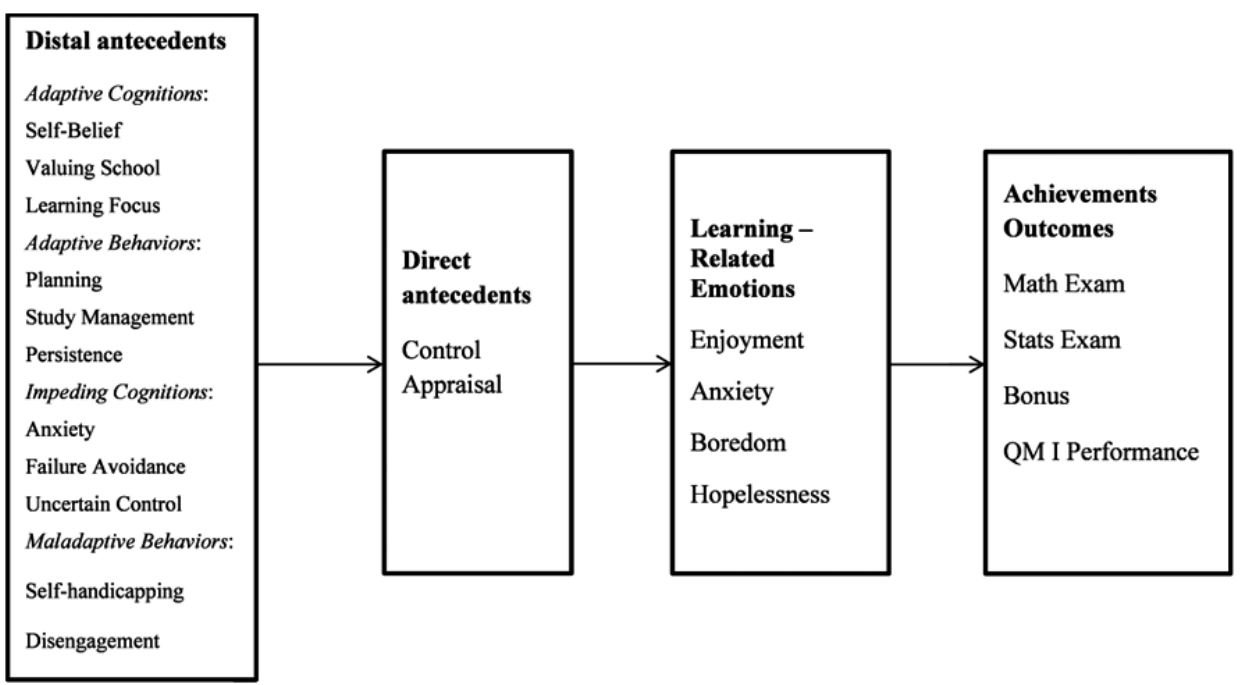

Figure 1. The conceptual framework of the study

\subsubsection{Learning - related emotions and academic performance}

While other settings have been extensively studied, such as the exam situation, few studies have investigated situations outside the class (Putwain, Larkin, \& Sander, 2013; Schutz \& Pekrun, 2006; Trautwein et al., 2009). Recent research discusses students' emotional experiences during individual learning activities such as mathematics homework (Dettmers et al., 2011; Goetz et al., 2012) in which the assignments are considered "emotionally charged activities" (Dettmers et al., 2011, p. 25). In the homework situation students seem to experience the most unpleasant emotions when compared with other academic situations (Leone \& Richards, 1989; Verma, Sharma, \& Larson, 2002). Furthermore, learning - related emotions (LREs) are of particular interest, as they demonstrate a strong relationship with achievement outcomes. While it is already known that positive emotions have a positive impact on academic performance (Dettmers et al., 2011; Pekrun et al., 2002), by focusing on the experience of unpleasant emotions during homework, Dettmers et al. (2011) demonstrates how elevated anxiety and boredom levels shape effort and disengagement in study, to predict negative achievement in mathematics. Considering the transition represented by the first year of university, more evidence is needed - particularly in this period about students' emotional experiences in learning situations. To our best knowledge, only few studies (Putwain, Sander, et al., 2013) have addressed this issue in the first year of 
university context. To our best knowledge, we found only one study (Tempelaar et al., 2012) which investigates how these emotions emerge and influence learning outcomes in the setting of an undergraduate introductory mathematics or statistics course. The present study builds further on the Tempelaar et al. (2012) work to look how distinct LREs emerge from course contextualized and generic antecedents and further, how they influence achievement outcomes in a first year university mathematics and statistics course.

\subsection{Research questions and hypotheses}

We have asked the following research questions:

RQ1. What role do distal and direct antecedents play in the development of LREs?

RQ2. To what extent can the direct and distal antecedents together explain student performance at the course level?

Furthermore, we hypothesize:

H1. The distal antecedents will have effects on both control appraisals and LREs, with differential roles for adaptive and maladaptive distal antecedents.

H2. The direct antecedents, control appraisals, will have an effect on LREs. This effect will be different for positive versus negative (or neutral) LREs. The control appraisals will influence positively enjoyment and negatively anxiety, boredom and hopelessness.

H3. Distal antecedents, direct antecedents and LREs all explain student performance in the course.

Research hypotheses are graphically depicted in the Figure 2, demonstrating the a priori structural model. To facilitate the reading of this conceptual model, all three negative emotions are taken together, as well as the two adaptive cognitions and behaviours, and the two maladaptive ones.

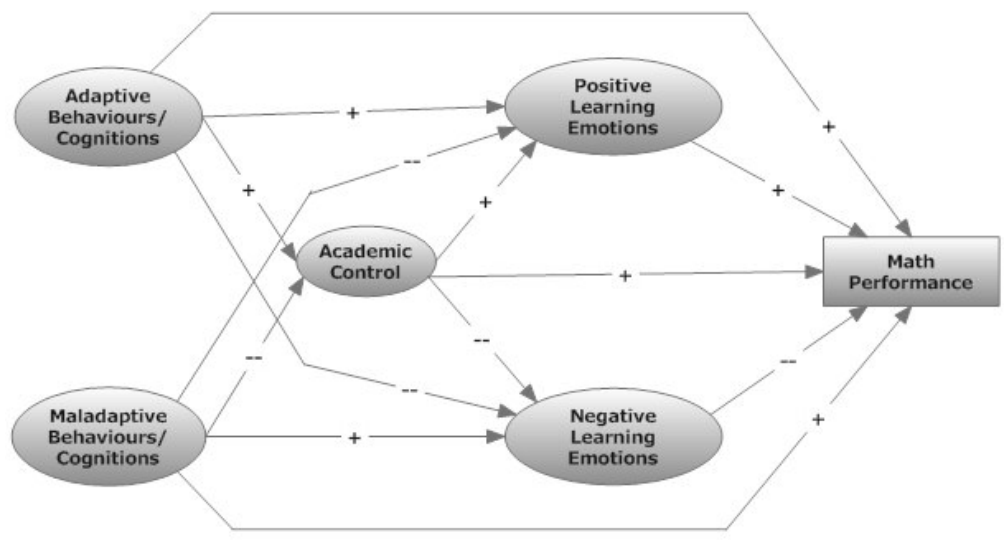

Figure 2. The hypothesized structural model 
The hypothesized structural model expresses that adaptive cognitions and behaviours, academic control, positive emotion, and performance are all hypothesized to be positively related, whereas maladaptive cognitions and behaviours and negative emotions are hypothesized to be positively related amongst them, but negatively related with the first subset of variables. Not explicit in this conceptual model is that distal antecedents are represented by second order factors of the motivation and engagement instrument, however allowing for path estimates being different from factor loadings.

\section{METHOD}

\subsection{Sample and setting}

The participants were 3451 freshmen (19 years old on average, $62.5 \%$ male) enrolled over four consecutive academic years $(10 / 11,11 / 12,12 / 13,13 / 14)$ in a Business and Economics program at a European University. Most students had an international background, a vast majority $(77.4 \%)$ holding an international education diploma and one third of the sample had been previously educated in the field of mathematics (mathematical major specialization).

The setting was a compulsory introduction course to mathematics and statistics, scheduled in the first term of the academic year. It had a duration of eight weeks out of which, seven weeks were scheduled for education and the last week was reserved for exams.

\subsection{Procedure}

In week two of the course students completed an online questionnaire concerning their adaptive and maladaptive cognitions and behaviors towards learning at university in general. In week four participants completed another online questionnaire, this time about their control appraisals and LREs regarding the specific subject of the course. The timing was chosen to capture sufficient experience with the learning activities.

In weeks three, five and seven of the course, voluntary mathematics and statistics quizzes were planned which, if performed successfully, added a bonus score to the final course grade. Every week, students were expected to prepare homework assignments which, if solved, granted students bonus points. In week eight of the course, students participated in the written exam. All students included in this study provided informed consent for the data collected by means of online questionnaires and for use of their study results.

\subsection{Measures and variables}

We measured Learning-related emotions through four scales: Enjoyment, Anxiety, Boredom and Hopelessness, of the Achievement Emotions Questionnaire (AEQ; Pekrun et al., 2011). The Enjoyment scale (10 items, e.g. "I enjoy accruing new knowledge"), Anxiety scale (11 items, e.g. "I get tense and nervous while studying"), Boredom scale (11 items, e.g. "The material bores me to death") and Hopelessness scale (11 items, e.g. "I feel hopeless when I 
think about studying") were slightly re-phrased to match the specific situation of our course. For reasons of consistency in our research, all items were answered on a 7-point Likert scale (1 $=$ 'completely disagree' and $7=$ 'completely agree').

Control appraisals were measured with the Academic Control Scale (ACS) of Perry et al. (2001). Academic control as described by Perry et al. is a domain, course-specific measure of college students' beliefs. The scale is composed of eight items, each answered on a 7point scale ( 1 = 'strongly disagree' and $7=$ 'strongly agree'), e.g. "I have a great deal of control over my academic performance in this course".

Adaptive and maladaptive cognitions and behaviors were measured with the Motivation and Engagement Scale (MES; Martin, 2007). The MES consists of four scales and eleven subscales subsumed under the four scales. The Adaptive Cognition scale is composed of three sub-scales: Self-Belief (e.g. "If I try hard, I believe I can do my university work well"), Valuing School (e.g. "Learning at university is important for me") and Learning Focus (e.g. "I feel very pleased with myself when I really understand what I'm taught at the university"). The second scale, Adaptive Behavior contains the following subscales: Persistence (e.g. "If I can't understand my university work at first, I keep going over until I do"), Planning (e.g. "If I start an assignment I plan out how I am going to do it") and Study Management (e.g. "When I study, I usually study in places where I can concentrate"). The third sub-scale, Maladaptive (Impeding) Cognition includes the Anxiety (e.g. "When exams and assignments are coming up, I worry a lot"), Failure Avoidance (e.g. "Often the main reason I work at university is because I don't want to disappoint others") and Uncertain Control (e.g. "I am often unsure how I can avoid doing poorly at university") sub-scales. Finally, Maladaptive Behavior includes the Self-Handicapping (e.g. "Sometimes I don't study very hard before exams so I have an excuse if I don't do as well as I hoped") and Disengagement (e.g. "I often feel like giving up at university") sub-scales.

Academic Achievement was measured with a performance portfolio consisting of three separate parts: MathPerformance, StatsPerformance and BonusPerformance. First, the two performance outcomes MathPerformance and StatsPerformance were assessed in a final written exam which covered a mathematics component and a statistics component, graded separately. Second, the BonusPerformance represented the sum of bonus scored in quizzes and homework. Quizzes, although optional, were available for both mathematics and statistics in an online format. Some further bonus could be achieved by doing weekly homework, containing assignments for mathematics and statistics. Finally, the three separate parts were summed in the QMPerformance which represented the total score for the course.

We accounted for any potential influences coming from gender (Female and Male) and level of introductory mathematics education (distinguishing between two tracks, MathMajor and MathMinor) as control variables.

\subsection{Statistical analyses}

As a preliminary step in the analysis, the four cohorts were checked upon invariance of mean levels and correlation structures. Next, beyond descriptive analyses, this study applies structural equation modelling. Models were estimated with LISREL (version 8.8) using 
maximum likelihood (ML) estimation. To prevent capitalization on chance, rather conservative model building rules were adapted: $\mathrm{p}$-values of $1 \%$ or less were required as a cutoff value for significance for the adoption of any structural path; correlated traits were only allowed for variables measured by the same instrument. As measurement model for the motivation and engagement constructs, a second order confirmatory factor model was postulated, with second the order factors Adaptive Cognitions, Adaptive Behaviors, Impeding Cognitions, and Maladaptive Behaviors (see Martin, 2007). We identified both second order and first order latent factors for motivation and engagement variables, and in order to derive a parsimonious model, we based the relationships with LRE's and control appraisal on the second order factors. However, we allowed for differentiated effects of first order factors, by testing if first order factors would add predictive power to the already included second order factors.

We report the Chi-square and degrees of freedom values, the Comparative Fit Index (CFI), the Non-Normed Fit Index (NNFI, also known as TLI) and the Root Mean Square Error of Approximation (RMSEA) as indicators of goodness of fit. Hu and Bentler (1999) suggested for CFI/TLI values larger than .90 for a satisfactory fit and for RMSEA values should not exceed .08 and preferably be .06 or lower.

\section{RESULTS}

\subsection{Preliminary analysis}

We checked the assumptions of normality through SPSS 22. Values of skewness and kurtosis were in the expected range of chance fluctuations in that statistic for all scales. To make the performance measures equivalent over cohorts, we transformed exam scores into cohort specific z-scores. These transformed variables were used in all subsequent analyses. We provide descriptive statistics and reliabilities (Table 1) - as well as measures for differences between gender and prior education track. All analyses were based on a subset of students for which background characteristics, LREs variables and performance data were all available (3355 of the 3451 students, 97\%). 
Table 1 Means (M), standard deviations (SD), Cronbach's alpha and test statistics for gender and prior mathematics education differences: $\mathrm{t}$-value and Cohen $\mathrm{d}$-value

\begin{tabular}{|c|c|c|c|c|c|c|c|}
\hline & \multirow[t]{2}{*}{ M } & \multirow[t]{2}{*}{ SD } & \multirow[t]{2}{*}{ A } & \multicolumn{2}{|c|}{ Gender difference } & \multicolumn{2}{|c|}{ Math prior education } \\
\hline & & & & $t$-value & $d$-value & $\overline{t-v a l u e}$ & $d$-value \\
\hline \multicolumn{8}{|l|}{ Adaptive Cognitions: } \\
\hline Self-Belief & 5.82 & 0.73 & 0.73 & 1.08 & 0.04 & $2.86^{* *}$ & 0.10 \\
\hline Valuing School & 5.84 & 0.67 & 0.67 & $-5.15^{* * *}$ & -0.18 & 1.65 & 0.06 \\
\hline Learning Focus & 5.95 & 0.73 & 0.80 & $-9.65^{* * *}$ & -0.34 & -0.14 & 0.00 \\
\hline \multicolumn{8}{|l|}{ Adaptive Behaviors: } \\
\hline Planning & 4.79 & 0.99 & 0.73 & $-9.73^{* * *}$ & -0.34 & 0.15 & 0.01 \\
\hline Study Management & 5.56 & 0.89 & 0.74 & $-9.04^{* * *}$ & -0.32 & $-2.66^{*}$ & -0.09 \\
\hline Persistence & 5.34 & 0.85 & 0.78 & $-6.79^{* * *}$ & -0.24 & 1.00 & 0.04 \\
\hline \multicolumn{8}{|l|}{ Impeding Cognitions: } \\
\hline Anxiety & 4.50 & 1.27 & 0.83 & $-16.12^{* * *}$ & -0.57 & $-6.07^{* * *}$ & -0.21 \\
\hline Failure Avoidance & 2.57 & 1.19 & 0.83 & 0.90 & 0.03 & -1.45 & -0.05 \\
\hline Uncertain Control & 3.45 & 1.18 & 0.80 & $-5.418^{* * *}$ & -0.19 & $-4.58^{* * *}$ & -0.16 \\
\hline \multicolumn{8}{|l|}{ Maladaptive Behaviors: } \\
\hline Self-handicapping & 2.43 & 1.08 & 0.81 & $5.68^{* * *}$ & 0.32 & -0.45 & -0.02 \\
\hline Disengagement & 1.97 & 0.90 & 0.74 & $7.09^{* * *}$ & 0.25 & 1.20 & 0.04 \\
\hline Academic Control & 5.26 & 0.89 & 0.82 & $3.868^{* * *}$ & 0.14 & $13.68^{* * *}$ & 0.48 \\
\hline \multicolumn{8}{|c|}{ Learning-related Emotions } \\
\hline Anxiety & 3.85 & 1.11 & 0.91 & $-11.41^{* * *}$ & -0.40 & $-15.13^{* * *}$ & -0.53 \\
\hline Boredom & 2.94 & 1.13 & 0.93 & $7.65^{* * *}$ & 0.27 & $-4.44^{* * *}$ & -0.16 \\
\hline Hopelessness & 3.01 & 1.22 & 0.94 & $-7.18^{* * *}$ & -0.25 & $-17.08^{* * *}$ & -0.60 \\
\hline Enjoyment & 4.11 & 0.92 & 0.85 & -0.55 & -0.02 & $10.40^{* * *}$ & 0.37 \\
\hline \multicolumn{8}{|l|}{ Performance outcomes } \\
\hline Math performance & & & & -1.03 & -0.04 & $20.47^{* * *}$ & 0.72 \\
\hline Stats performance & & & & 1.68 & 0.06 & $11.87^{* * *}$ & .042 \\
\hline Bonus performance & & & & $-6.70^{* * *}$ & -0.24 & $11.73^{* * *}$ & 0.41 \\
\hline QM performance & & & & -1.00 & -0.04 & $18.41^{* * *}$ & 0.65 \\
\hline
\end{tabular}

Note: performance scores are normalized scores; concerning gender differences, a negative score represents female students; a positive score in the differences in previous math education represents math major.

\subsection{Bivariate correlations}

Bivariate correlations are reported in Table 2. Due to the large number of manifest variables, the correlation table contains scale values rather than individual item values for the survey data based on the AEQ, ACS and MES instruments. The four performance measures are manifest variables too. 
Table 2. Correlations of scales of the AEQ, ASC, and MES instruments (1-16) and performance measures (17-20)

\begin{tabular}{|c|c|c|c|c|c|c|c|c|c|c|c|c|c|c|c|c|c|c|c|c|}
\hline & ol & 02 & 03 & 04 & 05 & 06 & 07 & 08 & $\infty$ & 10 & 11 & 12 & 13 & 14 & 15 & 16 & 17 & 18 & 19 & 20 \\
\hline 01 Self-Belicf & 1.00 & & & & & & & & & & & & & & & & & & & \\
\hline 02 Valuing School & 55 & 1.00 & & & & & & & & & & & & & & & & & & \\
\hline 03 Learring Focus & 56 & .63 & 1.00 & & & & & & & & & & & & & & & & & \\
\hline ot Planning & .27 & .33 & .35 & 1.00 & & & & & & & & & & & & & & & & \\
\hline OS Study Managemean & .34 & 40 & .43 & 54 & 100 & & & & & & & & & & & & & & & \\
\hline 06 Persistence & .47 & 47 & 49 & 49 & 44 & 5.00 & & & & & & & & & & & & & & \\
\hline 07 Anxiety &. .14 & .02 & II & 05 & .09 & -.01 & 1.00 & & & & & & & & & & & & & \\
\hline DS Fallure Avoidance & -26 & -.21 & -20 & 07 & .13 & -21 & .27 & 1.00 & & & & & & & & & & & & \\
\hline 09 Unceraia Control & -33 & -17 & .13 & .12 & -11 & .24 & 51 & 39 & 1.00 & & & & & & & & & & & \\
\hline 10 Self-handicapping & -.29 & -30 & -34 & .28 & .28 & -39 & 10 & 43 & 30 & 1.00 & & & & & & & & & & \\
\hline 11 Jisengagemert & .45 & -.47 & -47 & -23 & .30 & -38 & .07 & 41 & 32 & 53 & 1.00 & & & & & & & & & \\
\hline I2 Academic Control & .33 & .23 & .24 & .11 & .12 & .29 & -.32 & .22 &. .44 & -20 & .26 & 1.00 & & & & & & & & \\
\hline 13 Anxiety & -20 & os & .00 & -.04 & 00 & 13 & 61 & .25 & 48 & 17 & 14 & -57 & 100 & & & & & & & \\
\hline 14 Borodom & -.24 &,- 29 & -31 & -26 & .28 & -39 & 08 & .24 & 24 & 36 & 34 & -.34 & 35 & 1.00 & & & & & & \\
\hline 15 Hopelessness & .32 & -14 & -.16 & -.12 & -10 & -29 & 49 & .30 & 50 & .28 & .28 & -.70 & .82 & $.5 !$ & 1.00 & & & & & \\
\hline 16 Enjoyment & .22 & 21 & .26 & 25 & 21 & .35 & -.09 & .04 & -14 & .15 & .10 & 37 & -.31 & .50 & .45 & 1.00 & & & & \\
\hline 17 Math performanoe & 10 & 04 & .07 & 03 & .03 & .32 & -18 & -.12 & -17 & -16 & .12 & 36 & -32 & -20 & -39 & 24 & 1.00 & & & \\
\hline 15 Stats performance & .10 & .02 & .04 &,- 02 & .08 & .06 & -.21 & .14 & -.17 &., 16 & .14 & .27 & -24 & -.10 & .30 & .09 & .60 & 1.00 & & \\
\hline 19 Bocis pefformance & .09 & .08 & .12 & 11 & .09 & .16 & -.08 & -13 & -.12 & .22 & -17 & .25 & -.20 & -.24 & -30 & .22 & .56 & so & 1.00 & \\
\hline $20 \mathrm{QM}$ performance & 4) & 05 & .07 & .03 & .05 & 12 & -.21 & -15 & -19 & -20 & .16 & 36 & .32 & .20 & -30 & $2 !$ & 90 & $\$ 6$ & 31 & 1.00 \\
\hline
\end{tabular}

Note: all correlations larger or equal to .05 in absolute size, are statistically significant at the .01 level; performance scores are nonnaized scores.

The signs of the bivariate correlations express the divide into adaptive and maladaptive constructs. Adaptive cognitions and behaviours are positively correlated to 1) Academic Control, 2) the positive LRE of Enjoyment, and to 3) performance measures. Correlations with performance measures are however weak, and not fully consistent for Study Management. Correlations between Academic Control and Enjoyment versus performance measures are stronger, and consistently positive. A reverse pattern exists for the maladaptive cognitions and behaviours: positively correlated to negative LREs, negatively correlated to Academic Control, Enjoyment and performance measures. However, within the motivation and engagement variables, Anxiety is unique in that it acts as a maladaptive cognition dimension in relation to LREs and performance. Yet, it correlates weakly with other maladaptive MES variables, as well as with the adaptive constructs (Learning Focus, Study Management, and Planning) but to a lesser degree.

\subsection{Structural models}

Separate structural equation models were estimated for each of the four performance constructs, each of them having identical relationships between the motivation and engagement latent constructs, and the latent constructs based on LREs and Academic Control. Figure 3 contains the diagram of the structural part of the structural equation model (leaving out the measurement parts of the LRE, academic control and motivation and engagement constructs for reasons of readability), having only the mathematics score in the exam 
as performance construct. It is relevant to mention that structural models for the other performance constructs deviate only in terms of the equation predicting the performance constructs, and these equations are provided at the end of this section, in Table 3. All regression paths are expressed as standardized betas. Structural models were estimated in two multi-group specifications: on the basis of gender, and on the basis of prior mathematics track in high school. Both result in a rejection of invariant latent means, fully in line with the outcomes of the descriptive analyses: differences in mean scales between female and male students, and between students educated in the math major, versus math minor track, also show up as significant differences in latent means. However, at the stringent .01 significance level, no rejection of the hypothesis of invariant estimates in the variance-covariance structure was found: the structural relations appear to be the same for the subgroups. Fit indices of both two-group models were nearly identical, with $\chi^{2}=26,424$ and 25,946 respectively, and identical measures for $\mathrm{df}=9,030, \mathrm{CFI}=.98, \mathrm{NNFI}=.98, \mathrm{RMSEA}=.39$, $95 \%$ CI RMSEA $=(.38, .39)$, for the structural models including the mathematics score as performance measure.

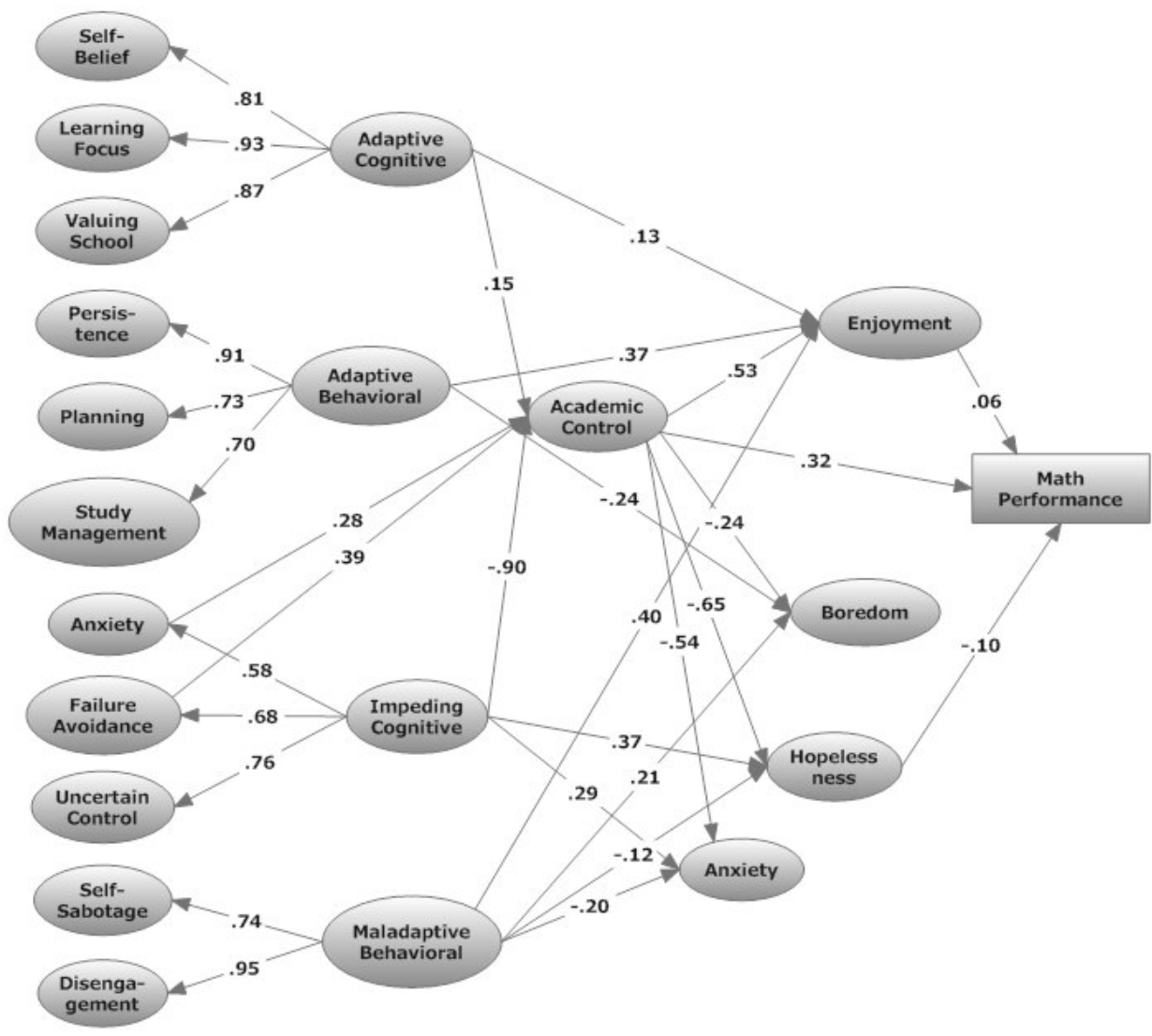

Figure 3. Path diagram of structural part with standardized estimates 


\subsubsection{Testing Hypotheses}

In $\mathrm{H} 1$ we expected that the distal antecedents will have effects on both control appraisals and LREs. In agreement with the CVTAE (Pekrun, 2006), Academic Control plays a central role in the antecedent-consequence relationship of adaptive and mal-adaptive cognitions and behaviours, and LREs. Academic Control is a pure cognitive construct: it builds on contributions from adaptive and maladaptive cognitions, excluding any behavioural influence. Impeding cognitions as a whole have a strong negative impact on Academic Control. This is explained by the fact that impeding cognition is most strongly reflected by Uncertain Control (.76). At the same time, that effect is attenuated by the two paths of Anxiety (.56) and Failure Avoidance (.68), which constitute the first order factor of impeding cognition. Since behaviours, both of adaptive and maladaptive type, do not contribute to Academic Control, the relationships between behaviours and emotions are only direct ones. The paths originating from adaptive cognitions are fully in line with the hypotheses: positive impact on Enjoyment (.13), negative impact on Boredom (-.24). However, the maladaptive behaviours do play a rather remarkable role. Although bivariate relations are all in the hypothesised direction (positive with negative emotions, negative with the positive emotion), within the full structural model, the additional impact of maladaptive behaviours on LREs is positive for Enjoyment (.40), whilst its impact on Anxiety is negative (-.20). This is the resultant of a multiple relationship with colinearity amongst maladaptive cognitions and behaviours: for given levels of academic control and maladaptive cognitions, the additional effect of maladaptive behaviours is adverse to the bivariate effect. Gender differences may also contribute to these adverse effects: male students score much higher than female students on maladaptive behaviours, but at the same time demonstrate less emotion of anxiety and hopelessness.

In $\mathrm{H} 2$ we assumed that control appraisals will influence positively enjoyment and negatively anxiety, boredom and hopelessness. As hypothesized and already shown in the bivariate relations analysis, Academic Control has indeed a strong effect on the four LREs. These effects are positive for Enjoyment and negative for all other three emotions. The strongest effect is observed for Hopelessness (-.65). Then, Enjoyment and Academic Control and Boredom and Academic Control respectively, relate rather weaker (.32, -.24). The relation between Academic Control and Anxiety (-.54) is rather strong and has a negative direction: the students in our sample are on average high in Academic Control $(M=5.26)$ which might result on a rather lower level of Anxiety $(\mathrm{M}=3.85)$.

In $\mathrm{H} 3$ we specified that the distal antecedents, direct antecedents and LREs all explain student performance in the course. We notice a consistent and dominant role of Academic Control on performance. Then, a secondary role of Hopelessness, with a crucial exception: for the bonus score (which is composed of the digital homework and quizzes). This result is very plausible: for students high in Hopelessness, it is rational to allocate relative high levels of time and effort to learning in the digital tool, given its intensive scaffolding. Since the share of the bonus is much smaller in the overall score than the share of Math and Stats exam scores, in the overall score the negative impact of Hopelessness is back. A remarkable role is played by Enjoyment: it impacts performance, as expected, positively for Math; nevertheless, it impacts performance negatively in Stats. Again, this finding can be regarded 
as very plausible, due to the different nature of mathematics and statistics education. Students who like mathematics a lot tend to prefer it over statistics. Evidence for this claim is indirect: t-test for independent groups indicates that students from the 'math major' track score different in Enjoyment, Hopelessness and Anxiety, from students from the 'math minor' track. European 'math major' tracks focus on mathematics only, not on stats, and very often contain less statistics subjects than the 'math minor' track. Since Enjoyment has opposite impact on Math and Stats Performance, it is no surprise that it drops out as explanatory variable in the total score, QM I Performance. Lastly, Self-Handicapping enters as explanatory variable in one performance category: Bonus. Again, this is very plausible: it requires discipline to do all the homework, so students high in Self-Handicapping will underperform. Since Bonus has only a small share in the total score, it is not visible for QM I performance. For a more detailed overview of each's variable contribution in each of the four performance outcomes, the relations between these variables are provided in the equations below (coefficients for each independent variable are expressed in standardized betas):

MathPerfomance $=0.32 \times$ AcademicControl $+0.06 \times$ Enjoyment $-0.10 \times$ Hopelessness

StatsPerfomance $=0.27 \times$ AcademicControl $-0.10 \times$ Enjoyment $-0.13 \times$ Hopelessness

BonusPerfomance $=0.24 \times$ AcademicControl $+0.09 \times$ Enjoyment $-0.16 \times$ SelfHandicapping

QM1Perfomance $=0.33 \times$ AcademicControl $-0.13 \times$ Hopelessness

\section{DISCUSSION}

Recent work suggests that learning-related emotions (LREs) play a crucial role in performance especially in the first year of university, a period of transition for most students; however, additional research is needed to show how these emotions emerge. To explain this classical problem, we developed a framework which links two types of antecedents of LREs: 1) the course-contextualized academic control in the Control Value Theory of Achievement Emotions (Pekrun, 2006) as a direct antecedent and 2) the generic adaptive and maladaptive cognitions and behaviors from the Motivation and Engagement Wheel framework (Martin, 2007) as distal antecedents. We used this framework to predict learning achievements in a mathematics and statistics course.

The main findings of this study bring forth the emergence of four distinct LREs (Enjoyment, Anxiety, Boredom and Hopelessness) and the fact that they standalone from students' individual performance. Such findings are reassuring: although LREs are important, they are not blocking students to perform academically. More importantly, the relations between LREs and performance are rather weak when taking into account their antecedents. Especially, in the mediational model comprising Academic Control, LREs and performance, we see that Academic Control plays a central role in the development of the four LREs investigated in our study as well as for what regards the performance outcomes in the course. The direct relationship between appraisals and performance strongly dominates the indirect relationship through LREs. Next, Academic Control has a strong effect on all of the four LREs with the strongest impact observed for Hopelessness and secondary, 
for Anxiety. The model explaining the four LREs is again of mediational type. Beyond the indirect effect through the control appraisal, there are direct effects from the four second order motivation and engagement factors to the LREs. In this part of the model, direct and indirect effects rather well balance in size.

Academic Control, on one hand, builds on contributions from adaptive and maladaptive cognitions solely, where the main impact is explained by the Uncertain Control dimension of impending cognitions. On the other hand, adaptive cognitions have a positive impact on Enjoyment and a negative one on Boredom. Where impeding cognitions confirm the hypotheses of positive relationship with the negative emotions, surprisingly though, the maladaptive behaviours impact the LREs positively for Enjoyment and negatively for Anxiety. It seems that amongst students scoring high on maladaptive behaviour (amongst them an over-representation of male students), there exists a dislike of the learning activities (increased levels of Boredom), but not of the learning content: high Enjoyment, low Anxiety. With respect to the implications on performance outcomes, the most consistent role is played by Academic Control; this is followed by Hopelessness (with the exception played for Bonus as detailed earlier). At last, an important role is also played by Enjoyment: it has opposite impact for Math (positive) and Stats (negative) performance.

Our findings are consistent with earlier research on the central role of control appraisals in the emergence of achievement emotions (Pekrun et al., 2002; Perry et al., 2001) as well predicting performance at the course level (Hall et al., 2006). This study also provides support for the positive relations between impeding cognitions and negative emotions (Martin \& Marsh, 2006). Conversely, it extends such evidence by showing maladaptive behaviours influencing positively Enjoyment and negatively Anxiety. We therefore extend on the Control Value Theory of Achievement Emotions (Pekrun, 2006) by integrating the distal antecedents of emotions from the Motivation and Engagement Wheel framework (Martin, 2007). Most notably, to the knowledge of the authors, the study is the first of its kind in using an integrated framework to ultimately explain achievement outcomes in the first year at university. We have provided a new approach to understand students' emotional experiences when they first enter a university study. In this respect, the two theories are complementary: on one side our results are an empirical validation of the CVTAE; on the other side, the concepts operating in the MES could provide practical solutions on how to facilitate educational change in the classroom by using the influence these variables have in the experience of emotions.

\subsection{Additional findings}

Although not the main focus of this study, we find interesting gender patterns and effects of prior education. They are described separately. First, in our descriptive analysis, we find gender patterns that match earlier research (Martin, 2007). Females score significantly higher on all adaptive dimensions, with one exception: Self-Belief, where no significant difference is found. Statistical significance of gender differences is however inflated by the large sample size; effect sizes are in the .2 to .4 range, therefore, small in size. With regard to the maladaptive dimension, we find the same pattern as described by Martin (2007): maladaptivity expresses itself stronger in the form of impeding cognitions in females, but in 
the form of maladaptive behaviours in males. The gender effect in Anxiety is not only significant, but also medium in size, again in line with previous research (Preckel, Goetz, Pekrun, \& Kleine, 2008). This divide between the cognitive and behavioural aspects of maladaptivity repeats itself in the LREs. It is in Boredom, the behavioural aspect of neutral emotions (see Pekrun et al., 2002), that males score higher than females, and in the cognitive aspects of the negative LREs, Anxiety and Hopelessness, that females score higher. The last gender effect refers to Academic Control, where male students score higher than female students, in line with outcomes of self- concept research (Frenzel et al., 2007).

The second effect we investigated refers to prior education: having been educated in high school in an advanced, rather than a basic mathematics track. The impact on the generic dimensions of motivation and engagement are quite small, as to be expected. Students from the advanced track are higher in Self-Belief, but lower in Study-Management and Anxiety; effect sizes are however very small. These findings contrast the impact of prior education on the LREs and Academic Control: the largest effect size, .6, is observed for Hopelessness; in rest we find medium size effects. These effects point in the direction that students from the advanced track are higher in Enjoyment and Academic Control and lower in Anxiety, Hopelessness, and Boredom.

\subsection{Limitations}

Using a large sample, our study proposed a framework linking control appraisals (as direct predecessor) with motivation and engagement concepts (as distal predecessors) in an attempt to better explain the emerge and consequences of LREs in a first year undergraduate mathematics and statistics course. However, we point out two limitations.

First of all, our LREs measures (assessed through self-reports) rely heavily on retrospective beliefs about emotions, which make them subject to the same biases as the selfappraisals (Robinson \& Clore, 2002). At the same time, self-reports still remain the most reliable measure (Zeidner, 1998b) and, for that reason - the most extensively used approach, which is able to capture in a non-invasive manner students' emotional experiences in an educational setting.

Second, while in the present study we tried to answer how emotions emerge in an introductory course, an important question for future studies remains: how students' emotions change over different courses in the first year at university. Future work should employ the use of a longitudinal design, over a period of time and different course subject which could cover ideally an entire year of study.

\subsection{Recommendations for further research}

Some general recommendations should be outlined. First, our results showed that amongst students scoring high on maladaptive behaviour, there is a dislike of the learning activities (increased levels of Boredom), but not of the learning content: high Enjoyment, low Anxiety. We propose that they solve this tension by designing their own learning trajectories, partici- 
pating at a lower level in homework and quizzes (as evident from the role of Selfhandicapping in explaining the bonus performance), and prepare independently for the exam.

We mentioned earlier that the evidence gained in our study could potentially inform the design of educational interventions to improve academic achievement while, at the same time, support building emotionally sound learning environments. In this respect, a first aspect to consider would be that any educational interventions in the classroom should foster students' sense of competency towards the specific learning activities required in a mathematics and statistics course. If such progress is acquired, then reinforcing - by means of feedback - the certainty of control over the activities and outcomes in which students engage is key. Increasing students enjoyment and decreasing their hopelessness seems intuitive, still these measures should be regarded in context together with the factors from which they emerge, the maladaptive behaviours. If emotions are more difficult, and less desirable, to influence directly, addressing students maladaptive behaviours could be a reasonable solution.

\subsection{Conclusion}

It can be concluded from our study that next to personal factors that bring their contribution (especially in the development of Academic Control), it is the contextual experience in a course that shapes students' emotional experiences and performance. Besides all other known factors, emotions seem to play a central role in any learning process as an input and as a major educational outcome next to academic performance (Pekrun, Frenzel, Goetz, \& Perry, 2007). Therefore, learning about the factors that play a role in how these emotions develop - and how, in turn, they further influence academic outcomes - is crucial. Good education should also care about how students feel and not only how well they can perform academically.

\section{REFERENCES}

Ainley, M., \& Ainley, J. (2011). Student engagement with science in early adolescence: The contribution of enjoyment to students' continuing interest in learning about science. Contemporary Educational Psychology, 36(1), 4-12. doi:10.1016/j.cedpsych.2010.08.001

Artino Jr., A. R., \& Jones II, K. D. (2012). Exploring the complex relations between achievement emotions and self-regulated learning behaviors in online learning. Emotions in Online Learning Environments, 15(3), 170175. doi:10.1016/j.iheduc.2012.01.006

Astleitner, H. (2000). Designing emotionally sound instruction: The FEASP-approach. Instructional Science, 28(3), 169-198.

Baker, R. W., \& Siryk, B. (1999). SACQ Student Adaptation to College Questionnaire (2 ${ }^{\text {nd }}$ ed.). Los Angeles: Western Psychological Services.

Dettmers, S., Trautwein, U., Lüdtke, O., Goetz, T., Frenzel, A. C., \& Pekrun, R. (2011). Students' emotions during homework in mathematics: Testing a theoretical model of antecedents and achievement outcomes. Students' Emotions and Academic Engagement, 36(1), 25-35. doi:10.1016/j.cedpsych.2010.10.001

Frenzel, A. C., Pekrun, R., \& Goetz, T. (2007). Girls and mathematics--A "hopeless" issue? A control-value approach to gender differences in emotions towards mathematics. European Journal of Psychology of Education, 22(4), 497-514. 
Goetz, T., Frenzel, A. C., Pekrun, R., \& Hall, N. C. (2006). The domain specificity of academic emotional experiences. Journal of Experimental Education, 75(1), 5-29.

Goetz, T., Nett, U. E., Martiny, S. E., Hall, N. C., Pekrun, R., Dettmers, S., \& Trautwein, U. (2012). Students' emotions during homework: Structures, self-concept antecedents, and achievement outcomes. Learning and Individual Differences, 22(2), 225-234. doi:10.1016/j.lindif.2011.04.006

Hall, N. C., Perry, R. P., Ruthig, J. C., Hladkyj, S., \& Chipperfield, J. G. (2006). Primary and secondary control in achievement settings: A longitudinal field study of academic motivation, emotions, and performance1. Journal of Applied Social Psychology, 36(6), 1430-1470.

Hu, L., \& Bentler, P. M. (1999). Cutoff criteria for fit indexes in covariance structure analysis: Conventional criteria versus new alternatives. Structural Equation Modeling:A Multidisciplinary Journal, 6(1), 1-55. doi:10.1080/10705519909540118

IBM Corp. Released 2013. IBM SPSS Statistics for Windows, Version 22.0. Armonk, NY: IBM Corp.

Jöreskog, K.G., Sörbom, D. (1996). LISREL 8 User’s Reference Guide. Scientific Software International: Chicago.

Leone, C., \& Richards, H. (1989). Classwork and homework in early adolescence: The ecology of achievement. Journal of Youth and Adolescence, 18(6), 531-548. doi:10.1007/BF02139072

Liem, G. A. D., \& Martin, A. J. (2012). The Motivation and Engagement Scale: Theoretical framework, psychometric properties, and applied yields. Australian Psychologist, 47(1), 3-13. doi:10.1111/j.17429544.2011.00049.x

Martin, A. J. (2007). Examining a multidimensional model of student motivation and engagement using a construct validation approach. British Journal of Educational Psychology, 77(2), 413-440. doi:10.1348/000709906X118036

Martin, A. J. (2009). Motivation and engagement across the academic life span: A developmental construct validity study of elementary school, high school, and university/college students. Educational and Psychological Measurement, 69(5), 794-824. doi:10.1177/0013164409332214

Martin, A. J. (2011). Holding back and holding behind: grade retention and students' non-academic and academic outcomes. British Educational Research Journal, 37(5), 739-763. doi:10.1080/ 01411926.2010.490874

Martin, A.J., Marsh, H. (2006). Academic resilience and its psychological and educational correlates: A construct validity approach. Psychology in the Schools, 43(3), 267-281.

Martin, A.J., Marsh, H.W., Debus, R.L. (2001). Self-handicapping and defensive pessimism: Exploring a model of predictors and outcomes from a self-protection perspective. Journal of Educational Psychology, 93, 87-102.

Pekrun, R. (2000). A social-cognitive, control-value theory of achievement emotions. In J. Heckhausen (Ed.), Motivational psychology of human development: Developing motivation and motivating development. (pp. 143163). New York, NY US: Elsevier Science.

Pekrun, R. (2006). The Control-Value Theory of Achievement Emotions: Assumptions, corollaries, and implications for educational research and practice. Educational Psychology Review, 18(4), 315-341. doi:10.1007/s10648-006-9029-9

Pekrun, R., Elliot, A. J., \& Maier, M. A. (2006). Achievement goals and discrete achievement emotions: A theoretical model and prospective test. Journal of Educational Psychology, 98(3), 583-597. doi:10.1037/00220663.98.3.583

Pekrun, R., Goetz, T., Frenzel, A. C., Barchfeld, P., \& Perry, R. P. (2011). Measuring emotions in students' learning and performance: The Achievement Emotions Questionnaire (AEQ). Contemporary Educational Psychology, 36(1), 36-48. doi:10.1016/j.cedpsych.2010.10.002

Pekrun, R., Goetz, T., Titz, W., \& Perry, R. P. (2002). Academic emotions in students' self-regulated learning and achievement: A program of qualitative and quantitative research. Educational Psychologist, 37(2), 91-106.

Perry, R. P., Hladkyj, S., Pekrun, R. H., Clifton, R. A., \& Chipperfield, J. G. (2005). Perceived academic control and failure in college students: A three-year study of scholastic attainment. Research in Higher Education, 46(5), 535-569. doi:10.1007/s11162-005-3364-4

Perry, R. P., Hladkyj, S., Pekrun, R. H., \& Pelletier, S. T. (2001). Academic control and action control in the achievement of college students: A longitudinal field study. Journal of Educational Psychology, 93(4), 776.

Preckel, F., Goetz, T., Pekrun, R., \& Kleine, M. (2008). Gender differences in gifted and average-ability students: Comparing girls' and boys' achievement, self-concept, interest, and motivation in mathematics. Gifted Child Quarterly, 52(2), 146-159.

Putwain, D. W., Larkin, D., \& Sander, P. (2013). A reciprocal model of achievement goals and learning related emotions in the first year of undergraduate study. Contemporary Educational Psychology, 38(4), 361-374. doi:10.1016/j.cedpsych.2013.07.003 


\section{CHAPTER 3}

Putwain, D. W., Sander, P., \& Larkin, D. (2013). Using the $2 \times 2$ framework of achievement goals to predict achievement emotions and academic performance. Learning and Individual Differences, 25(0), 80-84. doi:10.1016/j.lindif.2013.01.006

Robinson, M. D., \& Clore, G. L. (2002). Belief and feeling: Evidence for an accessibility model of emotional selfreport. Psychological Bulletin, 128(6), 934-960. doi:10.1037//0033-2909.128.6.934

Ruthig, J. C., Perry, R. P., Hladkyj, S., Hall, N. C., Pekrun, R., \& Chipperfield, J. G. (2007). Perceived control and emotions: interactive effects on performance in achievement settings. Social Psychology of Education, 11(2), 161-180. doi:10.1007/s11218-007-9040-0

Schutz, P. A., \& Pekrun, R. (2007). Introduction to emotion in education. In P. A. Schutz \& R. Pekrun (Eds.), Emotion in education. (pp. 3-10). San Diego, CA US: Elsevier Academic Press.

Stupnisky, R. H., Perry, R. P., Hall, N. C., \& Guay, F. (2012). Examining perceived control level and instability as predictors of first-year college students' academic achievement. Contemporary Educational Psychology, 37(2), 81-90. doi:10.1016/j.cedpsych.2012.01.001

Tempelaar, D. T., Niculescu, A., Rienties, B., Gijselaers, W. H., \& Giesbers, B. (2012). How achievement emotions impact students' decisions for online learning, and what precedes those emotions. The Internet and Higher Education, 15(3), 161-169. doi:10.1016/j.iheduc.2011.10.003

Tinto, V. (1997). Colleges as communities: Exploring the educational character of student persistence. Journal of Higher Education, 68(6).

Trautwein, U., Schnyder, I., Niggli, A., Neumann, M., \& Lüdtke, O. (2009). Chameleon effects in homework research: The homework-achievement association depends on the measures used and the level of analysis chosen. Contemporary Educational Psychology, 34(1), 77-88. doi:10.1016/j.cedpsych.2008.09.001

Verma, S., Sharma, D., \& Larson, R. W. (2002). School stress in India: Effects on time and daily emotions. International Journal of Behavioral Development, 26(6), 500-508. doi:10.1080/01650250143000454

Zeidner, M. (1998). Test anxiety: The state of the art. Springer. 


\section{CHAPTER 4}

\section{Extending the change-change model of achievement emotions}

\section{The inclusion of negative learning emotions}

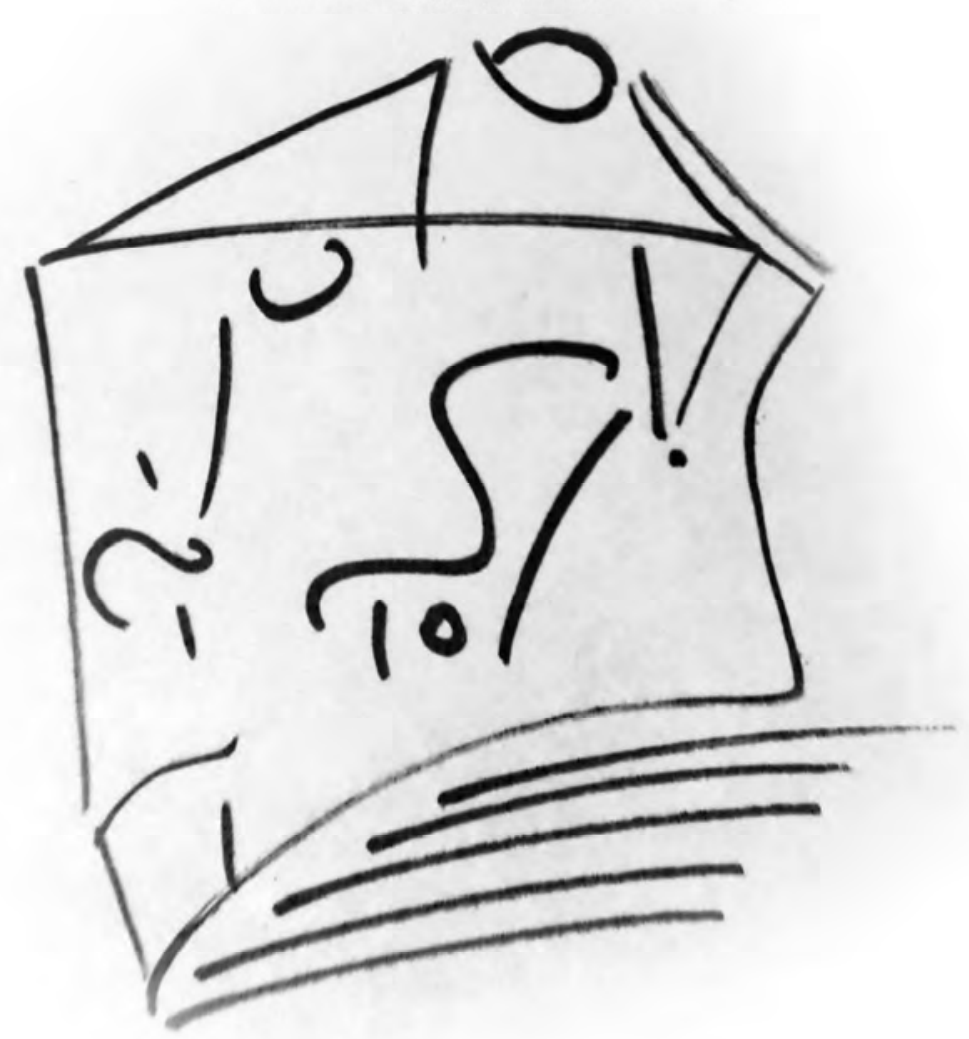

This chapter is submitted as:

Niculescu, A., Tempelaar, D., Dailey-Hebert, A., Segers, M., \& Gijselaers, W. (under review). Extending the change-change model of achievement emotions: The inclusion of negative learning emotions. Learning and Individual Differences 


\section{ABSTRACT}

Drawing upon the Control Value Theory of Achievement Emotions (CVTAE), this study tests the assumption that antecedents of learning-related emotions (LREs) change over the duration of a mathematics and statistics course. Our study focused on academic control as an antecedent of LREs. We investigated enjoyment (the positive emotion) and three negative LREs: anxiety, boredom and hopelessness. Using a repeated measures design for first year university students $(\mathrm{N}=908)$, we found that academic control and the levels of LREs remain, on average, stable over the duration of the course. Second, changes in academic control were positively related to changes in the positive emotion enjoyment, and negatively related to changes in the three negative emotions. These findings offer evidence to confirm the CVTAE change - change assumption that changes in control appraisals go together with changes in positive, as well as negative, LREs. 


\section{INTRODUCTION}

In today's educational and psychological research, it has become increasingly important to examine students' emotional experiences (Linnenbrink-Garcia \& Pekrun, 2011; Schutz \& Lanehart, 2002). Research on emotions in education shows that emotions are an inherent factor in any learning process (Schutz \& Lanehart, 2002) and that they can be particularly "ubiquitous" in academic settings (Pekrun \& Stephens, 2010). Emotions experienced in academic settings have an important contribution to students' motivation and can influence learning outcomes, such as academic performance (Pekrun, 2006). Academic emotions are a specific type of emotional experience, defined as "emotions that are directly linked to achievement activities and outcomes" (Pekrun, Goetz, Frenzel, Barchfeld, \& Perry, 2011, p.37). According to Goetz, Frenzel, Stoeger, and Hall (2010) both positive and negative emotions should be given equal attention in academic contexts. Furthermore, Goetz et al. (2010) recommend that future research should ascertain the inclusion of both negative and positive emotions. While positive emotions have a clear relevance as end states as well as processes in achieving positive outcomes in education (Fredrickson, 2001), negative emotions are particularly known for their adverse effects on students' academic achievement (Goetz, Pekrun, et al., 2006). Further investigation of these factors might contribute to the design of interventions aimed at decreasing the levels of negative emotions in educational settings (Pekrun et al., 2002).

The most obvious setting in which to conduct such an investigation is the first year at university study. Recent research has demonstrated that negative academic emotions are detrimental factors especially in this period (Tempelaar, Niculescu, Rienties, Gijselaers, \& Giesbers, 2012). First years' unpleasant emotions seem particularly intense and can influence how students perform within a course (Pekrun et al., 2011) with further consequences on the overall achievement at university (Hall, Perry, Ruthig, Hladkyj, \& Chipperfield, 2006). Given the importance of negative emotions, it appears relevant to develop further understanding on why students experience unpleasant emotions during this time. From a theoretical stand, one of the most influential contemporary frameworks addressing this question is the Control-Value Theory of Achievement Emotions (CVTAE; Pekrun, 2006). According to CVTAE, distinct negative emotions emerge from beliefs about a low capacity to influence outcomes (Frenzel, Pekrun, \& Goetz, 2007; Pekrun, 2000), generally referred to as control appraisals (Pekrun et al., 2002). For instance, when students are confronted with novel situations they usually perceive low control, yet still hold high expectations for success (Perry, Hladkyj, Pekrun, Clifton, \& Chipperfield, 2005). These perceived conditions typically create negative emotional reactions towards learning in academic situations (Stupnisky, Perry, Hall, \& Guay, 2012). Despite serious theoretical advances on the role of emotions in academic settings (Elliot \& Pekrun, 2007), empirical evidence rarely outlines negative academic emotions in relation to its antecedent factors (Goetz, Cronjaeger, Frenzel, Lüdtke, \& Hall, 2010). Furthermore, research is needed in the first year at university to help us understand how negative emotions emerge (Linnenbrink, 2006; Schutz \& Pekrun, 2006) and further develop over time (Buff, 2014). In this study we focus on control appraisals as antecedent factors for both positive and negative academic emotions in the first year at university. According to the CVTAE, we first investigate how these emotions 
emerge from control appraisals. Then, we investigate if changes in control appraisals relate to changes in academic emotions at two instances over the duration of a course.

In the following section we will: 1) describe the different types of settings in which academic emotions are encountered within a course; 2) describe control appraisals as antecedents of academic emotions, and 3) provide empirical evidence linking control appraisals and academic emotions. The aim of this study and the expected hypotheses are stated at the end of this section.

\subsection{Conceptual framework}

According to Pekrun et al. (2002), there are three important academic settings to experience emotions in a course: 1) being in class, 2) taking tests and exams, and 3) studying outside of class. Each of these settings raises a different type of emotion: class-related, testrelated and learning-related emotions. While other emotional settings have been extensively studied, such as the exam situation, few studies have actually paid attention to situations outside the class (Linnenbrink, 2006; Schutz \& Pekrun, 2007; Putwain, Sander, \& Larkin, 2013; Trautwein et al., 2009). These studies demonstrate a clear need to investigate learning-related emotions (LREs), since the first year at university puts an accent on heightened self-reliance and autonomy (Perry, Hladkyj, Pekrun, \& Pelletier, 2001), which are required in situations involving individual study or preparing the homework.

Of particular relevance is the role of LREs in abstract or difficult subjects, such as mathematics and statistics. Recent research on students' emotional experiences during mathematics homework (Dettmers et al., 2011; Goetz et al., 2012) shows that the homework assignments are considered "emotionally charged activities" (Dettmers et al. 2011, p. 25), where students seem to experience the most unpleasant emotions when compared with other academic situations (Leone \& Richards, 1989). Furthermore, Dettmers' et. al. (2011) found that elevated levels of negative emotions influence students' amount of effort and disengagement from study to negatively predict achievement in mathematics. In another secondary education study by Goetz et al. (2012), it was showed that emotional experiences during homework are not depending on students' age and seem not to change after grade eight. Tempelaar et al. (2012) build further to confirm similar mechanisms in higher education. Their study showed control appraisals as a mediator between negative effort views the belief students hold towards exerting effort as something which signals lacks of intelligence, therefore negative (Dweck, 1999) - and boredom towards learning in mathematics and statistics. More specifically, there was evidence for a strong positive direct relationship between negative effort and boredom. In addition, there was an indirect relationship through control, indicating that for given levels of negative effort, academic control contributes positively to boredom. Finally, these individual differences in achievement emotions had an impact on student' learning choices in mathematics and statistics. In general, studying or preparing homework for mathematics and statistics is recognized as a problem even for students with high cognitive abilities. Research shows that learning is impeded by negative attitudes and beliefs students hold towards such courses (Gal \& Ginsburg, 1994; Garfield \& Ben-Zvi, 2007). In summary, to understand the impact of negative LREs in domains which are perceived as difficult, such as mathematics and statistics, it is necessary 
to know: 1) whether students experience changes in the levels of their emotions over time and, 2) the factors from which these changes emerge. By knowing if negative academic emotions change over a course, as well as the factors that determine their change, can inform the design of educational interventions to create "emotionally sound" (Astleitner, 2000) learning environments. Implicitly, the re-design of educational environments which account for students' academic emotions as well as the factors that contribute to them, could potentially improve academic achievement.

For the purpose of our study, we build further on the work of Tempelaar et al. (2012) which acknowledges the importance of achievement motivation and emotion on learning when students enter university. In addition, we want to reveal how LREs emerge and develop over a mathematics and statistics course. We focus on four emotions experienced in learning situations: the positive emotion enjoyment and three negative emotions: anxiety, boredom and hopelessness. Control appraisals are considered as antecedents of the four LREs.

\subsection{Antecedents of learning-related emotions}

Within mathematics and statistics courses, distinct negative emotions emerge from students' beliefs about a low capacity to influence outcomes (Frenzel et al. , 2007; Pekrun, 2000) and the value attributed to these outcomes, generally referred to as control appraisals and value appraisals, respectively (Pekrun et al., 2002). For instance, anxiety during learning for mathematics and statistics can occur when a student does not feel very competent towards the course materials while obtaining a good grade is considered important. The Control-Value Theory of Achievement Emotions (CVTAE) postulates that appraisals of control and value act as direct or proximal antecedents of learning-related emotions (LREs): higher levels of control and value predict higher levels of positive emotions, and lower levels of negative emotions respectively (Pekrun, 2006). In a longitudinal context, this postulate implies that increasing levels of control and value appraisals raises the levels of positive emotions, (such as joy), and lowers the levels of negative emotions, (like anxiety). Likewise, a decrease in the levels of the antecedents has an opposite effect. In other words, this assumption - referred to as the change-change parameterization of CVTAE (Buff, 2014) has two practical implications: increasing the levels of LREs' antecedents is expected to raise the levels of positive emotions and decrease the levels of negative emotions. This assumption was empirically investigated and confirmed by Buff (2014) for the positive LRE of enjoyment. Indeed, Buff (2014) found that positive changes in perceived control and value lead to positive changes in enjoyment of learning in mathematics. Beyond this one study, which looks solely at a single, positive LRE enjoyment (as in Buff, 2014), no previous efforts tested the same assumption while accounting for multiple LREs, of both positive and negative valence. Furthermore, although the transition from high school to university shapes an excellent context to investigate changes in negative LREs, as a consequence of changes in antecedent variables, empirical evidence testing the change-change assumption in this period has not been previously dated.

The present investigation extends upon Buffs (2014) approach by including negative, as well as positive multiple LREs to further test the assumption that negative LREs also change over time in line with the CVTAE change-change hypothesis. 


\subsection{Empirical evidence concerning the relationship between control appraisals and learning- related emotions}

A substantial amount of research on the relation between learning-related emotions (LREs) in the homework context and their appraisal antecedents has been conducted in primary and secondary education (Dettmers et al., 2011; Goetz et al., 2012; Trautwein et al., 2009). The results of these studies indicate that LREs, as they emerge from control appraisals as their antecedents, are medium to strongly related. For example, Goetz et al. (2012) found correlations between homework emotions, as LREs, and academic self-concept, as their antecedents, in the range of $(.43 ; .71) /(.36 ; .69)$ for eight and eleventh graders, respectively. Similar relations have been reported in the first year at university (Goetz, Frenzel et al., 2010; Putwain et al., 2013; Tempelaar et al., 2012). For instance, Goetz, Frenzel, et al. (2010) reported that perceived control had a significant positive effect on enjoyment ( $\beta$ $=.35, p<.001)$. Furthermore, evidence shows that the appraisal of control, as an antecedent, longitudinally relates to emotions (Hall et al., 2006; Perry et al., 2001). For example, Perry et al. (2001) found that students who reported higher levels of perceived academic control also felt less bored (-.48) and less anxious (-.35) towards the course. Similar relations were shown by Hall et al. (2006): correlations between primary control and several emotions (anger, regret, happiness and pride) were of medium size. Overall, when investigating the relation between academic emotions and control appraisals, as their antecedents, evidence from both cross-sectional and longitudinal studies shows that these variables are medium to strongly related.

Finally, it is important to mention that change relations between control appraisals and LREs were explored on only one occasion (Buff, 2014). Buff s (2014) contribution brings evidence for the CVTAE assumption that changes in perceived control and value relate positively to changes in learning enjoyment. This was done in a sixth graders sample and for the single, positive LRE of enjoyment only. To our best knowledge, no previous contributions have captured the same assumption in a mathematics and statistics domain for first year university students. Therefore, to better understand how the levels of negative emotions can be decreased, additional efforts should especially emphasize on capturing this relationship: how the changes in negative LREs and their appraisal antecedents are related.

\subsection{Aim and hypotheses}

This study is drawing upon the Control-Value Theory of Achievement Emotions (CVTAE) and follows Buff s (2014) empirical study, in an attempt to investigate the relationships between changes in control appraisals and changes in both positive and negative learning-related emotion (LREs). As described in the previous section, Buffs (2014) work shows that changes in perceived control and value relate positively to changes in learning enjoyment. Our study builds further by including in our investigation multiple emotions, both positive and negative. Therefore, the first hypothesis refers to the conventional levels parameterization as described in the CVTAE: 
H1. The level of control appraisals at the first (time 1) measurement in the course will be positively related with the level of positive LRE of enjoyment, and negatively related to the levels of the negative LREs boredom, hopelessness, and anxiety - at time 1.

The second hypothesis refers the change-change parameterization introduced in Buff (2014):

H2. Changes in control appraisals will be positively related to changes in positive LRE of enjoyment, and negatively related to changes in the negative LREs boredom, hopelessness, and anxiety.

\section{METHOD}

\subsection{Sample and setting}

The participants were 908 freshmen (19 years old on average, $62.8 \%$ male) enrolled in a Business and Economics bachelor degree program at a medium-size European University. Most students had a predominantly international background, a vast majority $(74.6 \%)$ holding an international education diploma.

The course setting for this study had to meet the following criteria: 1) to be a first year undergraduate course, 2) to be perceived as difficult and 3) to evoke strong negative emotions for most students. The setting was a compulsory introduction to mathematics and statistics, scheduled in the first term of the academic year; this was the first in a series of required courses in this program. The course had a duration of eight weeks (out of which, seven weeks were scheduled for education and the last week was reserved for exams). This course has a high audience and is notoriously known among new students for two main reasons: 1) the course materials are often regarded as being difficult and unattractive for most students, 2) failing this course implies encountering issues of study delay or even exclusion from study.

\subsection{Procedure}

We collected data on two occasions: in week four of the course (time 1), students completed an online questionnaire concerning their appraisal of control and learning-related emotions (LREs) regarding the subject of the course. 793 students (87.3\%) responded to this survey (students were required to do a statistical project based on self-reports, for which they could use these survey data). The timing of the survey, exactly halfway the course, was chosen to ascertain that students were sufficiently familiar with the topics studied, the educational context and learning activities on one side, and leave sufficient time to do a post measurement on the other side. The second measurement (time 2) took place in week seven, the very last week of classes before the exam week. Exactly the same survey on control appraisals and LREs regarding the subject of the course now generated a response of 387 students (42.6\%). All students included in this study provided informed consent for the data collected by means of online questionnaires. 


\subsection{Measures and variables}

We measured learning-related emotions ( $L R E$ ) through the four learning scales, Enjoyment, Anxiety, Boredom and Hopelessness, of the Achievement Emotions Questionnaire (AEQ) developed by Pekrun et al. (2011). The Enjoyment scale (10 items, e.g. "I enjoy accruing new knowledge"), Anxiety scale (11 items, e.g. "I get tense and nervous while studying"), Boredom scale (11 items, e.g. "The material bores me to death") and Hopelessness scale (11 items, e.g. "I feel hopeless when I think about studying") were slightly re-phrased to match the specific situation of the course. For reasons of consistency in our research, all items were answered on a 7-point Likert scale ( 1 = 'completely disagree' and $7=$ 'completely agree').

Control appraisals were measured with the perceived Academic Control Scale of Perry et al. (2001). The scale is composed of eight items, each answered on a 7-point scale $(1=$ 'strongly disagree' and 7 = 'strongly agree'), e.g. "I have a great deal of control over my academic performance in this course".

\subsection{Statistical analyses}

Latent-change models allow for different model specifications, with different merits (Geiser, 2013). Latent change models have been estimated with the cross-lagged panel model structure (CLPM) or latent autoregressive model (LAM), as well as with equivalent parameterizations using latent difference variables. Such latent change (LC) parameterizations facilitate interpretations that focus on change over time, rather than emphasizing the stable characteristics within a context of variation over time (Geiser, 2013). Given our aim of investigating the relationships between changes in academic control and changes in LREs we will report on model estimates generated by the LC parameterization. This is the same approach as used by Buff (2014), who's study we are building upon.

As a preliminary step in the analysis, response patterns in the time 2 measurement were analyzed. Next, beyond descriptive analyses, this study applies latent class analysis, performed in Mplus (version 7), to discover different underlying student profiles in overall developments of academic control and the four LREs.

Following latent class analysis, structural equation modeling was applied to arrive at latent change structural models. As a preparatory step, items from the self-report instruments were parceled. The technique of item parceling, where items from the same scale are aggregated into several parcels or mini-scales, has been adopted in empirical studies for several reasons. These reasons include: a) obtaining more continuous and normally distributed observed data; b) reducing the number of model parameters to achieve a more attractive variable to sample size ratio; and, c) estimating stable parameters (Coffman \& MacCallum, 2005; Hau \& Marsh, 2004; Marsh, Hau, Balla, \& Grayson, 1998). In our study, the size of the model and the length of all AEQ scales, relative to the sample size necessitate in itself the parceling step in the estimation of the latent-change model. In parceling items, we made use of the subscales composition of the AEQ scales (each scale is composed of four components: motivational, affective, physiological and cognitive, which are identified by a numerical symbol in the item name: 1 to 4). We tried to reflect the original scale in the sense that each parcel contained one item for each of the four sub-components: motiva- 
tional, affective, physiological and cognitive. We then used these sub-components to create three parcels per scale (first parcel containing the four items labeled '1', second parcel containing the four items labeled '2', and third parcel containing items with labels ' 3 ' or ' 4 '). After this preparatory step, latent change models based on parcel scores were estimated with LISREL (version 8.8) using maximum likelihood (ML) estimation. To prevent capitalization on chance, rather conservative model building rules were adopted: starting from parsimonious models, $\mathrm{p}$-values of $1 \%$ or less were required as a cutoff value for significance for the adoption of any structural path. We report the Chi-square and degrees of freedom values, the Comparative Fit Index (CFI), the Non-Normed Fit Index (NNFI, also known as TLI) and the Root Mean Square Error of Approximation (RMSEA) as indicators of goodness of fit. $\mathrm{Hu}$ and Bentler (1999) suggested for CFI/TLI values larger than .90 for a satisfactory fit and for RMSEA values should not exceed .08 and preferably be .06 or lower.

A separate preliminary step in estimating longitudinal structural equation models, is establishing measurement invariance (Geiser, 2013; Buff, 2014).

\section{RESULTS}

\subsection{Descriptive statistics}

Students' learning Enjoyment is about the neutral value of four and this average value will not change substantially between the two measurements: see Table 1 and Figure 1 . The three negative LREs are below the neutral value of four, and Academic Control is at the positive side. All Cronbach alpha reliabilities are high and apparently do not suffer from the parceling step. Comparison of time 1 and time 2 measurements suggests that all LREs and Academic Control are stable constructs at the aggregate level: the single statistically significant change (be it only at the $5 \%$, not at the $1 \%$, level) is in Boredom. We have to note that, as can be seen from Figure 1, this change represents only a very small effect size.

Table 1. Means (M), standard deviations (SD), reliabilities and change values (Delta) of Academic Control and the four learning emotions

\begin{tabular}{|c|c|c|c|c|c|c|c|c|c|}
\hline & \multicolumn{3}{|c|}{ Week4 } & \multicolumn{3}{|c|}{ Week7 } & \multirow[b]{2}{*}{ Delta } & \multirow{2}{*}{$\begin{array}{l}\text { t-value } \\
\text { Delta }\end{array}$} & \multirow{2}{*}{$\begin{array}{l}\text { p-value } \\
\text { Delta }\end{array}$} \\
\hline & Mean & SD & $a$ & Mean & $\mathrm{SD}$ & $a$ & & & \\
\hline Academic Control & 5.29 & 0.95 & .83 & 5.26 & 0.97 & .87 & 0.03 & .711 & .477 \\
\hline Anxiety & 3.74 & 1.26 & .91 & 3.66 & 1.25 & .91 & 0.07 & 1.620 & .106 \\
\hline Boredom & 2.94 & 1.22 & .93 & 3.04 & 1.29 & .96 & -0.10 & -2.448 & .015 \\
\hline Helplessness & 2.99 & 1.31 & .95 & 2.99 & 1.30 & .95 & 0.00 & .000 & 1.000 \\
\hline Enjoyment & 4.17 & 1.03 & .85 & 4.21 & 1.01 & .89 & -0.05 & -1.282 & .201 \\
\hline
\end{tabular}




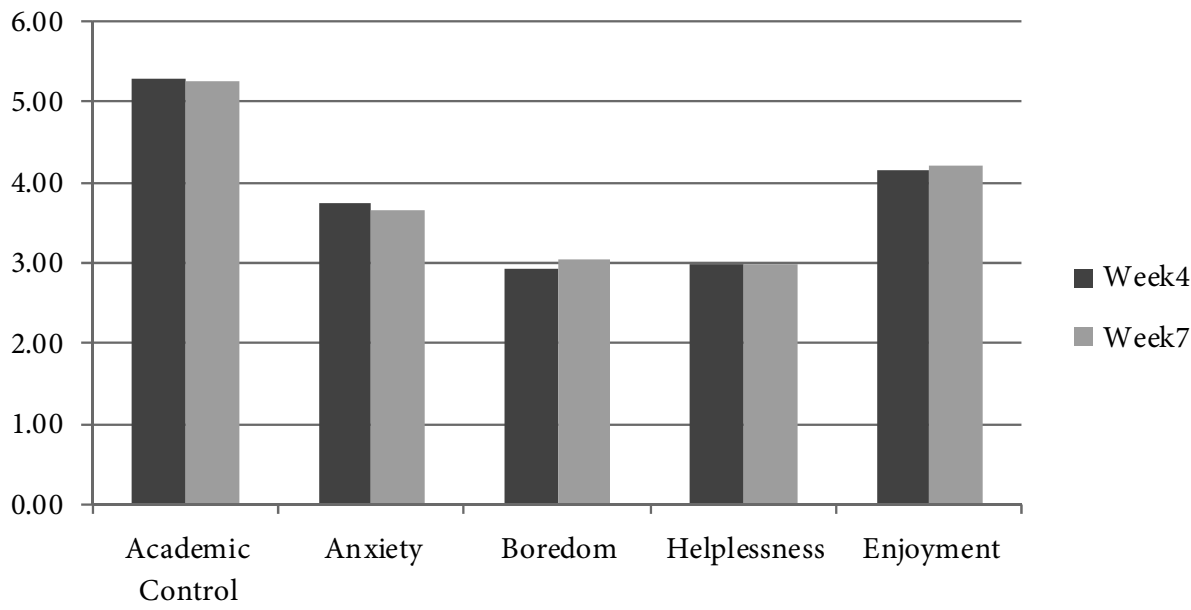

Figure 1. Time 1 and Time 2 measurements of Academic Control and the four learning emotions

\subsection{Latent class analysis}

However, underlying this overall aggregate stability, we can observe divergent developments within different groups of students, as becomes visible from a latent class analysis. Figure 2 describes change profiles within three classes of students. We opted for the three-class solution, although model fit indices slightly improve beyond the three-class solution, since four (and higher order) class solutions come down to further decompositions of one single latent class (labeled as the Latent Class Negative) into several very small classes with extreme scores, and a large class with moderate scores. The three-class decomposition depicted in Figure 2 tells the story that stable aggregate scores are the sum of worsening scores for 131 students (the Latent Class Negative), improving scores for 160 students (the Latent Class Positive), and relative constant scores for 96 students (the Latent Class Stable). In all three latent classes, the negative emotion Boredom is by far the most constant emotion (which is in contrast to this variable being the single one with a significant change at the aggregate level). Anxiety and Helplessness exhibit greatest variability amongst the three classes. 


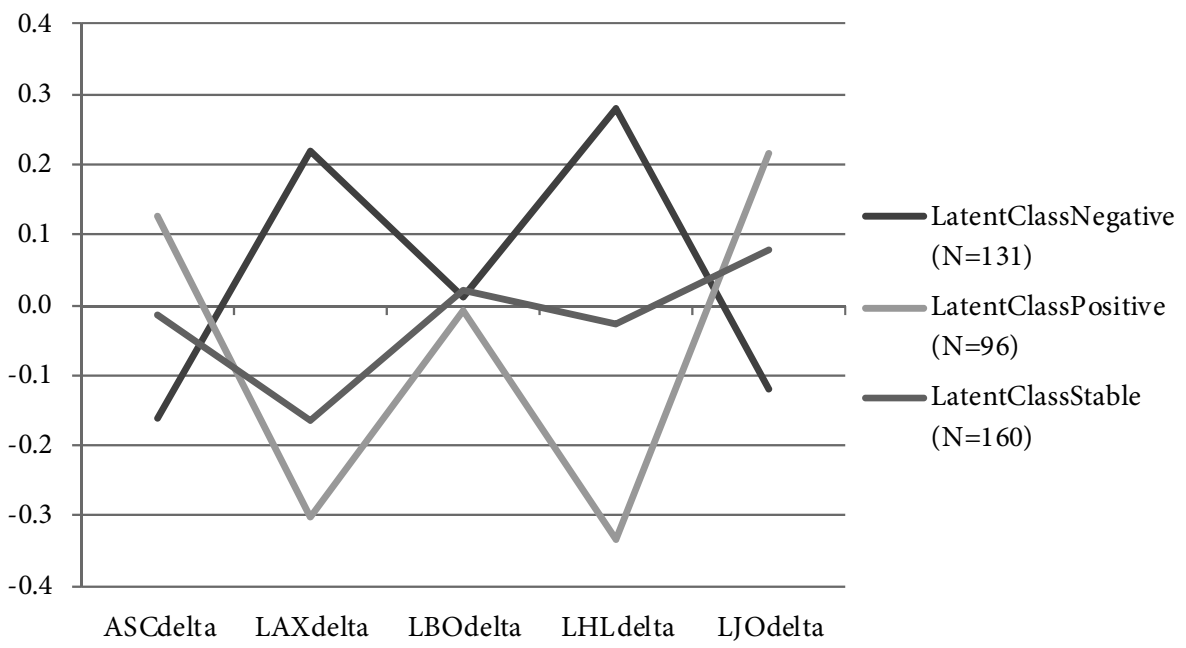

Figure 2. Latent Class Analysis

\subsection{Bivariate correlations}

Bivariate correlations are reported in Table 2, containing the levels of time 1 and time 2 measurements, as well as the change construct: the 'Delta' variable. Printed in bold are the autocorrelations: correlations between time 1 and time 2 measurements of the same constructs and between time 1 and the change variable. The first set of autocorrelations is all high positive, and consistent in value: those for LREs range from .75 to .78. These autocorrelations are always higher than any other correlation in the same row, consistent with the rather stable nature of the constructs. Correlations between time 1 measurements and the Delta constructs are all negative, suggesting a 'correction' or 'regression to the mean' effect: high pre-measurements are corrected downwards, low pre-measurements are corrected upwards. 


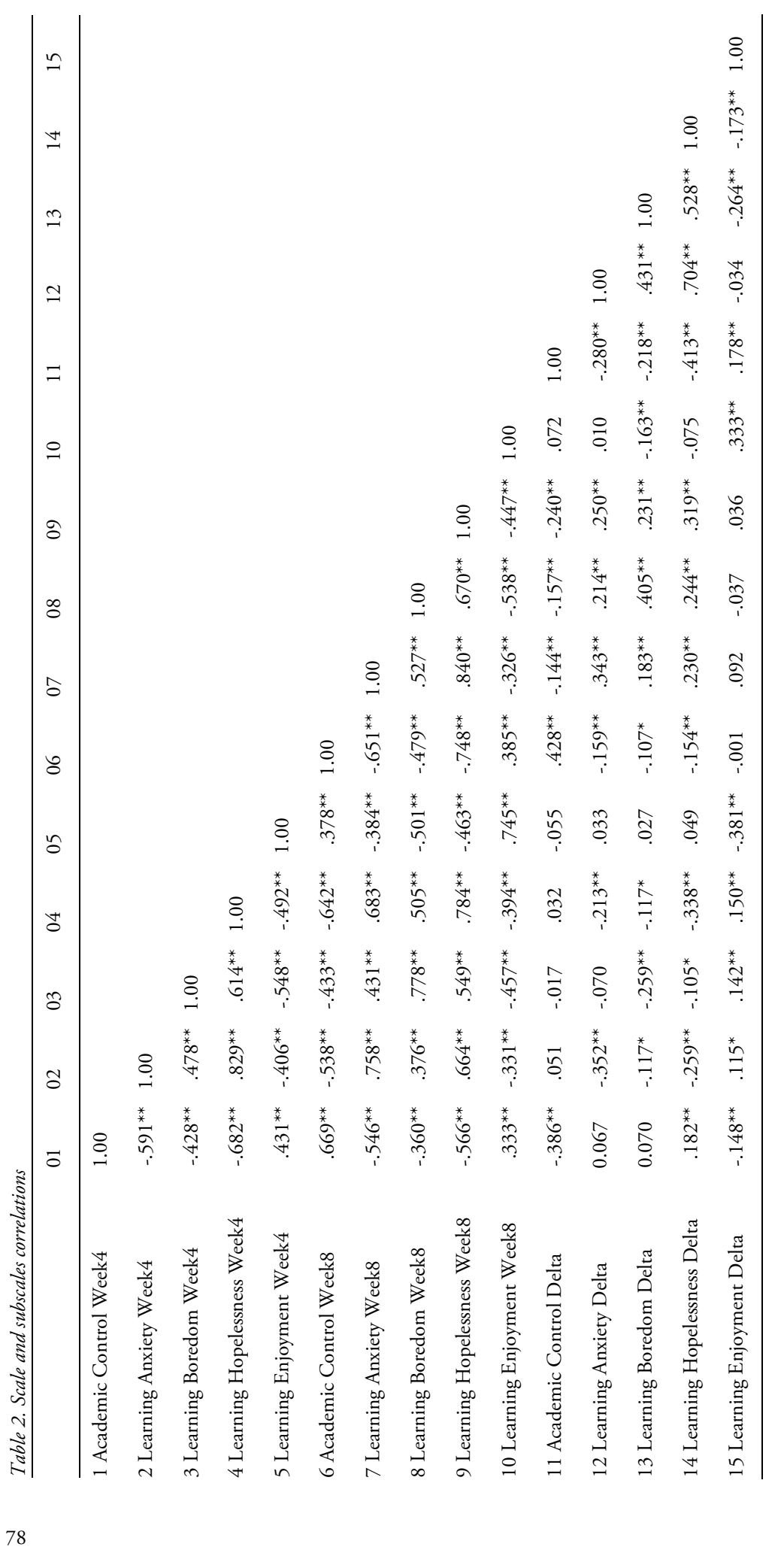




\subsection{Latent change models}

As a base model, we estimated the latent change model with configural and weak factorial invariance imposed. Model fit appeared to be adequate. Next, we freed the individual constraints induced by weak factorial invariance, but none of them proved to be significant at .01 level, neither was the $\nabla^{2}$ difference test testing for weak factorial invariance. Strong factorial invariance was however rejected; in this respect, no more than partial factorial invariance was established. As a last step, potential cross-over effects between LREs were investigated: does the change in any LRE depend on the time 1 measurement level of any other emotion, beyond the change in Academic Control and the level of the time 1 emotion itself? None of these potential paths appeared to be significant at the .01 level, so our final structural equation model coincides with the base model (as depicted in Figure 3 using non-standardized betas, as to make clear what betas were normalized). Fit indices are $\chi^{2}=$ 934.2 with $d f=428, \mathrm{CFI}=.99, \mathrm{NNFI}=.99, \mathrm{RMSEA}=.058$.

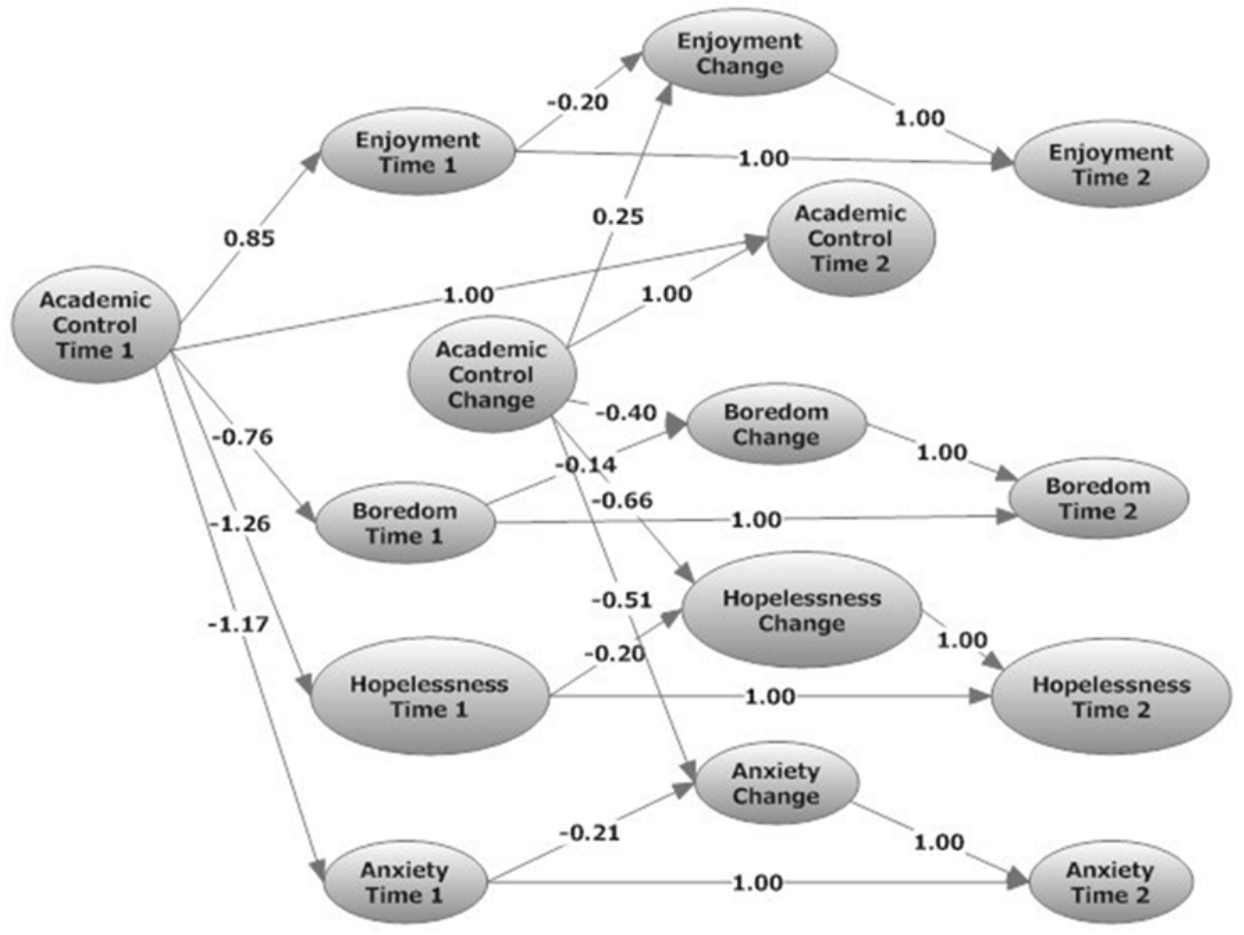

Figure 3. Path diagram

\section{DISCUSSION}

It is acknowledged that negative emotions are crucial factors for explaining students' experiences in the first year at university (Pekrun et al., 2011). From this point of view, it is im- 
portant to question how students unpleasant emotions emerge and change during this time. To date, little empirical evidence is available about negative academic emotions in relation to their antecedent factors ( Goetz, Cronjaeger et al., 2010; Pekrun et al., 2014). Using a repeated measures design, we have built upon the Control Value Theory of Achievement Emotions (CVTAE) to: 1) look at how learning-related emotions (LREs) emerged from control appraisals and, 2) investigate if changes in control appraisals were related to changes in both positive and negative LREs in a mathematics and statistics course.

\subsection{Hypothesis 1}

For the first hypothesis we expected the level of Academic Control at the first measurement (time 1) to be positively related to the level of the positive LRE of Enjoyment, and negatively related to the levels of the negative LREs Boredom, Hopelessness, and Anxiety. Our analyses confirmed this. Next, we found that the levels of LREs as well as of Academic Control remained, on average, stable over the duration of the course. While homework emotions within the mathematics domain have already been compared for eight and eleventh graders (Goetz et al., 2012), only limited research has been conducted in the first year at university (Putwain et al., 2013; Tempelaar et al., 2012). Drawing a parallel with the Goetz et al. (2012) study, our work shows that in comparison to secondary education, first year students experience higher levels of enjoyment but also more anxiety and boredom while learning for mathematics and statistics.

\subsection{Hypothesis 2}

The second hypothesis stated that changes in Academic Control are positively related to changes in the positive LRE of Enjoyment, and negatively related to changes in the negative emotions. This was indeed confirmed. Next, in agreement to Buffs (2014) study, we found relationships between levels and change constructs. The change in the positive emotion Enjoyment was related to the level of Enjoyment at time 1. At the same time, the changes in the negative LREs Boredom, Hopelessness, and Anxiety, were explained by the level of each of these constructs at time 1. Change in Academic Control was unrelated to the time 1 measurement levels: the path from the time 1 level in Academic Control to the change in the same construct was statistically insignificant. Our outcome is, as expected, in line with the CVTAE and, confirms the theory in this respect.

\subsection{Limitation and further research}

Our study used an ecological design for first year university students to further test the assumption that changes in academic control go together with changes in negative LREs in a mathematics and statistics course. As strong features, the design included a relatively large sample and a repeated measurement. However, some critical notes should be outlined.

We measured LREs at time 1, midway through the course, and at time 2 three weeks after the first measurement and one week before the exam. Two potential limitations might 
have appeared as a consequence of such a time line: first, we cannot be sure whether the period between the two measurements was too short to capture major changes in the development of the constructs. Second, the time 2 measurement which occurred in week 7 might have been too close to the exam week. Therefore, we cannot fully exclude that students' LREs might have been contaminated with anticipated emotions about the exam (test emotions). Although students need a minimum period to get an impression of the course, assessing their emotional experiences earlier in the course could have also proved to be useful.

Finally, concerning the relation between Academic Control and LREs, we found, besides an overall stability in the mean levels, some notable individual differences. These differences can be observed in the three different clusters of students who display different pattern of increase, decrease and stability in LREs and Academic Control. This points out to a "third variable" type of effect which might be able to explain these individual differences. Future research might also consider the integration of more distal antecedents (such as personal characteristics students already hold when they enter university) to make visible such differences.

\subsection{Recommendations for educational practice}

As outlined before, there is an urgent need for educational interventions which accommodate students' emotions in their own learning process as well as in pedagogy (Astleitner, 2000). After all, handling students' emotions is an essential yet, one of the most difficult challenges in an educational settings. We would like to refer to Taylor's (1994) concept of emotionally sound instruction which "consists of instructional strategies to increase positive and decrease negative feelings during regular instructional settings" (Astleitner, 2000, p. 173). In line with this philosophy, recommendations for improving educational practice are formulated and shared in this section.

One possibility to intervene on emotions in educational settings is through their antecedents. In this regards, it is already theoretically assumed (Pekrun, 2006) and empirically confirmed (Pekrun et al., 2014) that achievement feedback can impact both directly and indirectly students' achievement emotions. Next, it would be particularly important to identify which other type of feedback has an effect on emotions and for which type of students (for example based on the exhibited change profiles) a certain feedback would be more efficient.

A less invasive manner to influence students' emotions is working through their direct antecedents, the control appraisals. There is ample evidence on the power of feedback in achievement and the various levels at which the feedback can be formulated (Hattie \& Timperley, 2007). For instance, in our course re-design interventions, we showed that students' performance in various courses can be improved by providing both process- and task-related team feedback (Niculescu et al., 2012, 2014). In one of these experiments (Niculescu et al., 2014), conducted in a first year university mathematics and statistics course, we showed that if students were already experiencing intense negative emotions, these factors could confound the effect of tutor' feedback on individual performance. Drawing from this knowledge, a future feedback strategy that may prove effective could be 
also targeted at students' sense of competence or mastery towards tasks that need to be performed outside the classroom.

\section{CONCLUSIONS}

Previous research has investigated the relationship between learning-related emotions (LREs) and their appraisal antecedents (Dettmers et al., 2011; Goetz et al., 2010; 2012; Trautwein et al., 2009; Tempelaar et al., 2012). These studies have established the crucial role of mean levels of positive and negative emotional experiences in learning processes. In this study, we build further on the work of Tempelaar et al. (2012) and follow Buffs (2014) methodological approach to look at the relationships between changes in control appraisals and changes in LREs in a first year at university study. We expand on the important research of Buff (2014) to show the role of distinct positive and negative emotions while learning for mathematics and statistics. For this purpose, we first evaluated control appraisals as antecedents of LREs. Beyond that, we assessed the change-change assumption of the Control-Value Theory of Achievement Emotions (CVTAE), namely: if changes in the LRE levels were related to changes in their antecedents, the control appraisals.

The present study confirms first the distinctiveness of LREs in the CVTAE model. We were able to investigate if the changes in LRE's depend, beyond changes in control appraisals, on the initial levels of the same LRE only, or if there any cross-over effects between the different LRE's. In our empirical study, the existence of such cross-over effects was rejected: they change during course, but the change in each LRE depends only on the change in its antecedents and on its own initial level - but not on the level of other LREs. Indeed, as previously showed by Goetz et al. (2012), discrete emotions can be empirically distinguished in homework situations.

Second, we showed some notable individual differences in control appraisals and the four LREs. These differences can be observed in divergent longitudinal developments within different groups of students who display different pattern of increase, decrease and stability in LREs and Academic Control. This demonstrates the mechanism operating in the two opposite latent classes: a positive development in control appraisals pushes positive LREs upwards; whilst a negative development has the opposite impact. Thus, the second conclusion points out that there is a lot of change occurring under the surface of aggregate stability, on a more individual level in students' academic control and the four LREs.

Overall, our results provide compelling evidence that emotions in learning-related situations can be changed through their direct antecedents, the control appraisals. As we provided more insight into these changes, we showed that one size does not fit all and not surprisingly not all students' emotions change in the same way. Nevertheless, there are distinct patterns of - increase, decrease and stability in these emotional experiences and perceptions of control - which can be addressed separately. These findings should be reassuring for educators and instructional designers who wish to improve students' achievement by focusing on these factors. 


\section{REFERENCES}

Astleitner, H. (2000). Designing emotionally sound instruction: The FEASP-approach. Instructional Science, 28(3), 169-198.

Buff, A. (2014). Enjoyment of learning and its personal antecedents: Testing the change-change assumption of the control-value theory of achievement emotions. Learning and Individual Differences, 31(0), 21-29. doi:10.1016/j.lindif.2013.12.007

Coffman, D. L., \& MacCallum, R. C. (2005). Using parcels to convert path analysis models into latent variable models. Multivariate Behavioral Research, 40, 235-259.

Dettmers, S., Trautwein, U., Lüdtke, O., Goetz, T., Frenzel, A. C., \& Pekrun, R. (2011). Students' emotions during homework in mathematics: Testing a theoretical model of antecedents and achievement outcomes. Students' Emotions and Academic Engagement, 36(1), 25-35. doi:10.1016/j.cedpsych.2010.10.001

Dweck, C. S. (1999). Self-theories: Their role in motivation, personality, and development. Philadelphia: Psychology Press

Elliot, A. J., \& Pekrun, R. (2007). Emotion in the hierarchical model of approach-avoidance achievement motivation. In P. A. Schutz \& R. Pekrun (Eds.), Emotion in education. (pp. 57-73). San Diego, CA US: Elsevier Academic Press.

Frenzel, A. C., Pekrun, R., \& Goetz, T. (2007). Perceived Learning Environment and Students' Emotional Experiences: A Multilevel Analysis of Mathematics Classrooms. Learning and Instruction, 17(5), 478-493.

Fredrickson, B. L. (2001). The role of positive emotions in positive psychology: The broaden-and-build theory of positive emotions. American Psychologist, 56, 218-226.

Gal, I., \& Ginsburg, L. (1994). The Role of Beliefs and Attitudes in Learning Statistics: Towards an Assessment Framework. Journal of Statistics Education, V2N2: Gal. (n.d.). Retrieved from http://www.amstat.org/ publications/jse/v2n2/gal.html

Garfield, J., \& Ben-Zvi, D. (2007). How Students Learn Statistics Revisited: A Current Review of Research on Teaching and Learning Statistics. International Statistical Review, 75(3), 372-396. doi:10.1111/j.17515823.2007.00029.x

Geiser, C. (2013). Data Analysis with Mplus. New York, NY: The Guilford Press.

Goetz, T., Cronjaeger, H., Frenzel, A. C., Lüdtke, O., \& Hall, N. C. (2010). Academic self-concept and emotion relations: Domain specificity and age effects. Contemporary Educational Psychology, 35(1), 44-58. doi:10.1016/j.cedpsych.2009.10.001

Goetz, T., Frenzel, A. C., Stoeger, H., \& Hall, N. C. (2010). Antecedents of everyday positive emotions: An experience sampling analysis. Motivation and Emotion, 34(1), 49-62. doi:10.1007/s11031-009-9152-2

Goetz, T., Nett, U. E., Martiny, S. E., Hall, N. C., Pekrun, R., Dettmers, S., \& Trautwein, U. (2012). Students' emotions during homework: Structures, self-concept antecedents, and achievement outcomes. Noncognitive Skills in Education: Emerging Research and Applications in a Variety of International Contexts, 22(2), 225-234. doi:10.1016/j.lindif.2011.04.006

Goetz, T., Pekrun, R., Hall, N., \& Haag, L. (2006). Academic emotions from a social-cognitive perspective: Antecedents and domain specificity of students' affect in the context of Latin instruction. British Journal of Educational Psychology, 76(2), 289-308. doi:10.1348/000709905X42860

Hall, N. C., Perry, R. P., Ruthig, J. C., Hladkyj, S., \& Chipperfield, J. G. (2006). Primary and Secondary Control in Achievement Settings: A Longitudinal Field Study of Academic Motivation, Emotions, and Performance1. Journal of Applied Social Psychology, 36(6), 1430-1470.

Hattie, J., \& Timperley, H. (2007). The power of feedback. Review of Educational Research, 77(1), 81-112.

Hau, K. T., \& Marsh, H. W. (2004). The use of item parcels in structural equation modelling: Non-normal data and small sample sizes. British Journal of Mathematical Statistical Psychology, 57, 327-351.. Data Analysis with Mplus. New York, NY: The Guilford Press.

Hu, L., \& Bentler, P. M. (1999). Cutoff criteria for fit indexes in covariance structure analysis: Conventional criteria versus new alternatives. Structural Equation Modeling: A Multidisciplinary Journal, 6(1), 1-55. doi:10.1080/10705519909540118

Jöreskog, K.G., Sörbom, D. (1996). LISREL 8 User's Reference Guide. Scientific Software International: Chicago.

Leone, C., \& Richards, H. (1989). Classwork and homework in early adolescence: The ecology of achievement. Journal of Youth and Adolescence, 18(6), 531-548. doi:10.1007/BF02139072 
Linnenbrink, E. A. (2006). Emotion Research in Education: Theoretical and Methodological Perspectives on the Integration of Affect, Motivation, and Cognition. Educational Psychology Review, 18(4), 307-314. doi:10.1007/s10648-006-9028-x

Linnenbrink-Garcia, L., \& Pekrun, R. (2011). Students' emotions and academic engagement: Introduction to the special issue. Students' Emotions and Academic Engagement, 36(1), 1-3. doi:10.1016/j.cedpsych. 2010.11.004

Marsh, H. W., Hau, K. T., Balla, J. R., \& Grayson, D. (1998). Is more ever too much? The number of indicators per factor in confirmatory factor analysis. Multivariate Behavioral Research, 33, 181-220.

Muthén, L. K., \& Muthén, B. O. (1998-2011). Mplus User’s Guide. Sixth Edition. Los Angeles, CA: Muthén \& Muthén.

Niculescu, A., Segers, de Regt, E., \& Gijselaers, W. (2012), A Tutor Feedback Intervention in Problem-Based Learning and its Effects on Student Learning. Paper presented on the annual meeting of the American Educational Research Association, Vancouver, British Columbia, Canada, April 13 - April 17, 2012.

Niculescu, A., Tempelaar, D., Dailey-Hebert, A., Segers, M.,\& Gijselaers, W. (2014). How Structured Feedback Improves Student Performance and the Shadow Effect of Learning Emotion, International Conference of Motivation, Helsinki, Finland, June, 2014.

Pekrun, R. (2000). A social-cognitive, control-value theory of achievement emotions. In J. Heckhausen (Ed.), Motivational psychology of human development: Developing motivation and motivating development. (pp. 143163). New York, NY US: Elsevier Science.

Pekrun, R. (2006). The Control-Value Theory of Achievement Emotions: Assumptions, Corollaries, and Implications for Educational Research and Practice. Educational Psychology Review, 18(4), 315-341.

Pekrun, R., Goetz, T., Frenzel, A. C., Barchfeld, P., \& Perry, R. P. (2011). Measuring emotions in students' learning and performance: The Achievement Emotions Questionnaire (AEQ). Contemporary Educational Psychology, 36(1), 36-48. doi:10.1016/j.cedpsych.2010.10.002

Pekrun, R., Goetz, T., Titz, W., \& Perry, R. P. (2002). Academic emotions in students' self-regulated learning and achievement: A program of qualitative and quantitative research. Educational Psychologist, 37(2), 91-106.

Pekrun, R., Hall, N. C., Goetz, T., \& Perry, R. P. (2014). Boredom and academic achievement: Testing a model of reciprocal causation. Journal of Educational Psychology, 106(3), 696-710. doi:10.1037/a0036006

Pekrun, R., \& Stephens, E. (2010). Achievement Emotions in Higher Education. In J. C. Smart (Ed.), Higher Education: Handbook of Theory and Research (Vol. 25, pp. 257-306). Springer Netherlands. Retrieved from http://dx.doi.org/10.1007/978-90-481-8598-6_7

Perry, R. P., Hladkyj, S., Pekrun, R. H., Clifton, R. A., \& Chipperfield, J. G. (2005). Perceived Academic Control and Failure in College students: A Three-Year Study of Scholastic Attainment. Research in Higher Education, 46(5), 535-569. doi:10.1007/s11162-005-3364-4

Perry, R. P., Hladkyj, S., Pekrun, R. H., \& Pelletier, S. T. (2001). Academic control and action control in the achievement of college students: A longitudinal field study. Journal of Educational Psychology, 93(4), 776.

Putwain, D., Sander, P., \& Larkin, D. (2013). Academic self-efficacy in study-related skills and behaviours: Relations with learning-related emotions and academic success. British Journal of Educational Psychology, 83(4), 633-650. doi:10.1111/j.2044-8279.2012.02084.x

Schutz, P. A., \& Lanehart, S. L. (2002). Introduction: Emotions in Education. Educational Psychologist, 37(2), 67-68. doi:10.1207/S15326985EP3702_1

Schutz, P. A., \& Pekrun, R. (2007). Introduction to emotion in education. In P. A. Schutz \& R. Pekrun (Eds.), Emotion in education. (pp. 3-10). San Diego, CA US: Elsevier Academic Press.

Stupnisky, R. H., Perry, R. P., Hall, N. C., \& Guay, F. (2012). Examining perceived control level and instability as predictors of first-year college students' academic achievement. Contemporary Educational Psychology, 37(2), 81-90. doi:10.1016/j.cedpsych.2012.01.001

Taylor, B. (1995). Feeling, experiencing, and consciousing: diversity in the college classroom.

Thresholds in Education, 22, 23-27.

Tempelaar, D. T., Niculescu, A., Rienties, B., Gijselaers, W. H., \& Giesbers, B. (2012). How achievement emotions impact students' decisions for online learning, and what precedes those emotions. The Internet and Higher Education, 15(3), 161-169. doi:10.1016/j.iheduc.2011.10.003

Trautwein, U., Schnyder, I., Niggli, A., Neumann, M., \& Lüdtke, O. (2009). Chameleon effects in homework research: The homework-achievement association depends on the measures used and the level of analysis chosen. Contemporary Educational Psychology, 34(1), 77-88. doi:10.1016/j.cedpsych.2008.09.001 


\section{CHAPTER 5}

\section{Capturing the freshmen experience at}

university

An empirical study on how achievement emotions shape engagement in the curriculum

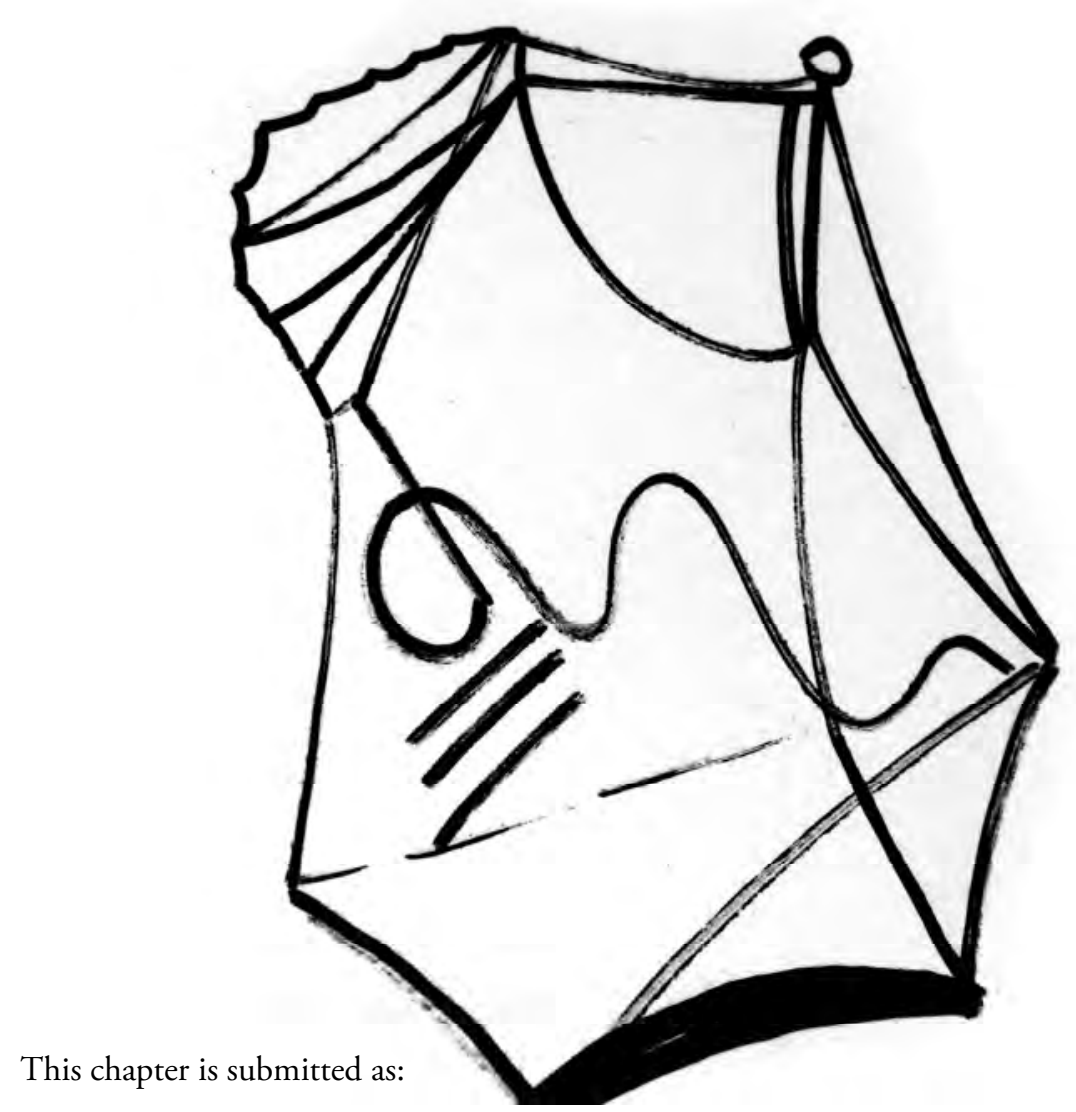

Niculescu, A., Tempelaar, D., Dailey-Hebert, A., Segers, M., \& Gijselaers, W. (submitted). Capturing the freshmen experience at university:

An empirical study on how achievement emotions shape engagement in the curriculum. Journal of College Student Development 


\section{ABSTRACT}

Aiming to investigate how emotions emerge and further develop in the first year of university, we sought to understand a classic problem - freshmen's emotional engagement at university. For this purpose, we used an integrated framework linking two contemporary theories on emotions and motivation: Pekrun's (2006) Control Value Theory of Achievement Emotions (CVTAE) and Martin's (2007) Motivation and Engagement Wheel framework. Using a longitudinal design employed in two course subjects and a relatively large sample ( $\mathrm{N}=908$ freshmen), we first found that learning-related emotions (LREs) are indeed distinct concepts: emotions in one course predict the same emotions in another subject, and do not cross-over to other emotions. Based on the evidence provided in this study, we can confirm that LREs in the first year of university are indeed contextualized experiences, as opposed to the characteristics that learners possess upon entering the university, which matter to a lesser degree. Second, we showed that emotional experiences during learning within a certain course subject are determined by beliefs about control within the same course. Such beliefs, in turn, can influence later experiences within another course and how these experiences may change over the first year at university. These findings, in relation to theory, implications for further research, and recommendations for educational practice, are considered and shared in this article. 


\section{INTRODUCTION}

Freshmen engagement has been an indicator of success for educational systems for decades (Pascarella \& Terenzini, 1991, 2005). A great deal of empirical research has shown its contribution to achievement outcomes and retention at university (Fredricks, Blumenfeld, \& Paris, 2004; Klem \& Connell, 2004; Martin, Papworth, Ginns, \& Liem, 2014). Over time, engagement has been conceptualized differently, from adjustment or adaptation (Baker \& Syrik, 1999; Tinto, 1987) to multifaceted views, including behavioral, cognitive and emotional aspects of engagement (Fredricks, Blumenfeld, \& Paris, 2004; Connell \& Wellborn, 1994). This wide range of indicators is needed to understand the totality of students' experiences in the context of first year at university. Such transition period brings several challenges for freshmen, among which an achievement setting that is different from high school, higher academic standards, increased competition, high expectations and perceived pressure to perform (Daniels et al., 2014; Perry, Hall, \& Ruthig, 2005). Much has been written about the uncertainty and negative emotional experiences accompanying this complex and difficult period (Hall et al., 2006); Linnenbrink-Garcia \& Pekrun, 2011; Ruthig et al., 2007). As yet, few scholars have conducted a comprehensive analysis covering the entire first year at university period, to most effectively understand students' engagement through emotional and affective variables (Beard et al., 2007; Perry et al., 2001; Putwain, Larkin, et al., 2013; Stupnisky et al., 2012). Using contemporary perspectives on motivation and emotions (Martin, 2007; Pekrun, 2006), the present study interprets the classic emotional adjustment (Tinto, 1987) problem to get more insight into freshmen's experiences at university.

The first year of university is recognized as a period of transition for most students (Baker \& Syrik, 1999; Tinto, 1997), in which unpleasant emotions seem particularly intense (Stupnisky et al., 2012). Emotions experienced in academic settings, known as achievement emotions, contribute to students' motivation and can influence academic performance within a course (Pekrun, 2006). Such emotions emerge from students' beliefs about their capacity to influence academic outcomes and the value given to these outcomes, referred to respectively as appraisals of control and value (Pekrun et al., 2002). At the same time, students enter university holding a set of generic predispositions toward learning in general, such as adaptive and maladaptive cognitions and behaviors, which will also influence their emotional experiences within a course (Martin, 2007). Furthermore, in a longitudinal context, reciprocal linkages can occur between these constructs (Pekrun, 2006) where appraisals, emotions and performance influence each other over time in a feedback loop beyond a course setting: the contribution of academic emotions in a certain course, for instance, can be observed later on in how students perform in another course. This is an important consideration for educational practice, as emotions are not only end states but also processes which can have long-lasting effects on students' academic achievement (Goetz, Pekrun, Hall, \& Haag, 2006; Pekrun, Hall, Goetz, \& Perry, 2014).

With few exceptions (Beard, Clegg, \& Smith, 2007; Perry, Hladkyj, Pekrun, \& Pelletier, 2001; Putwain, Larkin, \& Sander, 2013; Stupnisky, Perry, Hall, \& Guay, 2012), research in the first year of university has mainly focused on students' emotional experiences in introductory courses when entering study (Daniels et al., 2008; Ruthig et al., 2008; 
Putwain, Larkin, et al., 2013; Tempelaar et al., 2012). This paucity of evidence left unexplored the emotional processes that can occur, when they enroll in other courses beyond introductory courses. Given the crucial role of emotions during this transition period, it appears relevant to develop further understanding on how students' emotional experiences emerge and further change in time over the various courses students enroll in the first year of university.

We used a longitudinal design that includes two courses, covering the time span between the beginning until the end of the first year at university. We build further on our previous studies (Niculescu et al., 2015a, b) which investigated: 1) how achievement emotions emerge from direct and distal antecedents in an introductory mathematics and statistics course (Niculescu et al., 2015a) and 2) how appraisal of control, as an antecedent, predicts changes in achievement emotions at two points in time within such an introductory course (Niculescu et al., 2015b). Furthermore, we follow (Buff, 2014) methodological approach to look at the relationships between changes in control appraisals and changes in achievement emotions over two, first-year courses. To provide a more complete picture of the first year of university experience, we also included distal antecedents of achievement emotions (the prior characteristics students bring with them before they enter university) and their potential effects on these emotions and their changes.

\subsection{Theoretical framework}

A first iteration to explain students' engagement through their emotional experience in the first year of university was Tinto's (1987) work. Tinto (1987) argues that individuals enter institutions with a range of backgrounds, personal attributes, skills, previous education and experiences which can directly impact their adjustment, which can in turn, influence their persistence. For that purpose, he introduced the term of adjustment to college which was defined as a continuous interaction process between the student and the institution itself. More recently, self-regulated, motivational and emotional learning research has emphasized aspects of students' psychological well-being, and the resulting impact on academic achievements (Pekrun, 2000; Richardson, 2011; Tempelaar et al., 2007). In particular, research on achievement emotions prompts a re-appraisal of the classical models to address the student experience and engagement within a specific course (Pekrun, Goetz, Titz, \& Perry, 2002). Overall, in this perspective, the learning behavior is driven by personal factors which interact with determinants at the course level to ultimately affect students' emotional experiences and achievement outcomes.

In the following section we will: 1) introduce the achievement emotions concept and describe the different types of settings in which achievement emotions are encountered within a course; 2) describe how achievement emotions emerge from their antecedents, and 3) provide empirical evidence linking these antecedents and achievement emotions. The aim of this study and the research questions are stated at the conclusion of this section. 


\subsubsection{Achievement emotions}

Achievement emotions are defined as "emotions that are directly linked to achievement activities and outcomes" (Pekrun et al., 2011, p. 37). In the Control-Value Theory of Achievement Emotions (Pekrun, 2006b), emotional experiences have a situational context, meaning that they can be experienced in different academic situations within a course: 1) being in class, 2) taking tests and exams and, 3) studying outside of class (while learning or when preparing homework). Since in the first year of university students are expected to engage in more individual self-study beyond just attending lectures, the experience of achievement emotions in learning situations (such as when preparing the homework, for example) is particularly important. Indeed, according to the CVTAE, first year university students experience a variety of learning - related emotions, whether the emotions are positive or negative.

\subsubsection{Learning - related emotions and their antecedents}

According to the Control-Value Theory of Achievement Emotions (CVTAE; Pekrun, 2006), discrete learning-related emotions (LREs) arise from the appraisal of achievement activities and outcomes. Emotions that result from such appraisals can indirectly influence achievement outcomes. There are two dimensions of appraisals: control and value. The appraisal of control refers to a student's belief about whether he/she has control over learning activities/outcomes; the appraisal of value describes the subjective value attributed to these activities/outcomes. These appraisals are considered direct antecedents of LREs and are acquired at the course level (Pekrun, 2006). As a general rule, low and high levels of control appraisals influence emotions differently (Pekrun, 2000). For instance, low control leads to an increased level in negative emotions (e.g., learning anxiety) and a more elevated level of control favors a heightened experience of positive emotions (such as learning enjoyment). In a longitudinal context, this postulate implies that increasing levels of control and value appraisals will raise the levels of positive emotions, (such as joy), and lower the levels of negative emotions, (like anxiety). Likewise, a decrease in the levels of the antecedents has an opposite effect. In other words, this assumption - referred to as the changechange parameterization of CVTAE (Buff, 2014) - has two practical implications: increasing the levels of LREs' antecedents is expected to raise the levels of positive emotions and decrease the levels of negative emotions. This assumption was empirically investigated and confirmed by Buff (2014) for the positive LRE of enjoyment. Indeed, Buff (2014) found that positive changes in perceived control and value lead to positive changes in enjoyment of learning in mathematics for sixth graders. The transition from high school to university would shape an excellent context to investigate changes in negative LREs, as a consequence of changes in direct antecedent variables (such as appraisals of control, for instance). Nevertheless, empirical evidence testing the change-change assumption in this period has been dated on only one occasion (Niculescu et al., 2015b) in an introductory course setting only. On a previous study (Niculescu et al., 2015b) we tested the assumption that antecedents of four LREs (the positive enjoyment and the three negative anxiety, boredom and hopelessness) change over the duration of an introductory mathematics and statistics course. Our findings show that changes in academic control were positively related to changes in the 
positive emotion enjoyment, and negatively related to changes in the three negative emotions experienced in the introductory course.

There are also more general expectancies and predispositions towards learning at university that students already hold when entering a course, which can be considered generic antecedents of LREs. Since appraisals of control and value are based on these generic tendencies, the latter can be considered distal antecedents of learning emotions. Students enter a new course holding background characteristics (intelligence, personality, high school GPA etc.) but also possessing a set of adaptive and impeding cognitions, and adaptive and impeding behaviors, towards learning in the new setting of university (Martin, 2007). Therefore, we applied the 'motivation and engagement wheel' framework of Martin (2007, 2009) as a model for distal antecedents of learning-related emotions (LREs). The motivation and engagement wheel breaks down all motivation and engagement concepts into four categories: adaptive cognitions, adaptive behaviors, impeding cognitions, and maladaptive behaviors. These four categories each consist of two or three sub-dimensions. For adaptive cognitions, the dimensions consist of self-belief, valuing school, and learning focus. Furthermore, the adaptive behavioral dimensions include persistence, planning, and task management. Conversely, the impeding or deactivating antipodes of the cognitions (that obstruct learning rather than enhance it) include anxiety, failure avoidance and uncertain control. The maladaptive behaviors are twofold: self-handicapping and disengagement. The concepts operating in this motivation and engagement wheel represent generic orientations that are relatively stable over contexts (Martin, 2009). For this reason, in Pekrun's Theory, such generic orientations can be integrated as distal antecedents of both control and value appraisals and LREs. Although it may appear that some of the concepts (e.g. selfbelief/efficacy, persistency and control) from the "motivation and engagement wheel" are closely related to the appraisal of control in the CVTAE, it is important to ensure clarity between them: while the distal antecedents are more trait-type of constructs, the direct antecedent (appraisal of control) is a subject specific type of appraisal. Figure 1 summarizes the conceptual model used in our study.

To sum up, direct antecedents need sufficient exposure to the new course setting to emerge, while distal antecedents are already present when a student enters a course (Pekrun et al., 2002). The added value of integrating both direct and distal antecedents into one framework is to explain: 1) the emergence of distinct emotions through direct antecedents at the course level, and 2) through distal antecedents, the individual differences that arise in learning emotions when students enroll in a course. 


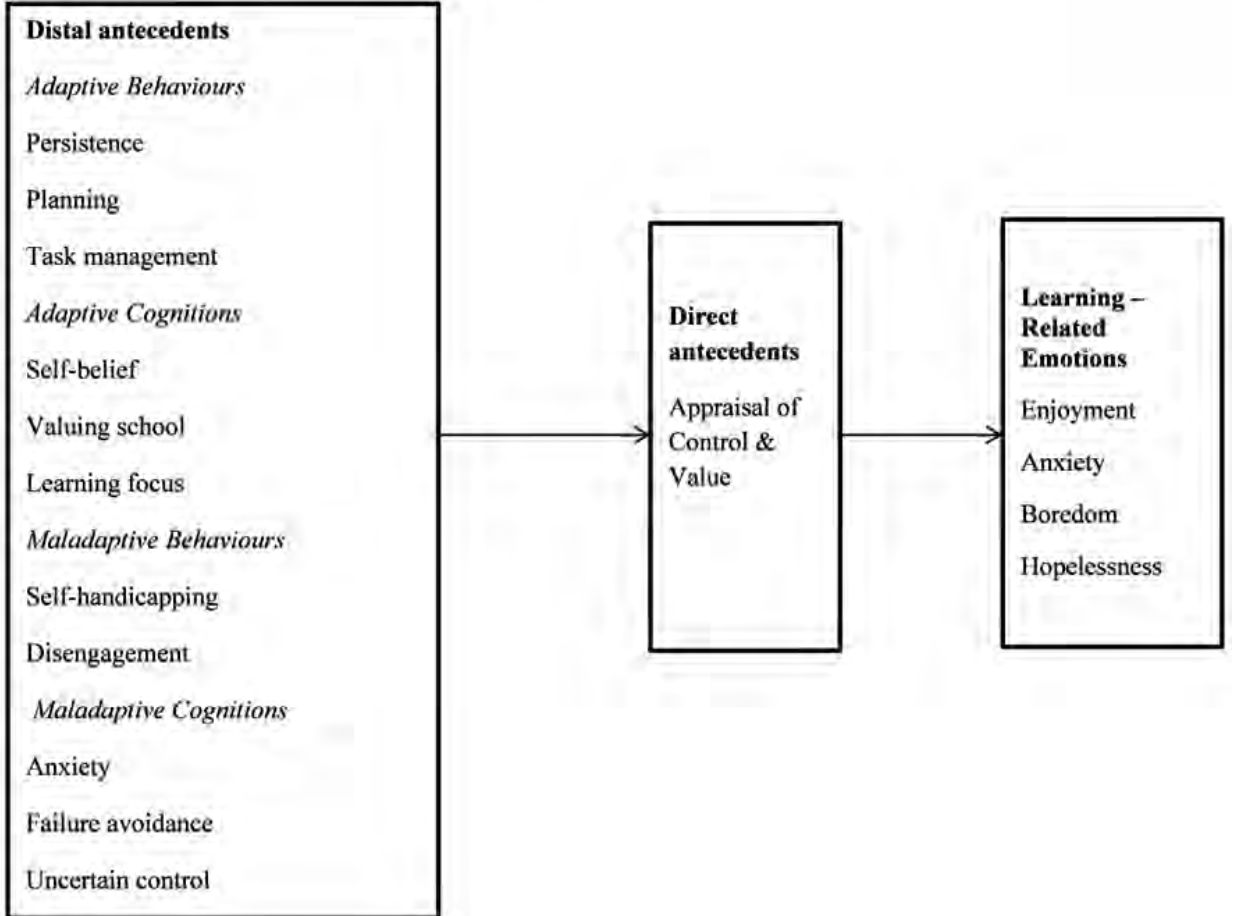

Figure 1. Conceptual framework of the study

\subsubsection{Empirical evidence on the antecedents and LREs}

Empirical evidence shows that direct antecedents of LREs, such as the appraisal of control, longitudinally relates to emotions (Perry et al., 2001, 2005), as well as to subsequent academic achievement in the first year of university (Hall et al., 2006; Ruthig et al., 2008; Stupnisky et al., 2012). For instance, Perry et al. (2001) found that students who reported higher levels of perceived academic control also felt less bored (-.48) and less anxious (-.35) towards the course, and obtained higher final grades (.27). Similar relations are shown by Hall et al. (2006): correlations between primary control and several emotions (anger, regret, happiness and pride) are in the range of -.27 to .24 ; primary control relates positively to the final course grade (.21) as well as to cumulative GPA (.25). The implications of studying direct antecedents of LREs is relevant when explaining the development of emotions within a course and, indirectly for understanding their consequences on achievement.

With respect to the distal antecedents of LREs, the motivation and engagement concepts play an important role in students' cognitive appraisals, in their emotions during learning, and in achievement outcomes (Martin, 2011; Martin \& Marsh, 2006). For instance, student's confidence to do well in university, their belief that learning will be useful and relevant, and their interest in learning new topics/developing new skills, all contribute to various academic outcomes (Martin, 2011). Furthermore, a study of Martin and Marsh 
(2006) shows that self-efficacy, control, planning, low anxiety, and persistence predict enjoyment and class participation.

Finally, it is important to mention that change relations between control (and value) appraisals and LREs were explored on only two occasions: First, Buff s (2014) contribution brings evidence for the CVTAE assumption that changes in perceived control and value relate positively to changes in learning enjoyment. This was done with a sample of sixth graders and for the single, positive LRE of enjoyment only. Second, in a previous study (Niculescu et al., 2015) we captured the same assumption in a mathematics and statistics domain for first year university students. In addition to Buff's study, we showed that changes in control appraisals go together with changes in positive, as well as negative, LREs. In order to better understand how the levels of negative emotions can be decreased over the first year at university, additional efforts should especially emphasize on capturing this relationship: how the changes in negative LREs and their appraisal antecedents are related in different courses over the first year at university.

\subsection{Aim and research questions}

It was our aim to look at how LREs emerge in the first year at university and how they further develop over two different course subjects. We extend upon Buff s (2014) approach by including negative, as well as positive multiple LREs to further test the assumption that negative LREs also change over time. This is in line with the CVTAE change-change hypothesis in two ways: within a course and over two different course subjects in the first year at university.

We asked the following research questions:

RQ1: How do LREs emerge from direct and distal antecedents in the two courses?

RQ2: What predicts changes in LREs in the two courses? Are changes in control appraisals related to changes in LREs?

\section{METHOD}

\subsection{Sample}

The participants were 908 first year students (19 years old on average, 62.8\% male) enrolled in a Business and Economics bachelor degree program at a medium-size European University. Most students had a predominantly international background, a vast majority (74.6\%) holding an international education diploma.

\subsection{Setting}

The setting for this study was comprised of two first year undergraduate courses. The first course was a compulsory introduction to Mathematics and Statistics, scheduled in the first period of the academic year. The course has a high attendance and is notoriously known among new students for two main reasons: 1) the course materials are often regarded as 
being difficult and unattractive for most students, 2) failing this course implies encountering issues of delay or even exclusion from study.

A course in Finance was the second domain of investigation, scheduled in the last course period of the academic year. This course is scheduled nine months after the beginning of the first course. Finance is again a high-attendance course which poses problems concerning its passing rate. Both courses have a duration of eight weeks (out of which, seven weeks are scheduled for education and the last week is reserved for exams).

\subsection{Design and Procedure}

We used a longitudinal design with five assessment points. We first collected data in the Mathematics and Statistics course on three occasions: in week two, students completed a questionnaire concerning their adaptive and maladaptive cognitions and behaviors towards learning at university in general. In week four, the students completed another questionnaire, this time about their appraisals of control and value and learning-related emotions (LREs) in this course. 793 students (87.3\%) responded to this survey which was administered online (students were required to do a statistical project based on self-reports, for which they could use these survey data). The timing of the second survey, exactly halfway the course, was chosen to ascertain that students were sufficiently familiar with the topics studied, the educational context and learning activities on one side, and leave sufficient time to do a post measurement on the other side. Exactly the same survey on control and value appraisals and LREs was repeated in week seven of the course, the very last week of classes before the exam. This third measurement now generated a response of 387 students (42.6\%).

In the Finance course, we collected data on two occasions: in week two, students completed a pen and paper questionnaire concerning their appraisal of control and LREs towards the Finance course. 313 students $(30 \%)$ responded to this survey. We repeated the same survey on control appraisals and LREs in week six, two weeks before the exam. This generated a response of 190 students $(20 \%)$. All students included in this study provided informed consent for the data collected by means of questionnaires.

\subsection{Measures and variables}

We measured learning-related emotions through the four learning scales, Enjoyment, Anxiety, Boredom and Hopelessness, of the Achievement Emotions Questionnaire (AEQ) developed by Pekrun et al. (2011). The Enjoyment scale (10 items, e.g. "I enjoy accruing new knowledge"), Anxiety scale (11 items, e.g. "I get tense and nervous while studying"), Boredom scale (11 items, e.g. "The material bores me to death") and Hopelessness scale (11 items, e.g "I feel hopeless when I think about studying") were slightly re-phrased to match the specific situation of each course. For reasons of consistency in our research, items were answered on a 7-point Likert scale ( $1=$ 'completely disagree' and $7=$ 'completely agree') in the Mathematics and Statistics course, while in Finance we used the original 5-point Likert scale.

Control appraisals were measured with the perceived Academic Control Scale (ACS) of Perry et al. (2001). The scale is composed of eight items, e.g. "I have a great deal of control 
over my academic performance in this course". Same reasons apply here when answering items in the Mathematics and Statistics course on a 7-point Likert scale ( 1 = 'completely disagree' and 7 = 'completely agree'), while in Finance on a 5-point Likert scale.

Value appraisals were taken from the Survey of Attitudes towards Statistics (SATS) instrument developed by Schau et al. (1995). Based on the Eccles' Expectancy-Value Theory (Eccles, 2005), the instrument distinguishes two subjective task-value constructs that encompass students' attitudes towards the value of the subject: the extrinsic oriented Value, and the intrinsic oriented Interest.

Adaptive and maladaptive cognitions and behaviors were measured with the Motivation and Engagement Scale (MES; Martin 2007). The MES consists of four scales and eleven subscales subsumed under the four scales. The Adaptive Cognition scale is composed of three sub-scales: Self-Belief (e.g. "If I try hard, I believe I can do my university work well"), Valuing School (e.g. "Learning at university is important for me") and Learning Focus (e.g. "I feel very pleased with myself when I really understand what I'm taught at the university"). The second scale, Adaptive Behavior contains the following subscales: Persistence (e.g. "If I can't understand my university work at first, I keep going over until I do"), Planning (e.g. "If I start an assignment I plan out how I am going to do it") and Study Management (e.g. "When I study, I usually study in places where I can concentrate"). The third sub-scale, Maladaptive (Impeding) Cognition includes the Anxiety (e.g. "When exams and assignments are coming up, I worry a lot"), Failure Avoidance (e.g. "Often the main reason I work at university is because I don't want to disappoint others") and Uncertain Control (e.g. "I am often unsure how I can avoid doing poorly at university") sub-scales. Finally, Maladaptive Behavior includes the Self-Handicapping (e.g. "Sometimes I don't study very hard before exams so I have an excuse if I don't do as well as I hoped") and Disengagement (e.g. "I often feel like giving up at university") sub-scales.

Academic Achievement in the Mathematics and Statistics course was measured through Performance QM. This consisted of three separate parts which were summed up: MathPerformance, StatsPerformance and BonusPerformance. MathPerformance and StatsPerformance were assessed in a final written exam which covered a mathematics component and a statistics component, graded separately. BonusPerformance represented the sum of bonus scored in quizzes and homework. Quizzes, although optional, were available for both mathematics and statistics in an online format. Some further bonus could be achieved by doing weekly homework, containing assignments for both mathematics and statistics.

Academic Achievement in Finance was measured through a constructed outcome variable Performance Finance, defined as the block test. The block test was mandatory and consisted of a Knowledge Test, which was a closed book exam.

\subsection{Statistical analyses}

Beyond descriptive analyses, this study uses structural equation modeling to arrive at latentchange models. Latent-change models allow for different model specifications, with different merits (Geiser, 2013). Latent change models have been estimated with the cross-lagged panel model structure (CLPM) or latent autoregressive model (LAM), as well as with equivalent parameterizations using latent difference variables. Such latent change (LC) 
parameterizations facilitate interpretations that focus on change over time, rather than emphasizing the stable characteristics within a context of variation over time (Geiser, 2013). Given our aim of investigating the relationships between changes in academic control and changes in LREs over two courses, we will report on model estimates generated by the LC parameterization.

A separate preliminary step in estimating longitudinal structural equation models is establishing measurement invariance (Geiser, 2013; Buff, 2014). As measurement model for the motivation and engagement constructs, a second order confirmatory factor model was postulated distinguishing the four second order factors Adaptive Cognitions, Adaptive Behaviors, Impeding Cognitions, and Maladaptive Behaviors, based on the corresponding eleven first order factors described earlier (see Martin, 2007). Since we identified both second order and first order latent factors for motivation and engagement variables, we based the relationships with LRE's and appraisals on the second order factors. Based on our conceptual model (depicted in Fig. 1), we allowed paths originating from first order factors only if they would add in predictive power to the already included second order factors.

As a next preparatory step, items from the LRE self-report instruments were parceled. The technique of item parceling, where items from the same scale are aggregated into several parcels or mini-scales, has been adopted in empirical studies for several reasons. These reasons include: a) obtaining more continuous and normally distributed observed data; b) reducing the number of model parameters to achieve a more attractive variable to sample size ratio; and, c) estimating stable parameters (Coffman \& MacCallum, 2005; Hau \& Marsh, 2004; Marsh, Hau, Balla, \& Grayson, 1998). In our study, the size of the model and the length of all scales, relative to the sample size necessitate in itself the parceling step in the estimation of the latent-change model. In parceling items, we made use of the subscales composition of the AEQ scales (each scale is composed of four components: motivational, affective, physiological and cognitive, which are identified by a numerical symbol in the item name: 1 to 4 ). We tried to reflect the original scale in the sense that each parcel contained one item for each of the four sub-components: motivational, affective, physiological and cognitive. We then used these sub-components to create three parcels per scale (first parcel containing the four items labeled '1', second parcel containing the four items labeled '2', and third parcel containing items with labels '3' or '4').

After these preparatory steps, structural equation modeling was applied to arrive at latent change structural models. Latent change models based on parcel scores were estimated with LISREL (version 8.8) using maximum likelihood (ML) estimation. To prevent capitalization on chance, rather conservative model building rules were adopted: starting from parsimonious models, p-values of $1 \%$ or less were required as a cutoff value for significance for the adoption of any new structural path. We report the Chi-square and degrees of freedom values, the Comparative Fit Index (CFI), the Non-Normed Fit Index (NNFI, also known as TLI) and the Root Mean Square Error of Approximation (RMSEA) as indicators of goodness of fit. $\mathrm{Hu}$ and Bentler (1999) suggested for CFI/TLI values larger than .90 for a satisfactory fit and for RMSEA values should not exceed .08 and preferably be .06 or lower. 


\section{RESULTS}

\subsection{Descriptive statistics}

In the first Mathematics and Statistics (QM) course, students' Academic Control and learning Enjoyment are above the neutral value of four. On the other side, the three negative LREs are below the neutral value of four showing that students enrolled in the first course experience on average only low negative learning-related emotions (LREs). These values will not change substantially between the two measurements within this course: see Table 1. In the Finance (F) course we observe similar patterns: students experience Academic Control and learning Enjoyment on the positive side (above the neutral value of three), while the three negative LREs are below the neutral value of three. None of these values changes substantially between the two measurements in Finance. All Cronbach alpha reliabilities are high and apparently do not suffer from the parceling step.

Table 1. Descriptive statistics and reliabilities for academic control and the four learning emotions

\begin{tabular}{|c|c|c|c|c|c|}
\hline Variable & $\mathrm{M}$ & SD & Possible range & Observed range & $\begin{array}{l}\alpha \\
\text { Original scale }\end{array}$ \\
\hline \multicolumn{6}{|c|}{ Academic control } \\
\hline QM Time 1 & 5.28 & .86 & $1-7$ & $2.38-7.00$ & .827 \\
\hline QM Time 2 & 5.38 & .90 & $1-7$ & $2.75-7.00$ & .866 \\
\hline F Time 1 & 4.16 & .51 & $1-5$ & $2.63-5.00$ & .753 \\
\hline F Time 2 & 4.00 & .51 & $1-5$ & $2.88-5.00$ & .792 \\
\hline \multicolumn{6}{|l|}{ Anxiety } \\
\hline QM Time 1 & 3.88 & 1.19 & $1-7$ & $1.00-6.45$ & .925 \\
\hline QM Time 2 & 3.70 & 1.23 & $1-7$ & $1.00-6.27$ & .934 \\
\hline F Time 1 & 2.06 & .65 & $1-5$ & $1.00-3.82$ & .896 \\
\hline F Time 2 & 2.36 & .77 & $1-5$ & $1.00-4.27$ & .914 \\
\hline \multicolumn{6}{|l|}{ Boredom } \\
\hline QM Time 1 & 2.90 & 1.16 & $1-7$ & $1.00-6.45$ & .938 \\
\hline QM Time 2 & 2.97 & 1.22 & $1-7$ & $1.00-6.64$ & .958 \\
\hline F Time 1 & 1.95 & .71 & $1-5$ & $1.00-4.64$ & .938 \\
\hline F Time 2 & 2.15 & .83 & $1-5$ & $1.00-4.45$ & .952 \\
\hline \multicolumn{6}{|l|}{ Hopelessness } \\
\hline QM Time 1 & 2.99 & 1.27 & $1-7$ & $1.00-6.64$ & .951 \\
\hline QM Time 2 & 2.95 & 1.26 & $1-7$ & $1.00-6.36$ & .961 \\
\hline F Time 1 & 1.63 & .60 & $1-5$ & $1.00-3.91$ & .939 \\
\hline F Time 2 & 1.93 & .72 & $1-5$ & $1.00-4.36$ & .944 \\
\hline \multicolumn{6}{|l|}{ Enjoyment } \\
\hline QM Time 1 & 4.13 & .93 & $1-7$ & $1.00-6.50$ & .865 \\
\hline QM Time 2 & 4.24 & 1.02 & $1-7$ & $1.40-6.70$ & .887 \\
\hline F Time 1 & 3.23 & .63 & $1-5$ & $1.30-5.00$ & .862 \\
\hline F Time 2 & 3.06 & .66 & $1-5$ & $1.30-5.00$ & .867 \\
\hline
\end{tabular}




\subsection{Bivariate correlations}

Bivariate correlations are depicted in Table 2. For this purpose we only report an average value of pre- and post-measurements for each course. Printed in bold are the autocorrelations: correlations between the Mathematics and Statistics (QM) and the Finance (F) measurements for the same constructs. The first set of autocorrelations, between Academic Control in QM and Finance, is positive and small to medium in size (.30). Those for LREs range from .36 to .41. We notice that Performance in Finance is stronger related to LREs experienced in the QM course (the strongest correlation, .20, is observed with Hopelessness) then the LREs in Finance itself. The two performance measures, for QM and Finance, are positive and to a medium to high degree correlated (.59). This is the highest correlation depicted for Performance in Finance, meaning that, above all other factors, its strongest predictor is how students perform first in the Mathematics and Statistics (QM) course. 


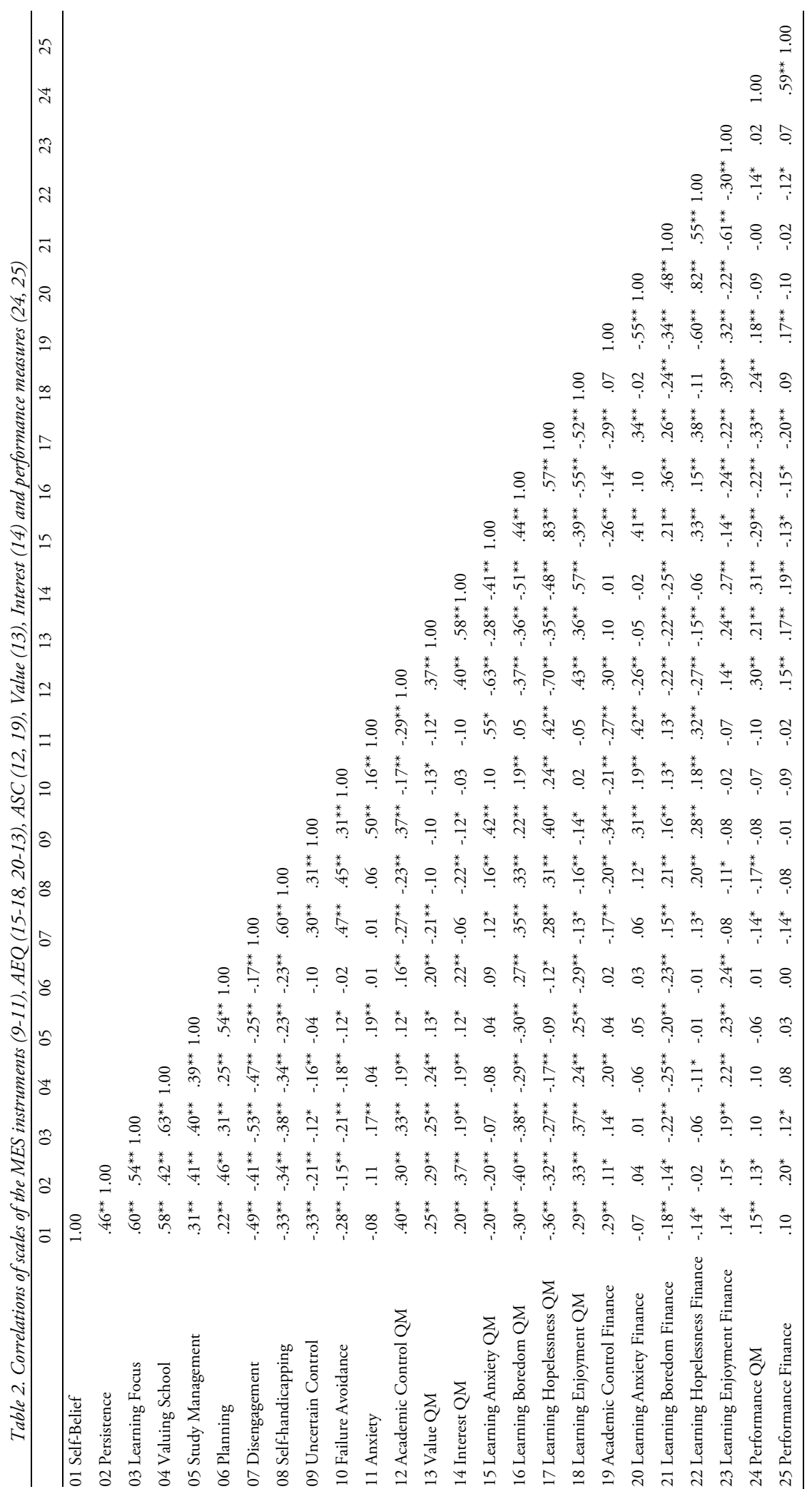




\subsection{Latent change models}

We started from a base model that was restricted to paths from Academic Control in the first course $(\mathrm{QM})$ to all LREs in the same course. Next, we freed paths from the level variables in the first course $(\mathrm{QM})$ to the corresponding latent change variables in the second course $(\mathrm{F})$. We therefore followed a model enlargement procedure to derive the final model. We used a conservative significance level of .01 to protect against capitalization on chance. The final model is depicted in Figure 2. To maintain readability in this figure, the non-significant second order motivation and engagement variables (on the left side) are not included in the path diagram. The fit of the final model is adequate: $\chi^{2} / d f=1.55$, CFI $=$ $0.97, \mathrm{NNFI}=0.96$, RMSEA $=0.037$.

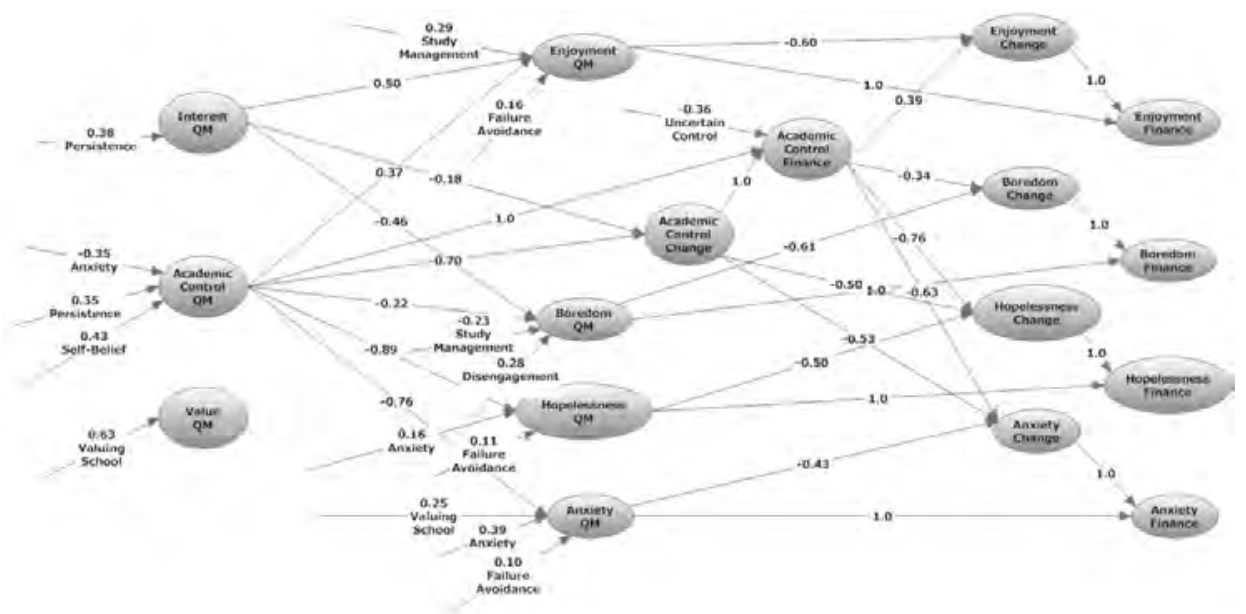

Figure 2. Path diagram of the structural model with standardized estimates *

* For reasons of readability only significant first order MES factors - as antecedents of LREs are depicted in the diagram

Control appraisals act as predictors of all LREs in the Mathematics and Statistics course, in accordance with the Control Value Theory of Achievement Emotions (CVTAE). Of the two value appraisals, only Interest, the intrinsic component, passes the strong significance threshold. Interest predicts both Enjoyment and Boredom. The remaining two negative LREs, Hopelessness and Anxiety, find additional predictors in the maladaptive cognitions Failure Avoidance and Anxiety. A remarkable path is that from the adaptive cognition Valuing School to the negative LRE, Anxiety. This path has a positive coefficient, indicating that high levels of Valuing School, next to potential positive effects, may induce raised levels of learning Anxiety.

Latent change in each of the four LREs experienced in Finance is predicted by the level of the same corresponding LRE in the first QM course, showing no cross-over effects. These relations are of "regression to the mean" type: students who experience extreme LRE values in the first course show a correction in the second course. Next, both change in 
control appraisal, as well as the level of control appraisal in Finance impact changes in LREs over the two courses.

\section{DISCUSSION}

Emotions are crucial factors for explaining students' experiences in the first year at university (Pekrun et al., 2011), a period of transition and adjustment for most students. We sought to understand a classic problem using a contemporary theory on emotions (CVTAE): how students engage emotionally in the first year of university and what makes this experience specific to various course subjects in which students enroll. Therefore, our aim was to investigate how emotions emerge and further develop in the first year of university. For this purpose, we used an integrated framework linking Pekrun's (2006) Control Value Theory of Achievement Emotions (CVTAE) and Martin's (2007) Motivation and Engagement Wheel framework. Using a longitudinal design, we followed how emotions in learning-related situations change in the first year of university over two course subjects to: 1) look at how learning-related emotions (LREs) emerged from control appraisals, as direct antecedents, and, adaptive and maladaptive cognitions and behaviors, as distal antecedents; and 2) investigate if changes in control appraisals were related to changes in both positive and negative LREs over the two courses.

We first found that LREs are indeed distinct concepts: emotions in one course predict the same emotions in another subject, and do not cross-over to other emotions. Furthermore, there is a lot of continuity in the emotional experiences in learning situations over time, which is stronger than the influence of the other factors. Based on the evidence provided in this study, we can confirm that LREs in the first year of university are indeed contextualized experiences, where prior characteristics that students possess when they enter university are important to a lesser degree.

Second, we showed that emotional experiences during learning within a certain course subject are determined by beliefs about control within the same course, which in turn influence: 1) later experiences within another course and, 2) how these experiences may change over the first year at university. This finding is in accordance with the CVTAE that indeed achievement emotions influence each other over time, in a feedback loop beyond one course setting.

\subsection{Limitation and further research}

Our study used an ecological design for freshmen at university to test how learning-related emotions (LREs) emerge and further change in the first year at university. As strong features, we used a longitudinal design in a relatively large-scale sample. However, one limitation should be considered.

In this study we tried to get insight into students' emotional experiences in the first year of university while looking at the change in control appraisals and learning-related emotions over two courses covering the beginning and the end of the academic year. In order to understand more of freshmen experiences in this context, future research might also incorporate a third assessment - half-way the year - which could prove useful in cap- 
turing the change in emotions and appraisals in between the beginning and the end of the first year at university.

\subsection{Recommendations for educational practice}

An important consideration for educational practice is that appraisals and emotions are not only end states but also processes which can have long-lasting effects on students' academic achievement (Goetz, Pekrun, Hall, \& Haag, 2006; Pekrun, Cusack, Murayama, Elliot, \& Thomas, 2014; Pekrun, Hall, et al., 2014). In this context, we would like to refer to Taylor's (1994) "emotionally sound instruction", which consists of "instructional strategies to increase positive and decrease negative feeling during regular instruction" (Astleitner, 2000, p. 173). This type of philosophy could accommodate students' uncertainty and lack of confidence in the first year of study, a very complex period at university. Furthermore, such approach goes beyond improving only students' knowledge and performance to include more of the totality of their experience. For this purpose, we refer to a previous intervention we run in an Economics course, in which we showed that the frequency of providing feedback together with the amount of attendance in the course could improve exam performance (Niculescu et al., 2012). This type of intervention shows that with minimum but persistent effort, observable gains can be attained in how students perform as well as how much they get involved in the course.

Another possibility to intervene on emotions in educational settings in a non-invasive manner is through their antecedents. There is ample evidence on the power of feedback in achievement and the various levels at which the feedback can be formulated (Hattie \& Timperley, 2007). However, the efficiency of feedback is known to depend on certain conditions. Such conditions could be very well described in terms of how students feel and appraise the situations in which they learn at university. For instance, in our course redesign interventions, we showed that students' performance in various courses can be improved by providing both process- and task-related team-feedback (Niculescu et al., 2012, 2014). In one of these experiments (Niculescu et al., 2014), which targeted the course discussed in this study but conducted in the next academic year, we showed that if students were already experiencing intense negative emotions, these factors could confound the effect of tutor' feedback on individual performance. We would like to suggest that these types of educational interventions could point to a more useful question: to go beyond how we can improve student achievement to how we can engage more the student in its own learning process.

\subsection{Conclusions}

Previous research has investigated the relationship between learning-related emotions (LREs) and their appraisal antecedents (Dettmers et al., 2011; Goetz et al., 2008; Goetz, Cronjaeger, et al., 2010; Goetz et al., 2012; Trautwein et al., 2009; Tempelaar et al., 2012). In this empirical examination, we build further on our previous studies (Niculescu et al., 2015a, b) to create the longitudinal aspect of changes in LREs over different course 
subjects in the first year of university. We therefore incorporate but also go beyond the changes encountered over the duration of only one course. For this purpose, we follow Buff s (2014) methodological approach to look at the relationships between changes in control appraisals and changes in LREs in a first year of university study. We first evaluated control appraisals as antecedents of LREs. Beyond that, we assessed the change-change assumption of the Control-Value Theory of Achievement Emotions (CVTAE), namely: if changes in the LRE levels were related to changes in their antecedents, the control appraisals. To provide a more complete picture of the first year of university experience, we also included distal antecedents of LRE (the prior characteristics students bring in before they enter university) as well as their potential effects on LREs and their changes.

The present study confirms first the distinctiveness of LREs in the CVTAE model. In our context of analyzing multiple LRE's, we were able to investigate if the changes in LRE's depend, beyond changes in control appraisals, on the initial levels of the same LRE only, or if any cross-over effect between the different LRE's would show up. In our empirical study, the existence of such cross-over effects was rejected: LRE's change over courses, but the change in each LRE depends only on the change in its antecedents and on its own initial level - but not on the level of other LREs. This is a strong finding given our longitudinal design of following students' LREs over a period of about nine months; this covers the period from the beginning of the academic year until the last course students enroll in. Indeed, as previously showed by Goetz et al. (2012), discrete emotions can be empirically distinguished in homework situations, and this finding holds for two different course subjects in the first year at university.

Second, in agreement with Buff s (2014) study, we found relationships between levels and change constructs. More precisely, a combination of both level of Academic Control in the first course and change in Academic Control in the second course, together with the initial level of the LRE in the first course, are able to predict changes in LREs in the second course. In a previous study (authors deleted \#2), in which we investigated the changes in LRE's within one course over a period of four weeks, we showed that two predictors were in play: changes in Academic Control over four weeks, and the initial level of the LRE, predicted changes in LREs over this period. The present study extends our previous one in two important aspects: 1) the time horizon, moving from changes within one eight-weeks course to changes over a full academic year, and 2) the subject horizon, demonstrating that identical LREs in different course subjects have a lot in common, in contrast to different LREs related to different course subjects.

Overall, our study shows that contemporary theories of emotions provide a more detailed picture of freshmen's emotional experiences at university, covering the entire first year of study. Such theories confirm classical approaches on emotional engagement - such as Tinto's (1987) perspective - in which students' experiences are an interaction between their personal characteristics and the effect of the learning environment. In a sense, this study adds to a large body of empirical research showing that Tinto was right and students do indeed build up a very strong connection to the educational institution. Through the continuity of their emotional experiences, students translate the emotional engagement they develop towards the learning environment. In other words, we can use these contemporary theories to interpret Tinto's work using an affective and emotional perspective. 
Ultimately, all these theoretical approaches can be useful in explaining and, through their empirical findings, suggest how achievement outcomes can be improved. We can conclude that the freshmen experience at university is a process of ongoing adaptation to which the higher-education institutions should pay attention throughout the entire academic year and not just the introductory period.

\section{REFERENCES}

Astleitner, H. (2000). Designing emotionally sound instruction: The FEASP-approach. Instructional Science, 28(3), 169-198.

Baker, R. W., \& Siryk, B. (1999). SACQ Student Adaptation to College Questionnaire (2 ${ }^{\text {nd }}$ ed.). Los Angeles: Western Psychological Services.

Beard, C., Clegg, S., \& Smith, K. (2007). Acknowledging the affective in higher education. British Educational Research Journal, 33(2), 235-252. http://doi.org/10.1080/01411920701208415

Buff, A. (2014). Enjoyment of learning and its personal antecedents: Testing the change-change assumption of the control-value theory of achievement emotions. Learning and Individual Differences, 31(0), 21-29. http://doi.org/10.1016/j.lindif.2013.12.007

Coffman, D. L., \& MacCallum, R. C. (2005). Using parcels to convert path analysis models into latent variable models. Multivariate Behavioral Research, 40, 235-259.

Connell, J., \& Wellborn, J. (1994). Engagement versus disaffection: Motivated patterns of action in the academic domain. Rochester, NY: University of Rochester.

Daniels, L. M., Haynes, T. L., Stupnisky, R. H., Perry, R. P., Newall, N. E., \& Pekrun, R. (2008). Individual Differences in Achievement Goals: A Longitudinal Study of Cognitive, Emotional, and Achievement Outcomes. Contemporary Educational Psychology, 33(4), 584-608.

Eccles, J. S. (2005). Subjective task value and the Ecles et al. model of achievement-related choices. In A. J. Elliot \& C. S. Dweck, Handbook of competence and motivation, pp.105-121. New York, NY: The Guilford Press.

Geiser, C. (2013). Data Analysis with Mplus. New York, NY: The Guilford Press.

Fredricks, J. A., Blumenfeld, P. C., \& Paris, A. H. (2004). School engagement: Potential of the concept, state of the evidence. Review of Educational Research, 74(1), 59-109.

Goetz, T., Cronjaeger, H., Frenzel, A. C., Lüdtke, O., \& Hall, N. C. (2010). Academic self-concept and emotion relations: Domain specificity and age effects. Contemporary Educational Psychology, 35(1), 44-58. http://doi.org/10.1016/j.cedpsych.2009.10.001

Goetz, T., Frenzel, A. C., Hall, N. C., \& Pekrun, R. (2008). Antecedents of Academic Emotions: Testing the Internal/External Frame of Reference Model for Academic Enjoyment. Contemporary Educational Psychology, 33(1), 9-33.

Goetz, T., Nett, U. E., Martiny, S. E., Hall, N. C., Pekrun, R., Dettmers, S., \& Trautwein, U. (2012). Students' emotions during homework: Structures, self-concept antecedents, and achievement outcomes. Noncognitive Skills in Education: Emerging Research and Applications in a Variety of International Contexts, 22(2), 225-234. http://doi.org/10.1016/j.lindif.2011.04.006

Goetz, T., Pekrun, R., Hall, N., \& Haag, L. (2006). Academic emotions from a social-cognitive perspective: Antecedents and domain specificity of students' affect in the context of Latin instruction. British Journal of Educational Psychology, 76(2), 289-308. http://doi.org/10.1348/000709905X42860

Hall, N. C., Perry, R. P., Ruthig, J. C., Hladkyj, S., \& Chipperfield, J. G. (2006). Primary and Secondary Control in Achievement Settings: A Longitudinal Field Study of Academic Motivation, Emotions, and Performance1. Journal of Applied Social Psychology, 36(6), 1430-1470.

Hattie, J., \& Timperley, H. (2007). The power of feedback. Review of Educational Research, 77(1), 81-112.

Hau, K. T., \& Marsh, H. W. (2004). The use of item parcels in structural equation modelling: Non-normal data and small sample sizes. British Journal of Mathematical Statistical Psychology, 57, 327-351.. Data Analysis with Mplus. New York, NY: The Guilford Press.

Jöreskog, K.G., Sörbom, D. (1996). LISREL 8 User’s Reference Guide. Scientific Software International: Chicago. 
Klem, A. M., \& Connell, J. P. (2004). Relationships matter: Linking teacher support to student engagement and achievement. Journal of School Health, 74(7), 262-273.

Linnenbrink-Garcia, L., \& Pekrun, R. (2011). Students' emotions and academic engagement: Introduction to the special issue. Students' Emotions and Academic Engagement, 36(1), 1-3. http://doi.org/10.1016/ j.cedpsych.2010.11.004

Martin, A. J. (2007). Examining a multidimensional model of student motivation and engagement using a construct validation approach. British Journal of Educational Psychology, 77(2), 413-440. doi:10.1348/ 000709906X118036

Martin, A. J. (2009). Motivation and engagement across the academic life span: A developmental construct validity study of elementary school, high school, and university/college students. Educational and Psychological Measurement, 69(5), 794-824. doi:10.1177/0013164409332214

Martin, A. J. (2011). Holding back and holding behind: grade retention and students' non-academic and academic outcomes. British Educational Research Journal, 37(5), 739-763. http://doi.org/10.1080/ 01411926.2010 .490874

Martin, A. J., \& Marsh, H. W. (2006). Academic resilience and its psychological and educational correlates: A construct validity approach. Psychology in the Schools, 43(3), 267-281. http://doi.org/10.1002/pits.20149

Martin, A. J., Papworth, B., Ginns, P., \& Liem, G. A. D. (2014). Boarding School, Academic Motivation and Engagement, and Psychological Well-Being: A Large-Scale Investigation. American Educational Research Journal, 51(5), 1007-1049. http://doi.org/10.3102/0002831214532164

Marsh, H. W., Hau, K. T., Balla, J. R., \& Grayson, D. (1998). Is more ever too much? The number of indicators per factor in confirmatory factor analysis. Multivariate Behavioral Research, 33, 181-220.

Niculescu, A., Segers, de Regt, E., \& Gijselaers, W. (2012), A Tutor Feedback Intervention in Problem-Based Learning and its Effects on Student Learning. Paper presented on the annual meeting of the American Educational Research Association, Vancouver, British Columbia, Canada, April 13 - April 17, 2012.

Niculescu, A., Tempelaar, D., Dailey-Hebert, A., Segers, M.,\& Gijselaers, W. (2014). How Structured Feedback Improves Student Performance and the Shadow Effect of Learning Emotion, International Conference of Motivation, Helsinki, Finland, June, 2014.

Niculescu, A., Tempelaar, D., Dailey-Hebert, A., Segers, M., \& Gijselaers, W. (under review). Extending the change-change model of achievement emotions: The inclusion of negative learning emotions. Learning and Individual Differences

Pascarella, E. T., \& Terenzini, R T. (1991). How college affects students: findings and insights from twenty years of research. San Francisco: Jossey-Bass.

Pascarella,E., \& Terenzini,P.(2005).How college affects students (Vol. 2): A third decade of research. SanFrancisco:Jossey-Bass.

Pekrun, R. (2000). A social-cognitive, control-value theory of achievement emotions. In J. Heckhausen (Ed.), Motivational psychology of human development: Developing motivation and motivating development. (pp. 143163). New York, NY US: Elsevier Science. Retrieved from http://search.ebscohost.com/login.aspx? direct=true\&db=psyh\&AN=2001-10168-007\&site=ehost-live\&scope=site

Pekrun, R. (2006). The Control-Value Theory of Achievement Emotions: Assumptions, Corollaries, and Implications for Educational Research and Practice. Educational Psychology Review, 18(4), 315-341. http://doi.org/10.1007/s10648-006-9029-9

Pekrun, R., Cusack, A., Murayama, K., Elliot, A. J., \& Thomas, K. (2014). The power of anticipated feedback: Effects on students' achievement goals and achievement emotions. Learning and Instruction, 29(0), 115-124. http://doi.org/10.1016/j.learninstruc.2013.09.002

Pekrun, R., Goetz, T., Frenzel, A. C., Barchfeld, P., \& Perry, R. P. (2011). Measuring emotions in students' learning and performance: The Achievement Emotions Questionnaire (AEQ). Contemporary Educational Psychology, 36(1), 36-48. http://doi.org/10.1016/j.cedpsych.2010.10.002

Pekrun, R., Goetz, T., Titz, W., \& Perry, R. P. (2002). Academic emotions in students' self-regulated learning and achievement: A program of qualitative and quantitative research. Educational Psychologist, 37(2), 91-106.

Pekrun, R., Hall, N. C., Goetz, T., \& Perry, R. P. (2014). Boredom and academic achievement: Testing a model of reciprocal causation. Journal of Educational Psychology, 106(3), 696-710. http://doi.org/10.1037/ a0036006

Perry, R. P., Hladkyj, S., Pekrun, R. H., Clifton, R. A., \& Chipperfield, J. G. (2005). Perceived Academic Control and Failure in College students: A Three-Year Study of Scholastic Attainment. Research in Higher Education, 46(5), 535-569. http://doi.org/10.1007/s11162-005-3364-4 
Perry, R. P., Hladkyj, S., Pekrun, R. H., \& Pelletier, S. T. (2001). Academic control and action control in the achievement of college students: A longitudinal field study. Journal of Educational Psychology, 93(4), 776.

Putwain, D. W., Larkin, D., \& Sander, P. (2013). A reciprocal model of achievement goals and learning related emotions in the first year of undergraduate study. Contemporary Educational Psychology, 38(4), 361-374. http://doi.org/10.1016/j.cedpsych.2013.07.003

Richardson, J. T. E. (2011). Approaches to studying, conceptions of learning and learning styles in higher education. Applying Styles Research to Educational Practice, 21(3), 288-293. http://doi.org/10.1016/ j.lindif.2010.11.015

Ruthig, J. C., Perry, R. P., Hladkyj, S., Hall, N. C., Pekrun, R., \& Chipperfield, J. G. (2007). Perceived control and emotions: interactive effects on performance in achievement settings. Social Psychology of Education, 11(2), 161-180. http://doi.org/10.1007/s11218-007-9040-0

Ruthig, J., Perry, R., Hladkyj, S., Hall, N., Pekrun, R., \& Chipperfield, J. (2008). Perceived control and emotions: interactive effects on performance in achievement settings. Social Psychology of Education, 11(2), 161180 .

Schau, C., Stevens, J., Dauphinee, T. L., \& Del Vecchio, A. (1995). The development and validation of the Survey of Attitudes Toward Statistics. Educational and psychological measurement, 55, 868-875.

Stupnisky, R. H., Perry, R. P., Hall, N. C., \& Guay, F. (2012). Examining perceived control level and instability as predictors of first-year college students' academic achievement. Contemporary Educational Psychology, 37(2), 81-90. http://doi.org/10.1016/j.cedpsych.2012.01.001

Taylor, B. (1995). Feeling, experiencing, and consciousing: diversity in the college classroom. Thresholds in Education, 22, 23-27. doi:10.1016/j.iheduc.2011.10.003

Tempelaar, D. T., Gijselaers, W. H., Schim van der Loeff, S., \& Nijhuis, J. F. H. (2007). A structural equation model analyzing the relationship of student achievement motivations and personality factors in a range of academic subject-matter areas. Applications of Latent Variable Modeling in Educational Psychology Research, 32(1), 105-131. http://doi.org/10.1016/j.cedpsych.2006.10.004

Tempelaar, D. T., Niculescu, A., Rienties, B., Gijselaers, W. H., \& Giesbers, B. (2012). How achievement emotions impact students' decisions for online learning, and what precedes those emotions. The Internet and Higher Education, 15(3), 161-169. http://doi.org/10.1016/j.iheduc.2011.10.003

Tinto, V. (1987). Leaving college, Rethinking the causes and cures of student attrition. Chicago: The University of Chicago.

Tinto, V. (1997). Colleges as communities: Exploring the educational character of student persistence. Journal of Higher Education, 68(6).

Trautwein, U., Schnyder, I., Niggli, A., Neumann, M., \& Lüdtke, O. (2009). Chameleon effects in homework research: The homework-achievement association depends on the measures used and the level of analysis chosen. Contemporary Educational Psychology, 34(1), 77-88. http://doi.org/10.1016/j.cedpsych.2008.09.001 

CHAPTER 6

General Discussion

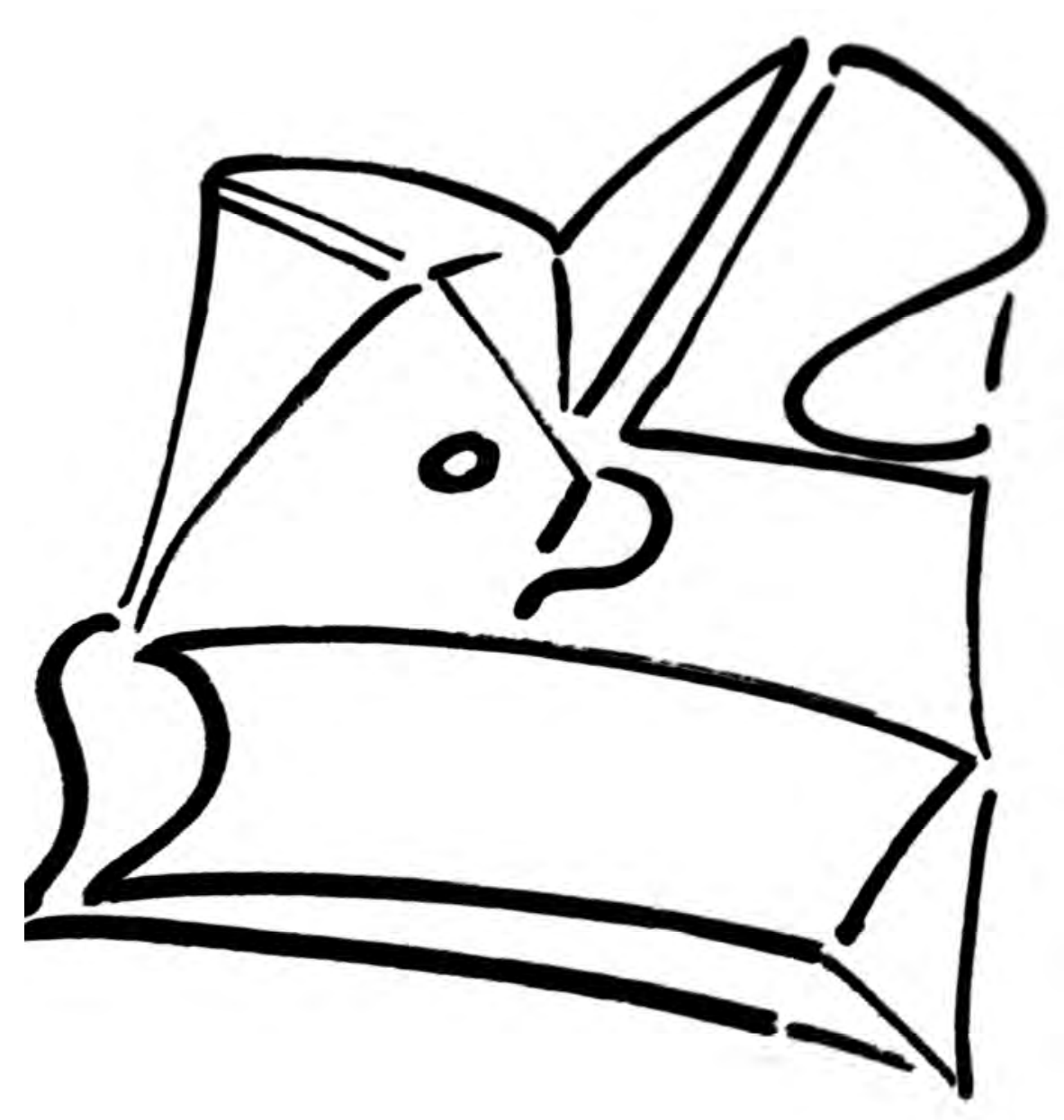

107 


\section{A NEW PERSPECTIVE ON HIGHER EDUCATION}

Today's higher education faces challenges that are without precedent. One of these challenges is how to make education itself successful. As early as 1997, the United Kingdom Department of Education was describing education in its White Paper, "Excellence in Schools", as a "vital investment in human capital for the twenty-first century" and was arguing that "one of the problems in education is the low expectations of young people's abilities and that it is essential to raise morals, motivation and self-esteem in schools" (as cited in The National Advisory Committee on Creative and Cultural Education, 1998, p. 5). Beyond common sense issues of literacy and numeracy, the White Paper also acknowledged that in order to meet the challenges that face education it is essential to change its current perspectives:

"If we are to prepare successfully for the twenty-first century we will have to do more than just improve literacy and numeracy skills. We need a broad, flexible and motivating education that recognises the different talents of all children and delivers excellence for everyone. " (as cited in The National Advisory Committee on Creative and Cultural Education, 1998, para. 1)

This statement equally holds true for higher education today and meeting these challenges calls for new perspectives. They include changing old paradigms about how do understand the role of the student, the responsibility of the educational environment and how do we design curricula and hand over teaching that accommodate the current needs of the student and the requirements of today's job market. We have argued in the introduction of this thesis that the old paradigms are still in place and govern the way higher education institutions function: the students are placed less and less at the core of the educational systems while, at the same time, they are made solely responsible for their own learning (Barab \& Plucker, 2002; Boud, 2006). Based on traditional views on learning, ability and intelligence - which consider that these characteristics are placed "in the head of the learner" (Barab \& Plucker, 2002, p.166), we gave reasons to believe that these paradigms are: 1) outdated and, 2) isolated from the educational context in which the learning takes place. In other words, learning and implicitly, the well-acclaimed academic success, seem to be traditionally seen as a collection of single-moment personal experiences, instead of a process which occurs while interacting with the educational environment. In the introduction of this thesis, we highlighted on the former lines, that success is a function of the individual placed in a certain achievement context that is favourable for learning and engagement. We argued then that in order to understand success, it is necessary to examine the interaction between the learner and the environment.

One of the first ground-breaking works which acknowledged the interaction between the student and the educational environment was Tinto's (1987) Theory of Institutional Departure. Tinto (1987) described student integration and engagement as a continuous process of adaption, also called adjustment, to the institution. In his view, academic, social and personal-emotional adjustment - in contrast to academic departure or dropout, were a degree to which the student fitted the educational environment. An important note is that Tinto's work was inspired from Durkheim's (1897) sociological study of suicide, who was 
the first to argue that the causes of suicide were to be found in social factors and not individual personalities. Tinto draw a parallel between dropout and suicide, in a similar way that Durkheim looked at the degree to which individuals feel integrated into the structure of society and their social surroundings as factors inducing suicide, to argue that suicide is affected by the social context in which it emerges. Although the term "suicide" might sound too extreme for an academic discourse, the parallel is actually fitting: In Tinto's view, academic departure was a form of "social suicide", in which the individual gave up the institution because he could not adjust to, and was not supported by the educational environment.

Maybe one of the most salient forms of withdrawal in today's higher education institutions is emotional. It is a long time before the seat is actually left empty, that the student has already disengaged emotionally. This is even more alarming, as most students actually have the intellectual abilities to perform academically. But to succeed academically and further in life, being smart is not enough. Above being able to digest abstract knowledge, it requires persistence, discipline (Duckworth \& Seligman, 2005), maintaining motivation and an overall positive mood over long periods of time (Stipek, 2011) in which gratification is often delayed. Going beyond what makes students successful, the question we tried to answer in the present thesis was how could we meaningfully engage the students in their learning process?

\section{MAIN FINDINGS}

Using contemporary perspectives on motivation and emotions (Martin, 2007; Pekrun, 2006), the present work interprets the classic emotional adjustment (Tinto, 1987) problem to get more insight into freshmen's experiences at university. Overall, we tried to show how the individual experiences the new pedagogical environment through the interaction with the characteristics a person brings in a new setting of first year at university. Understanding this interaction allows the possibility to formulate practical strategies for intervening on students' characteristics which are changeable such as the way the educational environment is appraised and reacted emotionally upon..

We used Pekrun's (2006) framework as the leading approach and built further on the work of Tempelaar et al. (2012) which acknowledges the importance of achievement motivation and emotion on learning when students enter university. Furthermore, we followed (Buff, 2014) methodological approach to look at the relationships between changes in control appraisals and changes in achievement emotions over the first-year at university. To provide a more complete picture of the first year of university experience, we also included distal antecedents of achievement emotions (the prior characteristics students bring with them before they enter university) from Martin's $(2007,2009)$ framework and their potential effects on these emotions and their changes. We looked in particular at achievement emotions experienced in learning-related situations within a course, a setting particularly relevant for this difficult period of transition. Finally, our work linked the learning-related emotions (LREs) with achievement outcomes at the course level.

Over four different studies described in Chapters 2 - 5 of this thesis, we asked the main research question: How do achievement learning-related emotions and their direct and 
distal antecedents explain students' achievement in the first year at university? For this purpose we used a large sample $(\mathrm{N}=3451)$, employed in a longitudinal design that included two courses, covering the time span between the beginning until the end of the first year at university. More specifically, the first three chapters looked at freshmen's emotional experiences in learning situations within an introductory mathematics and statistics course, a subject notoriously known as abstract and difficult for most students. In Chapter 2 we tried to show that achievement emotions - when compared with other classic measures of emotional engagement (such as Tinto's adjustment, for example) are better able to predict learning outcomes at the course level. To validate our findings, this study used three cohorts of students $(\mathrm{N}=2337)$ measured in different academic years within the same course. Chapter 3 went further to explain how LREs emerge from direct and distal antecedents and how all these factors together are able to explain achievement outcomes within the same course. For this study we used an integrated theoretical framework linking control appraisals as direct antecedents (from Pekrun's framework) with prior characteristics students bring in before entering university as distal antecedents (from Martin's framework). Chapter 4 brought in the time dimension of how appraisals and emotional experiences change within the course. This study looked beyond the average changes in our sample, regarding the control appraisals and LREs; it looked for individual differences which could be observed in divergent longitudinal developments within different groups of students. Finally, Chapter 5 sought to show how LREs emerge and further develop in the first year of university. This last study extended the previous ones in two important aspects: 1) the time horizon, moving from changes within one course to changes over a full academic year, and 2) the subject horizon, to include two course subjects. The results of each chapter are outlined below.

Chapter 2 first looked at the role of LREs in predicting achievement outcomes in the first year of university. Most notably, we found that learning hopelessness, together with a previous mathematics background, were able to predict substantially academic achievement. More concretely, higher hopelessness predicts a lower grade while having a Mathmajor background leads to a higher grade. Furthermore, this relation was confirmed over different cohorts in three consecutive academic years. The first finding, that having a previous mathematics background in high-school enabled students to obtain a higher grade was indeed to be expected: recent studies have already confirmed this finding (Alexander, 2005; Tempelaar et al., 2012). However, showing a negative emotion, Hopelessness, as the strongest predictor of academic achievement was an important outcome that deserves further elaboration. On one hand, it aligns with the studies of Dettmers et al. (2011) and Trautwein et al. (2009) which showed that indeed negative emotions during homework predict negative achievement. On the other hand, it differs from these studies in two regards: these authors used either single items (Dettmers et al., 2011) or composite measures of negative emotions including anger, anxiety and boredom (Trautwein et al., 2009). In this study, we showed that discrete learning hopelessness - measured with multiple items were the strongest factor for achievement in mathematics and statistics.

Chapter 2 looked secondly at differences in LREs between students who attended, as compared to those who were absent for the first round of final examination. In line with earlier studies (Ruthig et al., 2008), it was found that students who were absent for the 
exam experienced less enjoyment, more anxiety, more boredom and more hopelessness than the students who attended the final exam.

Next, Chapter 3 showed how distinct LREs emerge from course contextualized and generic antecedents and further, how they influence achievement outcomes in a first year university mathematics and statistics course. The main findings of this study brought forth the emergence of four distinct LREs (Enjoyment, Anxiety, Boredom and Hopelessness) and the fact that they standalone from students' individual performance. Such findings are reassuring: although LREs are important, they are not blocking students to perform academically. More importantly, the relations between LREs and performance were rather weak when taking into account their antecedents. In other words, while LREs share a relevant contribution to how students perform academically, the most important role is held by their appraisal of control towards success in this course. Especially, we saw that Academic Control played a central role in the development of the four LREs investigated in our study as well as for what regarded its impact on the performance outcomes in the course. Next, Academic Control had a strong effect on all of the four LREs with the strongest impact observed for Hopelessness (-.65) and secondary, for Anxiety (-.54) and Enjoyment (.53). The model explaining the four LREs was again of mediational type. Beyond the indirect effect through the control appraisal, there were direct effects from the four second order MEW factors (adaptive and maladaptive cognitions and behaviours) to the LREs.

Academic Control, on one hand, built on contributions from adaptive and maladaptive cognitions solely, where the main impact was explained by the Uncertain Control dimension of impending cognitions. On the other hand, adaptive cognitions had a positive impact on Enjoyment and a negative one on Boredom. Where impeding cognitions confirmed the hypotheses of positive relationship with the negative emotions, surprisingly though, the maladaptive behaviours impacted the LREs positively for Enjoyment and negatively for Anxiety. It seemed that amongst students scoring high on maladaptive behaviour (amongst them an over-representation of male students), there existed a dislike of the learning activities (increased levels of Boredom), but not of the learning content: high Enjoyment, low Anxiety. With respect to the implications on performance outcomes, the most consistent role was played by Academic Control; this was followed by Hopelessness (with the exception played for Bonus as detailed earlier). At last, an important role was also played by Enjoyment: it had opposite impact for Math (positive) and Stats (negative) performance.

The findings from Chapter 3 were consistent with earlier research on the central role of control appraisals in the emergence of achievement emotions (Pekrun et al., 2002; Perry et al., 2001) as well predicting performance at the course level (Hall et al., 2006). Chapter 3 also provided support for the positive relations between impeding cognitions and negative emotions (Martin \& Marsh, 2006). Conversely, it extended such evidence by showing maladaptive behaviours influencing positively Enjoyment and negatively Anxiety.

Chapter 4 used a repeated measures design to: 1) look at how LREs emerged from control appraisals and, 2) investigate if changes in control appraisals were related to changes in both positive and negative LREs in a mathematics and statistics course. For the first hypothesis we expected the level of Academic Control at the first measurement (time 1) to be positively related to the level of the positive LRE of Enjoyment, and negatively related to 
the levels of the negative LREs Boredom, Hopelessness, and Anxiety. Our analyses confirmed this. Next, we found that the levels of LREs as well as of Academic Control remained, on average, stable over the duration of the course. Drawing a parallel with the Goetz et al. (2012) study, our work showed that, in comparison to secondary education, first year students experienced higher levels of enjoyment but also more anxiety and boredom while learning for mathematics and statistics.

The second hypothesis of the study described in Chapter 4 stated that changes in Academic Control to be positively related to changes in the positive LRE of Enjoyment, and negatively related to changes in the negative emotions. This was indeed confirmed. Next, in agreement to Buffs (2014) study, we found relationships between levels and change constructs. More specifically, how Enjoyment changed over the course was related to its initial level. This also held true for the three negative LREs Boredom, Hopelessness and Anxiety: their changes at the end of the course were explained by their staring levels. The change in Academic Control however, was not related to its initial value. Our outcome was, as expected, in line with the Control Value Theory of Achievement Emotions (CVTAE; Pekrun, 2006) and, confirmed the theory in this respect.

Chapter 5 used a longitudinal design to follow how LREs change in the first year of university over two course subjects to: 1) look at how LREs emerged from control appraisals, as direct antecedents, and, adaptive and maladaptive cognitions and behaviors, as distal antecedents; and 2) investigate if changes in control appraisals were related to changes in both positive and negative LREs over the two courses.

It was first found that LREs were indeed distinct concepts: emotions in one course predicted the same emotions in another subject, and did not cross-over to other emotions. Furthermore, there was a lot of continuity in the emotional experiences in learning situations over time, meaning that LREs in one course were stronger related when compared to the influence of the other factors. Based on the evidence provided in this study, we were able to confirm that LREs in the first year of university are indeed contextualized experiences, where prior characteristics that students possess when they enter university are important to a lesser degree.

Second, Chapter 5 showed that emotional experiences during learning within a certain course subject were determined by beliefs about control within the same course, which in turn influenced: 1) later experiences within another course and, 2) how these experiences may change over the first year at university. This finding was in accordance with the CVTAE that indeed achievement emotions influence each other over time, in a feedback loop which goes beyond one course setting.

\section{MAIN CONTRIBUTIONS}

Chapter 2 provides extra empirical evidence on the role of role of achievement emotions experienced in learning-related situations on learning outcomes in an introductory mathematics and statistics course. To our best knowledge, only few studies in first year samples (Putwain, Larkin et al., 2013) tried to prove similar relations (Putwain, Sander et al., 2013; Tempelaar et al., 2012). Next, this research tried to identify the differences in emotional experiences between students who attended as compared to those who were absent at the 
final exam. What was particularly relevant was that these differences were already visible in week four, half-way through the course. This knowledge offers the opportunity to intervene early in an educational setting, using these emotions as potential indicators for early withdrawal at the course level.

Chapter 3 extends on the Control Value Theory of Achievement Emotions (Pekrun, 2006) by integrating the distal antecedents of emotions from the Motivation and Engagement Wheel (MEW) framework (Martin, 2007). The added value of integrating both direct and distal antecedents into one framework is to explain: 1) the emergence of distinct emotions through direct antecedents, and 2) through distal antecedents, the individual differences that arise in learning emotions when students enrol in a course. Most notably, to the knowledge of the authors, this study was the first of its kind in using an integrated framework to ultimately explain achievement outcomes in the first year at university. We have provided a new approach to understand students' emotional experiences when they first enter a university study. In this respect, the two theories were complementary: on one side our results were an empirical validation of the CVTAE; on the other side, the concepts operating in the MEW framework could provide practical solutions on how to facilitate educational change in the classroom by using the influence these variables have in the experience of emotions.

Chapter 4 builds upon Buff s (2014) approach by including negative, as well as positive multiple LREs to further test the assumption that negative LREs also change over time in line with the CVTAE change-change hypothesis. It is important to mention that change relations between control appraisals and LREs were explored only by Buff (2014) in a sixth graders sample and for the single, positive LRE of enjoyment only. While homework emotions within the mathematics domain have already been compared for eight and eleventh graders (Goetz et al., 2012), only limited research has been conducted in the first year at university (Putwain et al., 2013; Tempelaar et al., 2012). Furthermore, to our best knowledge, no previous contributions have captured the change-change assumption in a mathematics and statistics domain among freshmen at university. Therefore, this study provided compelling evidence on how the changes in negative LREs and their appraisal antecedents are related. As a consequence, Chapter 4 offers valuable knowledge on how the levels of negative emotions can be decreased.

Chapter 5 went beyond the course level to create the longitudinal aspect of changes in LREs over different course subjects in the first year of university. We therefore incorporated but also went beyond the changes encountered over the duration of only one course, which is a novelty in its own. Overall, this study shows that contemporary theories of emotions provide a more detailed picture of freshmen's emotional experiences at university, covering the entire first year of study. Such theories confirm classical approaches on emotional engagement - such as Tinto's (1987) perspective - in which students' experiences are an interaction between their personal characteristics and the effect of the learning environment. In a sense, this last study adds to a large body of empirical research showing that Tinto was right and students do indeed build up a very strong connection to the educational institution. 


\section{RECOMMENDATIONS FOR EDUCATIONAL PRACTICE}

The results of this thesis become particularly relevant when considering how they can be translated into everyday practice. Accordingly, this could help both students as well as educators in participating to- and co-creating what has been previously referred to as "emotionally sound" educational environments (Astleitner, 2005). As outlined before, there is an urgent need for educational interventions which accommodate students' emotions in their own learning process as well as in pedagogy (Astleitner, 2000). After all, handling students' emotions is an essential yet, one of the most difficult challenges in educational settings. We would like to further refer to Taylor's (1994) concept of emotionally sound instruction which "consists of instructional strategies to increase positive and decrease negative feelings during regular instructional settings" (Astleitner, 2000, p. 173). In line with this philosophy and based on the findings described in the chapters of this thesis, recommendations for improving educational practice are formulated and shared in this section.

In Chapter 2, the first finding refers to the role of hopelessness in how students perform academically. From this perspective, educational interventions could focus particularly at decreasing its intensity - as early as possible in a course - as hopelessness is an outcomefocused, prospective emotion which needs time to develop over a course. There is consensus that emotions can be influenced through their antecedents (Pekrun et al., 2006), so hopelessness could be indirectly targeted at this level. For instance, in a previous study (Tempelaar et al., 2012) we focused on epistemological views about effort in mathematics and statistics course - a component of the implicit theories of intelligence model (Dweck, 1999) - as distal antecedents of achievement emotions (Tempelaar et al., 2012). We concluded that negative effort views - the belief students hold towards exerting effort as something which signals lacks of intelligence, therefore negative - had a substantial impact on learning hopelessness (as expressed in a $\beta$ estimate of .86). Effort beliefs however, are in Dweck's (1990) view still malleable and can be intervened upon. Future interventions could address an antecedent such effort beliefs, in a try to prevent the development of hopelessness over a mathematics and statistics course.

The second finding of Chapter 2 refers to the role of previous knowledge, having been previously educated in mathematics, in how students perform in the course. In this respect, effective interventions are known in helping students' performance by improving their prior knowledge (Rienties et al., 2008). Rienties et al. (2008) designed a series of online remedial programs especially for prospective first year students at university. One of these interventions was conducted in a mathematics course and showed that is possible to improve deficient prior knowledge of students before entering the university. The effects were shown on both short term on student performance in the course, and on long term on study success in the first year at university. Educational practice could adopt such programs given their proved effectiveness in improving student success as well as for their costeffectiveness.

As a general recommendation to consider from Chapter 3 would be that any educational interventions in the classroom should foster students' sense of competency towards the specific learning activities required in a mathematics and statistics course. If such progress is acquired, then reinforcing - by means of feedback - the certainty of control over 
the activities and outcomes in which students engage is key. Increasing students enjoyment and decreasing their hopelessness seems intuitive, still these measures should be regarded in context together with the factors from which they emerge, the maladaptive behaviours. If emotions are more difficult, and less desirable, to influence directly, addressing students appraisal of control and maladaptive behaviours, such as disengagement and selfsabotaging, could be an alternative solution.

The results of Chapter 4 suggest the possibility to intervene on emotions in educational settings through their antecedents. First, in this regards, it is already theoretically assumed (Pekrun, 2006) and empirically confirmed (Pekrun et al., 2014) that achievement feedback can impact both directly and indirectly students' achievement emotions. Next, it would be particularly important to identify which other type of feedback has an effect on emotions and for which type of students (for example based on the exhibited change profiles) a certain type of feedback would be more efficient. From this perspective, there is ample evidence on the power of feedback in achievement and the various levels at which the feedback can be formulated (Hattie \& Timperley, 2007). However, the efficiency of feedback is known to depend on certain conditions. Such conditions could be very well described in terms of how students feel and appraise the situations in which they learn at university. For instance, in our course re-design interventions, we showed that students' performance in various courses can be improved by providing both process- and task-related team feedback (Niculescu et al., 2012, 2014). In one of these experiments (Niculescu et al., 2014), conducted in a first year university mathematics and statistics course, we showed that if students were already experiencing intense negative emotions, these factors could confound the effect of tutor' feedback on individual performance. Drawing from this knowledge, a future feedback strategy that may prove effective could be also targeted at students' sense of competence or mastery towards tasks that need to be performed outside the classroom. In other words, such interventions should try to engage more meaningfully the students with their homework and assignments in an attempt to ensure enough competency over tasks and future attendance in the classroom and tutorials.

Finally, the findings described in Chapter 5 point towards an important consideration for educational practice, which is that appraisals and emotions are not only end states but 'they have a continuity over the first year at university, which relates to students' later academic achievement (Goetz, Pekrun, Hall, \& Haag, 2006; Pekrun, Cusack, Murayama, Elliot, \& Thomas, 2014; Pekrun, Hall, et al., 2014). In this respect, we remind the reader Taylor's (1994) concept of "emotionally sound instruction". This type of philosophy, which takes into account how student appraise the educational situations, their emotional experiences and motivational processes, could accommodate their uncertainty and lack of confidence in the first year of study, a very complex period at university. Furthermore, such approach goes beyond improving only students' knowledge and performance to also include the affective aspects of their experience. For this purpose, we refer to an intervention we run in an Economics course, in which we showed that the frequency of providing feedback together with the amount of attendance in the course could improve exam performance (Niculescu et al., 2012). This intervention showed that with minimum but persistent effort, observable gains can be attained in how students perform as well as how much they get involved in the course. Overall, we suggest that these types of educational interven- 
tions actually point to our initial question: to go beyond how we can improve student achievement to how we can engage more the student in its own learning process.

\section{LIMITATIONS AND FURTHER RESEARCH}

Our studies used ecological designs to make a good case for the value of LREs in learning and academic achievement in the first year at university. For this purpose we used a large sample $(N=3451)$, employed in a longitudinal design that included two courses, covering the time span between the beginning until the end of the first year at university. However, as with any new design, several limitations exist.

First, in the study described in Chapter 2, we measured LREs midway through the course, assuming that they would remain relatively stable. Although students need a minimum period to get an impression of the new educational environment, we cannot be sure whether assessing their emotional experiences earlier in the course could have also proven to be useful for a reliable prediction of outcomes. Future research could make use of an earlier assessment and test the individual stability of students' emotional experiences; this could be used to longitudinally predict if students will attend the final exam and, for those who will, explain their performance in the course.

Second, the LREs measures (assessed through self-reports) described in Chapter 3 rely heavily on retrospective beliefs about emotions, which, unlike more physiological measures, make them subject to the same biases as the self-appraisals (Robinson \& Clore, 2002). At the same time, self-reports still remain the most reliable measure (Zeidner, 1998) and, for that reason - the most extensively used approach, which is able to capture in a non-invasive manner students' emotional experiences in an educational setting.

Third, concerning the study from Chapter 4, we measured LREs at time 1, midway through the course, and at time 2 three weeks after the first measurement and one week before the exam. Two potential limitations might have appeared as a consequence of such a time line: first, we cannot be sure whether the period between the two measurements was too short to capture major changes in the development of the constructs. Second, the time 2 measurement which occurred in week 7 might have been too close to the exam week. Therefore, we cannot fully exclude that students' LREs might have been contaminated with anticipated emotions about the exam (test emotions). As stated above, although students need a minimum period to get an impression of the course, assessing their emotional experiences earlier in the course could have also proved to be useful.

Forth, in Chapter 5 we tried to get insight into students' emotional experiences in the first year of university while looking at the change in control appraisals and learning-related emotions over two courses covering the beginning and the end of the academic year. In order to understand more of freshmen experiences in this context, future research might also incorporate a third assessment - half-way the year - which could prove useful in capturing the change in emotions and appraisals in between the beginning and the end of the first year at university.

Finally, we would like to elaborate on a few methodological issues which deal with the generalisability of our findings. In a first instance all studies have been conducted in one university. This is a specific educational environment with particular features, such as: a 
large proportion of Dutch and foreign (mostly German) students, using English as the main educational language and Problem Based Learning (PBL) as its instructional approach. From this reason, extending our results over other universities in Europe, which use traditional forms of instruction in native languages should be taken into account. Second, we only included students from business and economics. With respect to this aspect, the results from this thesis are especially important for the first year of study in this discipline. We are aware that the same conclusions can't be extended over other samples And third, our choice of subjects was restricted to quantitative courses. Although this may pose an in initial limitation in the generalisation of our findings over different subjects, these courses remain relevant for being particularly difficult and abstract to a large majority of freshmen.

\section{CONCLUDING THOUGHTS}

So where are we now? In order to enhance academic success and prevent dropout, we started this thesis by asking how could we meaningfully engage the students in their learning process? A central assumption underlying our work was that success is not an individual trait but the result of an interaction process between the student and the conditions offered by the educational environment. We consider this an important consideration, as it seems that for many years in educational research, still dominated by the post-Cartesian dualism line of thought (Barak \& Plucker, 2002), it was believed that most efforts should be focused on changing the student. As a consequence, a common belief encountered in practice is that when students fail, they are not smart, prepared or motivated enough. They are just not enough. And this is a true fact: students, disconnected from the contexts in which they learn (Snow, 1992), are not enough in the equation of success (Lave, 1997). But to overcome this conceptual limitation, " it requires us to give up our normal ways of thinking and behaving, which is easier said than done” (Hagen, 2013, p. 168). To accomplish such a requirement, it would first be necessary to shift the responsibility placed on the student to the educational environment - in the sense of creating the right conditions for learning and success to occur (Barak \& Plucker, 2002). Indeed, as stated by the same authors: "this initiation cannot be handed to the student all at once” (Barak \& Plucker, 2002, p. 175). Furthermore, "a central responsibility of the educators is to engage students in experiences that expand their functioning (...). Educators do not design learning or talented individuals; instead, they design contexts for engaging talent development and support successful participation" (Barak \& Plucker, 2002, p. 175).

The assumption outlined in this thesis, that academic success is not an ability existing within the student, is supported by a few contemporary theories on intelligence and ability (Ceci, 1990; Gardner, 1983; Sternberg, 1985). Ceci' s (1990) bio-ecological treatise on intellectual development, Sternberg's (1985) triarchic theory of intelligence and Gardner's (1983) theory of multiple intelligence, all discuss the role of the environment and the application of intelligence in the interaction which comes with this context. Maybe even more challenging is Goleman's (1995) theory on emotional intelligence, which offers a totally different perspective on the abstract way of looking at this concept. What Goleman brings new is that it provides insight on why the traditional high IQ is no guarantee for success. In addition, he points to the fact that the "two minds" - the rational and the emotional- 
(Goleman, 1995) are only different facets of the same coin we call intelligence. From this perspective, it can be said that Goleman's main contribution is that he proposes a different way about what does it mean to be smart, which doesn't exclude but integrate the emotional mind.

This brings our discussion to the next level, where cognition is not separated from emotion. Indeed, contemporary theory of emotions (Pekrun, 2006; Scherer, 2000) describe them as "sets of interrelated psychological processes including affective, cognitive, physiological and motivational components" (Pekrun et al. 2011, p. 37). In particular, research on achievement emotions prompts a re-appraisal of the classical models to address the student experience and engagement within a specific course context (Pekrun, Goetz, Titz, \& Perry, 2002). In this perspective, the learning behavior is driven by personal factors which interact with determinants at the course level to ultimately affect students' emotional experiences and achievement outcomes. Furthermore, as we have seen from the results of this thesis, both positive and negative emotions, are necessary for students' motivational reinforcement and academic performance to occur. Overall, what our work suggests is that cognition (we referred to it as appraisals) and emotion (both negative and positive) together are part of the same learning mechanism which ultimately explains academic success.

All the aspects outlined above are relevant for designing the so-called "emotionally sound education" that can foster academic success and prevent dropout, as we have referred to in the previous chapters of this dissertation. Dropout, in fact, as Ken Robinson (2013) debated:

"is just the tip of an iceberg. What it doesn't count are all the kids who are in school but being disengaged, who don't enjoy it, who don't get any real benefit from it. And the reason is not that we don't spend enough money on it. The trouble is that it's all going in the wrong direction. "(Robinson, 2013, "How to escape education's death valley", para. 4)

After all, education is about learning beyond all testing and measuring tools currently used to standardize and, in fact, reduce student success to a quantitative variable. What we suggest from this work is to go beyond mechanistic views about training students only how to become academic smarter in a hope that they will also become successful, to embracing the view that there are certain conditions under which smart students can become successful. In the light of our research, these conditions include giving student' emotions the same status in learning as we give to their cognitions.

So, in the end, when is education successful? What is the meaning of education? What does it mean to be successfully educated? Our work implies that success does not depend on finding the Holy Grail of interventions which will make students learn instantly and effortlessly, magic interventions that can transform "failures" into "top performers". It's about going back to what we have forgotten. Something which it's hidden in plain sight: that students are human beings. Based on our findings, we suggest that teachers, curriculum designers and education as a system in general, should also care about how students feel. On top of providing them with the necessary yet not sufficient content knowledge, it's about teaching them how to think while still experiencing their emotions (both positive and negative) towards the learning process. We propose that meaningful education should provide students with knowledge that is powerful not only intellectually. It should give 
knowledge that has authority because it touched their passions, interests, beliefs and values - knowledge that can be applied from school to home and further, in life.

\section{REFERENCES}

Alexander, P. A. (2005). Psychology in learning and instruction. Prentice Hall.

Astleitner, H. (2000). Designing emotionally sound instruction: The FEASP-approach. Instructional Science, 28(3), 169-198.

Barab, S. A., \& Plucker, J. A. (2002). Smart people or smart contexts? Cognition, ability, and talent development in an age of situated approaches to knowing and learning. Educational Psychologist, 37(3), 165-182.

Buff, A. (2014). Enjoyment of learning and its personal antecedents: Testing the change-change assumption of the control-value theory of achievement emotions. Learning and Individual Differences, 31(0), 21-29. http://doi.org/10.1016/j.lindif.2013.12.007

Ceci, S. J. (1990). On intelligence-more or less: A bio-ecological treatise on intellectual development. Englewood Cliffs, NJ: Prentice Hall

Dettmers, S., Trautwein, U., Lüdtke, O., Goetz, T., Frenzel, A. C., \& Pekrun, R. (2011). Students' emotions during homework in mathematics: Testing a theoretical model of antecedents and achievement outcomes. Students' Emotions and Academic Engagement, 36(1), 25-35. http://doi.org/10.1016/j.cedpsych.2010.10.001

Duckworth, A. L., \& Seligman, M. E. P. (2005). Self-Discipline Outdoes IQ in Predicting Academic Performance of Adolescents. Psychological Science, 16(12), 939-944. http://doi.org/10.1111/j.1467-9280.2005.01641.x

Durkheim, E. (1897). Le suicide: étude de sociologie. Alcan.

Dweck, C. S. (1999). Self-theories: Their role in motivation, personality, and development. Philadelphia: Psychology Press

Gardner, H. (1983). Frames of mind: The theory of multiple intelligences. New York: Basic Books

Goetz, T., Nett, U. E., Martiny, S. E., Hall, N. C., Pekrun, R., Dettmers, S., \& Trautwein, U. (2012). Students' emotions during homework: Structures, self-concept antecedents, and achievement outcomes. Noncognitive Skills in Education: Emerging Research and Applications in a Variety of International Contexts, 22(2), 225-234. http://doi.org/10.1016/j.lindif.2011.04.006

Goleman, D. (1995) Emotional Intelligence, New York, NY, England: Bantam Books, Inc.

Hagen, J. (2015). Confronting Mistakes. Basingstoke: Palgrave Macmillan. Retrieved from http://dx.doi.org/ $10.1057 / 9781137276186$

Hall, N. C., Perry, R. P., Ruthig, J. C., Hladkyj, S., \& Chipperfield, J. G. (2006). Primary and Secondary Control in Achievement Settings: A Longitudinal Field Study of Academic Motivation, Emotions, and Performance1. Journal of Applied Social Psychology, 36(6), 1430-1470.

Hattie, J., \& Timperley, H. (2007). The power of feedback. Review of Educational Research, 77(1), 81-112.

Lave, J. (1997). The culture of acquisition and the practice of understanding. In D. Kirshner \& J. A. Whitson (Eds.), Situated cognition: Social, semiotic, and psychological perspectives (pp. 17-36). Mahwah, NJ:

Lawrence Erlbaum Associates, Inc

Martin, A. J. (2007). Examining a multidimensional model of student motivation and engagement using a construct validation approach. British Journal of Educational Psychology, 77(2), 413-440. http://doi.org/10.1348/ 000709906X118036

Martin, A. J. (2009). Motivation and engagement across the academic life span: A developmental construct validity study of elementary school, high school, and university/college students. Educational and Psychological Measurement, 69(5), 794-824. doi:10.1177/0013164409332214

Martin, A. J., \& Marsh, H. W. (2006). Academic resilience and its psychological and educational correlates: A construct validity approach. Psychology in the Schools, 43(3), 267-281. http://doi.org/10.1002/pits.20149

Martin, A. J., Papworth, B., Ginns, P., \& Liem, G. A. D. (2014). Boarding School, Academic Motivation and Engagement, and Psychological Well-Being: A Large-Scale Investigation. American Educational Research Journal, 51(5), 1007-1049. http://doi.org/10.3102/0002831214532164

Niculescu, A., Segers, de Regt, E., Gijselaers, W. (2012), A Tutor Feedback Intervention in Problem-Based Learning and its Effects on Student Learning. Paper presented on the annual meeting of the American Educational Research Association, Vancouver, Canada, April 2012. 
Niculescu, A., Tempelaar, D., Dailey-Hebert, A., Segers, M.,\& Gijselaers, W. (2014). How Structured Feedback Improves Student Performance and the Shadow Effect of Learning Emotion, International Conference of Motivation, Helsinki, Finland, June, 2014.

Pekrun, R. (2006). The Control-Value Theory of Achievement Emotions: Assumptions, Corollaries, and Implications for Educational Research and Practice. Educational Psychology Review, 18(4), 315-341. http://doi.org/10.1007/s10648-006-9029-9

Pekrun, R., Cusack, A., Murayama, K., Elliot, A. J., \& Thomas, K. (2014). The power of anticipated feedback: Effects on students' achievement goals and achievement emotions. Learning and Instruction, 29(0), 115-124. http://doi.org/10.1016/j.learninstruc.2013.09.002

Pekrun, R., Goetz, T., Frenzel, A. C., Barchfeld, P., \& Perry, R. P. (2011). Measuring emotions in students' learning and performance: The Achievement Emotions Questionnaire (AEQ). Contemporary Educational Psychology, 36(1), 36-48. http://doi.org/10.1016/j.cedpsych.2010.10.002

Pekrun, R., Goetz, T., Titz, W., \& Perry, R. P. (2002). Academic emotions in students' self-regulated learning and achievement: A program of qualitative and quantitative research. Educational Psychologist, 37(2), 91-106.

Pekrun, R., Hall, N. C., Goetz, T., \& Perry, R. P. (2014). Boredom and academic achievement: Testing a model of reciprocal causation. Journal of Educational Psychology, 106(3), 696-710. http://doi.org/10.1037/a0036006

Perry, R. P., Hladkyj, S., Pekrun, R. H., \& Pelletier, S. T. (2001). Academic control and action control in the achievement of college students: A longitudinal field study. Journal of Educational Psychology, 93(4), 776.

Putwain, D., Sander, P., \& Larkin, D. (2013). Academic self-efficacy in study-related skills and behaviours: Relations with learning-related emotions and academic success. British Journal of Educational Psychology, 83(4), 633-650. http://doi.org/10.1111/j.2044-8279.2012.02084.x

Putwain, D. W., Larkin, D., \& Sander, P. (2013). A reciprocal model of achievement goals and learning related emotions in the first year of undergraduate study. Contemporary Educational Psychology, 38(4), 361-374. http://doi.org/10.1016/j.cedpsych.2013.07.003

Putwain, D. W., Sander, P., \& Larkin, D. (2013). Using the $2 \times 2$ framework of achievement goals to predict achievement emotions and academic performance. Learning and Individual Differences, 25(0), 80-84. http://doi.org/10.1016/j.lindif.2013.01.006

Rienties, B., Tempelaar, D., Dijkstra, J., Rehm, M., \& Gijselaers, W. (2008). Longitudinal Study of Online Remedial Education Effects. In N. Barsky, M. Clements, J. Ravn, \& K. Smith (Eds.), The Power of Technology for Learning (Vol. 1, pp. 43-59). Springer Netherlands. Retrieved from http://dx.doi.org/10.1007/978-14020-8747-9_3

Robinson, K. (2013). How to escape education's death valley (Video webcast). Retrieved April 1, 2015, from http://www.ted.com/talks/ken_robinson_how_to_escape_education_s_death_valley

Robinson, M. D., \& Clore, G. L. (2002). Belief and feeling: Evidence for an accessibility model of emotional selfreport. Psychological Bulletin, 128(6), 934-960. http://doi.org/10.1037//0033-2909.128.6.934

Ruthig, J. C., Perry, R. P., Hladkyj, S., Hall, N. C., Pekrun, R., \& Chipperfield, J. G. (2007). Perceived control and emotions: interactive effects on performance in achievement settings. Social Psychology of Education, 11(2), 161-180. http://doi.org/10.1007/s11218-007-9040-0

Scherer, K. R. (2005). What are emotions? And how can they be measured? Social Science Information, 44(4), 695-729. http://doi.org/10.1177/0539018405058216

Snow, R. E. (1992). Aptitude theory: Yesterday, today, and tomorrow. Educational Psychologist, 27(1), 5-32.

Sternberg, R. J. (1985). Beyond IQ: A triarchic theory of human intelligence. Cambridge, MA: Cambridge University Press

Stipek, D. (2011). Education Is Not a Race. Science, 332(6037), 1481-1481. http://doi.org/10.1126/science. 1209339

Taylor, B. (1995). Feeling, experiencing, and consciousing: diversity in the college classroom. Thresholds in Education, 22, 23-27

Tempelaar, D. T., Niculescu, A., Rienties, B., Gijselaers, W. H., \& Giesbers, B. (2012). How achievement emotions impact students' decisions for online learning, and what precedes those emotions. The Internet and Higher Education, 15(3), 161-169. http://doi.org/10.1016/j.iheduc.2011.10.003

Tinto, V. (1987). Leaving college, Rethinking the causes and cures of student attrition. Chicago: The University of Chicago.

Trautwein, U., Schnyder, I., Niggli, A., Neumann, M., \& Lüdtke, O. (2009). Chameleon effects in homework research: The homework-achievement association depends on the measures used and the level of analysis chosen. Contemporary Educational Psychology, 34(1), 77-88. http://doi.org/10.1016/j.cedpsych.2008.09.001 
UK National Advisory Committee on Creative and Cultural Education. (1998). All Our Futures: Creativity, Culture and Education. Report to the Secretary of State for Education and Employment, the Secretary of State for Culture, Media and Sport. Retrieved from http://sirkenrobinson.com/pdf/allourfutures.pdf

Zeidner, M. (1998b). Test Anxiety:: The State of the Art. Springer. 

Valorisation addendum 
The results of our work are particularly relevant and have direct application for Maastricht University (UM). To understand how the knowledge gained in this research can be practically used, through this chapter, we will place our findings in context. Our efforts were pointed to solving an urgent problem encountered at UM in general and, School of Business and Economics (SBE), in particular: the prevention of dropout among first year students. For this purpose, we have first tried to get more insight into the factors that play role in student dropout. Second, by knowing which factors matter most in freshmen's experiences, we tried to suggest practical ways which could improve success at course level.

The research described in our thesis originates from the UM project "Study success in the first year". Its aim was to support freshmen in passing their first year. For this purpose we initially conducted research to understand the adaption problems specific for the first year transition period (the adaptation problem and the theoretical approaches to address it were discussed extensively in Chapter 1). In a first study (Niculescu, Nijhuis, Gijselaers, 2010), we examined how international first year students - as compared to local students adapt to two different kinds of programs: the fixed curriculum at SBE versus the free curriculum at University College Maastricht (UCM). The results of this study indicated that is not the students' nationality but the type of curricula that plays a role in their adaption to university. The fact that SBE students who follow a fixed curriculum adapted better than those following a free curriculum at UCM represented an interesting finding. We concluded from this work that further research is needed to elucidate the role of nationality in adaptation without ignoring the learning environment in which this process takes place. Knowing that a fixed curriculum, as an educational factor, played a role in how first years at UM adapt, we further looked into more changeable individual factors which could give additional insight into what contributes to adaptation and further academic success at UM. In this respect, we developed an e-tool which could detect students at risk of dropping out. The instrument, called "The Students Self-Assessment", could provide insight into weaknesses and strengths with regard to study situations and learning, academic and social and personal life. It was designed to generate personalized computer feedback, which could be used for self-reflection or for starting a discussion with a study adviser. The instrument was used at SBE as well as other faculties within the UM. Overall, these initiatives represented the starting point for finding the best predictor of academic success and dropout - which, potentially, could be integrated in curriculum design at SBE.

In a second attempt of becoming more precise into which factors should be investigate for the best prediction of how SBE students perform, we moved from a program level to a course level. In this context, we chose to conduct our main research in the setting of QM I, a course notoriously known among freshmen for being particularly difficult and unattractive for most students. Another important factor for this choice was that failing QM I - the first of the required QM courses - has consequences on study delay and even exclusion from the educational program at SBE. In addition, we considered that this entry course was not sufficient in giving an overview of the entire first year at university experience, so we also included Finance, as the last course in the program to capture this picture. The results of our studies are presented in detail over Chapter $2-5$, so we only briefly summarize the added value of our main findings below: 
Chapter 2 provided extra empirical evidence on the role of role of achievement emotions experienced in learning-related situations on learning outcomes in QM I course. In addition, it tried to identify the differences in emotional experiences between students who attended as compared to those who were absent at the final exam. What was particularly relevant was that these differences were already visible in week four, half-way through the course. This knowledge offered the opportunity to intervene early in an educational setting, using these emotions as potential indicators for early withdrawal at the course level.

Chapter 3 provided a new approach to understand students' emotional experiences when they first enter a university study. In this respect, the two theories we used for this study were complementary: on one side our results were an empirical validation of the CVTAE; on the other side, the concepts operating in the MES could provide practical solutions on how to facilitate educational change in the classroom by using the influence these variables have in the experience of emotions.

Chapter 4 provided compelling evidence on how the changes in negative LREs and their appraisal antecedents are related. As a consequence, it offered valuable knowledge on how the levels of negative emotions can be decreased.

Chapter 5 went beyond the course level to create the longitudinal aspect of changes in LREs over different course subjects in the first year of university. We therefore incorporated but also went beyond the changes encountered over the duration of only one course, which is a novelty in this own. Overall, this study showed that contemporary theories of emotions provide a more detailed picture of freshmen's emotional experiences at university, covering the entire first year of study.

Overall, in order to be able to design interventions that can account for the role of students' emotional experiences and perceptions about the educational environment, the findings presented in this thesis point to the necessity of assessing as early as possible in a course and then afterwards through the first year at university. This can be achieved by the use of longitudinal designs, implemented at the course level.

The last part of our work, which was only briefly mentioned in this thesis, concerns the authors' course design efforts within the project "Feedback in the first blocks" at SBE which was aimed to enhance learning and prevent dropout among freshmen. The reason these efforts are mentioned here together with the findings from this thesis is that these course - redesigns were based on the insights from the research on emotions.

To give an overview, in the "Feedback in the first blocks" project, the main task was to advise SBE about how to change course formats in such a way that student performance can improve. From a content horizon, the central mechanism for these course-redesign interventions was the feedback provided by the tutors. A complementary mechanism was the tasks (problems or exercises) students were supposed to solve, inspired from the so-called "shadow cases" used in medical education, designed to promote the transfer of knowledge. We experimented with different types of feedback (performance or process types of feedback, provided for a group or at an individual level) and a variety of problems specific for the subject of each course redesigned. Our results showed that depending on the type of feedback provided we could achieve about 1point (on a scale 1-10) higher in performance for the students who took part in the experiments. This effect increased with frequency of delivering the feedback and 
the participation of students in the tutorials. In addition, the interventions were designed to be robust enough to how students feel about a course.

More precisely, after conducting the research in the QM I course, in the next academic year we designed a feedback intervention in the same course based on these insights. This course intervention (Niculescu et al., 2014) strengthened collaboration and facilitated the transfer of knowledge by providing structured feedback on tasks jointly prepared by students. Using an experimental design, we found that students who received feedback in a structured manner scored significantly .4 grade point higher (on a scale from 1 to 10 ) than students in the control condition. However, the intervention was effective after taking into account how students appraised the tasks to be solved and their learning emotions towards the course. In particular, only Learning Enjoyment and Hopelessness appeared as significant covariates. We concluded that future interventions could be improved by including more individual factors, such as students' learning emotions, which could blind the intervention impact if not accounted for.

On a related note, the results from the research described in this thesis about students' emotional experiences in QM I were used to re-design the Macroeconomics course, in period 3 of the same academic year. This experiment (Niculescu et al., 2012) showed that the frequency of providing structured feedback by the tutors as well as, the amount of attendance in course can give an extra half to 1 point on the final exam. As shown in the course evaluations, this intervention was very well received by the students and course planning group and, as a consequence, was adopted in structure of the course for the following academic year. Overall, we can conclude that these efforts were successful and helped the ERD Department to take the lead in a series of projects dedicated to reducing drop-out rates through improved feedback practices.

Finally, the results of the studies described in Chapters 2-5, together with the course design interventions, show that student success can be improved at SBE. From our perspective, it requires a few important conditions such as: applying the basic principles of Problem Based Learning when designing various courses (for instance, providing frequent and structured feedback, encouraging team work and tasks which are reflected in the final assessment) as well as accounting for how students receive both cognitively and emotionally the educational settings with its requirements. We consider these necessary conditions to engage the students in their learning in order to make the necessary efforts necessary for obtaining success. 
Summary 
Freshmen engagement has been an indicator of success for educational systems for decades (Pascarella \& Terenzini, 1991; 2005). A great deal of empirical research has shown its contribution to achievement outcomes and retention at university (Fredricks, Blumenfeld, \& Paris, 2004; Klem \& Connell, 2004; Martin, Papworth, Ginns, \& Liem, 2014). Over time, engagement has been conceptualized differently, from adjustment or adaptation (Baker \& Syrik, 1999; Tinto, 1987) to multifaceted views, including behavioral, cognitive and emotional aspects of engagement (Fredricks, Blumenfeld, \& Paris, 2004; (Connell \& Wellborn, 1994). This wide range of indicators is needed to understand the totality of students' experiences in the context of first year at university. Such transition period brings several challenges for freshmen, among which an achievement setting that is different from high school, higher academic standards, increased competition, high expectations and perceived pressure to perform (Daniels et al., 2014 Perry, Hall, \& Ruthig, 2005). Much has been written about the uncertainty and negative emotional experiences accompanying this complex and difficult period (Nathan C. Hall et al., 2006); Linnenbrink-Garcia \& Pekrun, 2011; Ruthig et al., 2007). As yet, few scholars have conducted a comprehensive analysis covering the entire first year at university period, to most effectively understand students' engagement through emotional and affective variables (Beard et al., 2007a; Perry et al., 2001; D. W. Putwain, Larkin, et al., 2013; Stupnisky et al., 2012a). Using contemporary perspectives on motivation and emotions (Martin, 2007; Pekrun, 2006), the present thesis conceptualizes the classic emotional adjustment (Tinto, 1987) problem through learningrelated emotions (LREs) to get more insight into freshmen's experiences at university. Recent work suggests that LREs play a crucial role in performance especially in the first year of university, a period of transition for most students; however, additional research is needed to show how these emotions emerge, further develop and finally, relate to achievement outcomes in the first year at university.

In Chapter 2 we examined the predictive value of four learning emotions - Enjoyment, Anxiety, Boredom and Hopelessness - on achievement outcomes. Using a large sample (N = 2337) of undergraduate first year students enrolled in a mathematics and statistics course, we first showed significant differences in the emotional experiences between the students who attended - as compared to those who were absent for the exam. Second, the present study revealed emotions, particularly learning hopelessness, and a prior mathematics background, to have a strong predictive value for student performance in the course. This relation was consistent over three consecutive academic years. Recommendations for improving educational practice have been formulated and shared in this chapter.

In chapter 3, we developed a framework which links a course-contextualized antecedent - academic control in Pekrun's (2006) Control Value Theory of Achievement Emotions - with generic antecedents - adaptive and maladaptive cognitions and behaviors from Martin's (2007) Motivation and Engagement Wheel framework - to explain a classical problem: the emergence of LREs in a transition period. Using a large sample $(\mathrm{N}=3451)$ of first year university students, our study explores these two antecedents to better understand how four LREs (enjoyment, anxiety, boredom and hopelessness) emerge in a mathematics and statistics course. Through the use of path-modelling, we found that academic control has a strong effect on all four LREs - with the strongest impact observed for learning hopelessness and secondary, for learning anxiety. Academic control, on its turn, builds on contribu- 
tions from adaptive and mal-adaptive cognitions. Furthermore, adaptive cognitions have an impact on learning enjoyment (positive) and on boredom (negative). Surprisingly though, the maladaptive behaviors impact positively learning enjoyment and negatively learning anxiety. Following this, we predicted performance outcomes in the course and found again academic control as the main predictor, followed by learning hopelessness. Overall, the findings described in this chapter bring evidence that adaptive and maladaptive cognitions and behaviors act as important antecedents of academic control, the main predictor of LREs and course performance outcomes.

In Chapter 4 we draw upon the Control Value Theory of Achievement Emotions (CVTAE), to test the assumption that antecedents of learning-related emotions (LREs) change over the duration of a mathematics and statistics course. This study focused on academic control as an antecedent of LREs. We investigated enjoyment (the positive emotion) and three negative LREs: anxiety, boredom and hopelessness. Using a repeated measures design for first year university students $(\mathrm{N}=908)$, we found that academic control and the levels of LREs remain, on average, stable over the duration of the course. Second, changes in academic control were positively related to changes in the positive emotion enjoyment, and negatively related to changes in the three negative emotions. These findings offer evidence to confirm the CVTAE change - change assumption that changes in control appraisals go together with changes in positive, as well as negative, LREs.

Finally, in Chapter 5 by aiming to investigate how emotions emerge and further develop in the first year of university, we sought to understand a classic problem - freshmen's emotional engagement at university. For this purpose, we used an integrated framework linking two contemporary theories on emotions and motivation: Pekrun's (2006) Control Value Theory of Achievement Emotions (CVTAE) and Martin's (2007) Motivation and Engagement Wheel framework. Using a longitudinal design employed in two course subjects and a relatively large sample $(\mathrm{N}=908$ freshmen $)$, we first found that learning-related emotions (LREs) are indeed distinct concepts: emotions in one course predict the same emotions in another subject, and do not cross-over to other emotions. Based on the evidence provided in this study, we can confirm that LREs in the first year of university are indeed contextualized experiences, as opposed to the characteristics that learners possess upon entering the university, which matter to a lesser degree. Second, we showed that emotional experiences during learning within a certain course subject are determined by beliefs about control within the same course. Such beliefs, in turn, can influence later experiences within another course and how these experiences may change over the first year at university. These findings, in relation to theory, implications for further research, and recommendations for educational practice, have been considered and shared in Chapter 5.

In conclusion, the present thesis shows that contemporary theories of emotions provide a more detailed picture of freshmen's emotional experiences at university, covering the entire first year of study. Such theories confirm classical approaches on emotional engagement - such as Tinto's (1987) perspective - in which students' experiences are an interaction between their personal characteristics and the effect of the learning environment. In a sense, our work adds to a large body of empirical research showing that Tinto was right and students do indeed build up a very strong connection to the educational institution. Through the continuity of their emotional experiences, students translate the emotional 
engagement they develop towards the learning environment. In other words, we can use these contemporary theories to interpret Tinto's work using an affective and emotional perspective. Furthermore, all these theoretical approaches can be useful in explaining and, through their empirical findings, suggest how achievement outcomes can be improved. We can conclude that the freshmen experience at university is a process of ongoing adaptation to which the higher-education institutions should pay attention throughout the entire academic year and not just the introductory period. Ultimately, this research shows that student engagement and success at university are not just a function of the individual but more the result of a combined effect coming from personal characteristics which flourish under the convenient circumstances offered by the educational environment. 
Acknowledgments 
This chapter is dedicated to all those who had a contribution, direct or indirect, to my development as a profesional and as a person. Writing this part is both a relief and a great pleasure since I have been carrying my gratitude for these special people for a long time. Above all, it is a source of joy since, this is the only chapter where Wim can not suggest any changes, remarking that he can almost hear me talking while reading my text. Next, I imagine there is a high probability that this will be the only section read by everyone with curiosity. That's why I will share my experience exactly as I felt it.

I had the chance to be surrounded by some of the best specialists in the field of educational research: Wim, Mien, Amber, Dirk and Jan. They tried to taught me the best they considered for me. But mostly, they taught me how to act as a professional. And they did it by living their own example. What I appreciated most is that they went beyond being professional to being human. For this reason, I pay all the deserved respect and gratitude to everything my supervisers taught me content wise but mostly focus on the human aspect of our interactions. This interaction made what I am today and I could nor cherish something more. Wim, Mien, Dirk, Amber and Jan, thank you all for this wonderful opportunity.

The first person that comes to my mind when thinking about my $\mathrm{PhD}$ is Wim. Wim has been a mentor and a parent and shaped me as an educationalist. I don't consider myelf an educationalist but he does. For those of you who don't know Wim, he is capable of seeing the best in anyone. Put it differently, if someone would have a single quality, Wim could spot it, focus on it and get the best of it! I have never seen someone with such a talent and dedication of getting the best out of people. If I could thank you for one thing Wim, besides giving me thefreedom to be and express myself, encouraging my passion, supporting my decisions (even when they were expensive) or not giving up on me when I felt there was no tomorrow, I thank you for showing me how to focus on the positive side of people! I would also like to thank his wife, Marjan: after many years I understood that some of his personal advices came actually from her.

The second first person, I would like to thank to is Mien. I associate the imagine of Mien with her office and in particular the door's office. I would actually spend a few second behind the door watching Mien at her desk. It gave me a feeling of safety, like when my mother was somewhere in the house, and I knew nothing can go wrong. So, I would knock the door and ask for " 2 minutes". Mien always had the time, a smile and a good word. I would leave with all the writing issue I have had struggling for the last three weeks solved in fifteen minutes. Mien is probably one of the best examples showing hoe relative time is: in these fifteen minutes, we would talk about research, relationships and life in general. Mien, you are my favorite example of how a female leader should be but my favorite part was that I could share my emotions with you. Thank you for holding me when I was crying: after a breakup, after my father passed away and finally, of joy!

The next first person I would like to thank, also a parent figure is Dirk. I have never told you this Dirk, but you actually remind me of my father. The analogy is not difficult: loving Math, dedicated to his work and never taking things dramatically. My $\mathrm{PhD}$ took a radical shift when Dirk came in. I decided to change from Feedback experiments to the role of emotions. Dirk's support was both unexpected and beyond expectations: Dirk would correct my papers over night. I can not describe the feeling to open the email box the next 
morning and already read Dirk's feedback. Besides bringing my statistical knowledge to the next level, Dirk was never impressed when a paper got rejected. Working next to you, Dirk, I felt like everything was possible. I would like to thank you for your patience, your time and availability. I could have not done this without your support!

If Wim, Mien and Dirk were my parents, Amber would be the God-mother. The one you always go to when you need advice. The one who would always be there when you need advice. Amber, I look at you as a mentor, you literally taught me how to write academically. I also looked at you as a friend. Thank you for welcoming me in your house and for letting me do the math homework with your girls. With you I re-discovered over and over again that success in any work comes from one's passion and the pleasure to share this passion with like-minded people.

The last person I would like to thank as a mentor, although he was not my official superviser, is Jan. Jan, however, was my first 'coach' within the department and I could never forget that my work derived from his initial ideas. Jan remained over years, the person I would go to when I needed strategical advice. I also counted on his angelic patience and kindness. It took me a while to understand his sense of humor, but one I got it, I always cherished it. Jan, thank you for being there for me and for showing that. Your words, left on little notes on my desk, have put a smile on my face and gave me hope when I thought I would never finish that Introduction! I used to play a musical birthday card you send me once every time I felt hopeless about my research: Happy happy sunshiny day to you... this is how I remember you. Thank you for being my paranimph with this special occasion!

To my other paranimph and dear friend, Christian! Christian and I have a long collaboration history. What few people actually know is that QM and Christian's teaching style inspired my work on the feedback experiments. Christian's experience was very valuable when planning these interventions and I would not exaggerate to say that part of the success of these experimnets was also due to his contribution. Christian, thank you for being such a powerful teaching example, your dedication to your students was a source of inspiration for me. Thank you also for being one of my most reliable (in the methodological sense) friends and for your milimetric measuments when hanging a painting on my wall 1 It is a great honor to have you by my side on my promotion!

As a mentor from a distance, I would like to thank Reinhart Pekrun himself for guiding my first steps on doing reaserch on achievement emotions. Reinhart, your precise advice and feedback on my work gave me insight in your theory while, at the same time, helped me clarify my own ideas and choices.

This PhD had a foundation and, with this occasion, I would like to remember three important people who shaped my formation before starting this work and even after.

First, Hein de Vries, my master thesis superviser at Maastricht University who achieved an important step in teaching me how to do professional research for the first time. Hein, also thank you for your wise advice when I needed it!

Second, to Erik. My big thanks for one of the most useful courses I ever took in my life. It happened to take place at University of Groningen and it was called Measuring Concepts. Erik and I we used to call it, Measuring Carpets because basic research should 
start with good measurement. Erik, you taught me fundamental research methodology up to the point that statiscal analysis is not necessary anymore. Thank you for making it clear for me that methodology means logical methods and, that good research actually starts with common sense!

Third, to Arno, for demonstrating me that only after experiencing emotions one can understand them.

On a related work-note, I would like to thank to all my colleagues and friends from ERD. Starting with Henny, Jeannette, Paul, Tamerius, Simon, Therese, and ending with Bas, Bart, Janine and Catherine. Here you can see I am already from a previous version of the department. I am even afraid I am forgetting someone but what I still remember is how I always felt in this department. Irrespective of my singular memories with each one of you, I have always considered you all my Dutch family. Thank you for making me feel at home!

To my other Dutch friends, Kierty and the Wu-shu crew! In particular, to Levy, Jan \& Ilse, Omar and Jesse. Guys, thank you for always being there for me and for never saying no when I asked for instrumental support! To Basima and Friederik, I am so happy for you and for myself for having you as my friends!

Basima, my little girlfriend, thank you for your warmt, for your kind words and support, for remaining by my side in the coldest days of my PhD winter. Thank you for never letting me down!

To Ilir! My dear professor, in all these years you have always been just a call away! Thank you for your friendship!

To my Romanian friends, from Maastricht, at home and above seas!

Claudia, ma bucur ca ne am inalnit si ne am regasit dupa atatia ani.

Marius, iti multumesc pentru toate momentele de prezenta si de impartasire a fiintei!

Voi doi ati fost pt mine un colt de acasa.

Pentru Alex! Iti multumesc ca mi ai reamintit cat de importanta este muzica in viata mea!

Pentru Clau, Catalina si Adrian, prietenii mei de 25 ani.

Clau, iti multumesc pt toate datile in care mi ai carat bicicleta pe scari, de cand aveam 12 ani pana la Maastricht. Intelegi ce vreau sa spun, nu mai intru in detalii.

Aditza, dupa scoala generala si liceu vine facultatea. Tu ai ramas undeva acolo pana la doctorat si sper ca vei ramane si in anii ce vor veni.

Cata, iti multumesc pentru toate momentele de insotire, de ascultare si de impartasire. Prietenia noastra a crescut in timp si sunt curioasa unde ne va duce mai departe.

Pentru Andreea! Ratusco, iti multumesc pentru toate gesturile frumoase cu care mi ai amintit ca trebuie sa sarbatoresc momentele de success. Ai fost langa mine in fiecare urare pe care mi ai facut o si iti multumesc pentru asta! 
To one special person, who showed up in my life during the last months of my time in Maastricht to make it one of the most beautiful I can remember. Lukas, thank you for passing through my life exactly in the last moments of my $\mathrm{PhD}$. You showed me that sometimes just being, even for a short while, is enough. Thank you for your presence!

A big speacil thank you to all my students: those who took part in my research and experiments, those I tutored, supervised or coached! You have been the reason we did this research in the first place: because we cared how you feel and perform! You have also been my personal reason: teaching you was where I took my own passion and joy from!

Finally, I would like to thank my parents for their love. This work is dedicated to the memory of my father who was a source of inspiration and an example of what it means to have passion for what you do. Indeed, if you love your work you don't have to work a single day in your life.

Draga Mama, nu cred ca este intamplator faptul ca esti langa mine exact acum cand scriu multumirile. Tu ai fost mereu prezenta din umbra care $\mathrm{m}$ a vegheat, calauzit, ascultat, sfatuit si crezut in mine NECONDITIONAT. Tie nu pot sa ti spun doar multumesc. $\mathrm{Cu}$ adanca recunostinta, te iubesc. 

About the author 

After graduating in 2004 from the University of Bucharest, Alexandra worked as a psychologist for the National School of Public Health and Management in Bucharest, Romania. During that time, she also completed a master in Management of Organizations at the National School of Political and Administrative Studies, Bucharest. Her previous research experience consisted of being involved in national and international projects run under institutions like Romanian Ministry of Health, Global Fund, WHO and Harvard Medical School. In 2006 she was awarded an MTEC (Matra Training for European Cooperation) Scholarship, facilitated by the Dutch Ministry of Foreign Affairs, to participate in the MSc Programme Public Health of Maastricht University. In 2007 she was granted an Ubbo Emmius Scholarship by the University of Groningen and admitted as a research student in the field of Health Psychology at the University Medical Center Groningen. In June 2009, Alexandra joined the Department of Educational Research and Innovation, Maastricht School of Business and Economics, where she was involved as a researcher in educational projects focused on educational design. In these project, her main task was to advise the School of Business and Economics (SBE) at Maastricht University (UM) about how to change course formats in such a way that student performance can improve. In addition, she served in several teaching roles at UM: tutor in undergraduate and graduate courses, thesis supervisor, mentor $\&$ coach in the professional development trajectory of the Master Management of Learning at UM. Besides advising the SBE on curriculum design, her research lead to a $\mathrm{PhD}$ thesis focused on understanding differences between successful students and dropouts by looking at the role of emotional experiences in how students perform in the first year at university. Since April 2015, Alexandra is based in Lausanne Switzerland, where she is working for the Department of Education at the European Respiratory Society (ERS) Headquarters. Within ERS, she is coordinating educational projects and activities, including curriculum development and implementation, assessments, teaching $\&$ learning and accreditation of training in the field of Respiratory Medicine. 

List of publications 


\section{REFEREED PUBLICATIONS}

\section{Books \& Book Chapters}

Gijselaers, W.H., Dailey-Hebert, A., \& Niculescu, A. (2014). Shaping the new professional for the new profession. In Baroncelli, S. , Farneti, R., Horga, I., Vanhoonacker, S. (Eds) Teaching European Union studies: Patterns in traditional and innovative teaching methods and curriculum. (p.40-63).

\section{Journal Articles}

Niculescu, A. C., Tempelaar, D.T., Dailey-Hebert, A., Segers, M., \& Gijselaers, W. H. (2015). Exploring the Antecedents of Learning Emotions and their Relations with Achievement Outcomes. Frontline Learning Research.

Tempelaar, D. T., Niculescu, A., Rienties, B., Giesbers, B., \& Gijselaers, W. H. (2012). How achievement emotions impact students' decisions for online learning, and what precedes those emotions. Internet and Higher Education. DOI: 10.1016/j.iheduc. 2011.10.003.

\section{Manuscripts under Review}

Niculescu, A., Tempelaar, D., Dailey-Hebert, A., Segers, M., \& Gijselaers, W. (submitted). Capturing the freshmen experience at university: An empirical study on how achievement emotions shape engagement in the curriculum. Journal of College Student Development

Niculescu, A., Tempelaar, D.T., Dailey-Hebert, A., Segers, M., \& Gijselaers, W. H. (under review). Exploring the Change-Change Model of Achievement Emotions: the Inclusion of Negative Emotions. Learning and Individual Differences.

Niculescu, A. C., Tempelaar, D.T., Leppink , J., Dailey-Hebert, A., Segers, M., \& Gijselaers, W. H. (under review). Feelings and Performance: Learning Emotions as Predictors of Learning Outcomes at the Course Level. European Journal of Psychology of Education.

Niculescu, A., Nijhuis, J., \& Gijselaers, W. (under review). Is the grass greener abroad? The impact of Curriculum Design and Nationality on Student Adaptation in a Period of Transition. Book chapter in the Edited Volume: Internationalizing Undergraduate Education: Critical Conversations for 21st Century Practitioners under Contract with Sense Publishers.

Works in Progress

Niculescu, A., Nijhuis, J., Tempelaar, D.T., Dailey-Hebert, A., Segers, M., \& Gijselaers, W. H. (in progress). Structured Feedback in the Classroom improves Student Perfomance. Journal article. 


\section{Professional Publications}

Franssen R., Niculescu A., \& Nijhuis, J. (2010), Vrijheid = Blijheid? Studenten zonder keuzevrijheid passen zich beter aan, Expertise 1, jaargang 4, Januari 2010.

Franssen, R., Niculescu, A., \& Nijhuis, J. (2009), Vakmanschap = Meesterschap, Expertise 10, jaargang 3, December 2009.

Niculescu, A., \& Tufanaru, C. (2005), 'The Qualitative Research: Participant Observation' In: 'Management in Health', Edited by The National Institute for Research and Development in Health, September 2005, ISSN 1453-4541.

\section{International Peer-Reviewed Conference Papers}

Niculescu, A. C., Tempelaar, D.T., Leppink , J., Dailey-Hebert, A., Segers, M., \& Gijselaers, W. H. (2014). Subject Specificity of Learning Emotions and Achievement Outcomes: How Feelings Impact Performance. Paper accepted for presentation on the annual meeting of the American Educational Research Association, Philadelphia, April 3 - April 7, 2014.

Niculescu, A., Segers, de Regt, E., \& Gijselaers, W. (2012), A Tutor Feedback Intervention in Problem-Based Learning and its Effects on Student Learning. Paper presented on the annual meeting of the American Educational Research Association, Vancouver, British Columbia, Canada, April 13 - April 17, 2012.

Niculescu, A., Nijhuis, J., \& Gijselaers, W. (2010), Curriculum design, student's nationality and its effects on adaptation to university: What makes the difference? Paper presented on the annual meeting of the American Educational Research Association, Denver, April 2010 .

Peer-Reviewed Conference Presentations (select)

Niculescu, A., Tempelaar, D., Dailey-Hebert, A., Segers, M.,\& Gijselaers, W. (2014). How Structured Feedback Improves Student Performance and the Shadow Effect of Learning Emotion, International Conference of Motivation, Helsinki, Finland, June, 2014.

Niculescu, A., Tempelaar, D., Dailey-Hebert, A., \& Gijselaers, W. (2012). Opening Pandora's Box in the Classroom: How Emotions Play a Role in Achievement Settings, International Conference of Motivation, Frankfurt, Germany, August, 2012.

Niculescu, A., \& Nijhuis, J. (2011), Is the grass greener abroad? The impact of student adaptation on dropout: local versus foreign students. EARLI Conference, September 2011, Exeter, UK. 
Niculescu, A., Segers, M., Nijhuis, J., Gijselaers, W. (2011), Does it matter to get a sense of control and a better feeling on studying in PBL? An emotional perspective on study progress in the first year at university. ORD Conference, June 2011, Maastricht, The Netherlands.

Niculescu, A., \& Nijhuis, J., (2010), Challenging the very idea of measuring learning in the professions. An interplay between a measure of learning strategies and learning theory, EDINEB Conference, June 2010, London. 
